\title{
STUDENT PERSONALITY, CLASSROOM ENVIRONMENT, AND STUDENT OUTCOMES: A PERSON-ENVIRONMENT FIT ANALYSIS
}

\author{
A Thesis \\ by \\ DAGMARA K. PAWLOWSKA
}

\begin{abstract}
Submitted to the Graduate School
Appalachian State University

in partial fulfillment of the requirements for the degree of MASTER OF ARTS
\end{abstract}

May 2011

Department of Psychology 


\author{
A Thesis \\ by \\ DAGMARA K. PAWLOWSKA \\ May 2011
}

APPROVED BY:

James W. Westerman

Chairperson, Thesis Committee

Shawn M. Bergman

Member, Thesis Committee

Timothy J. Huelsman

Member, Thesis Committee

James C. Denniston

Chair, Department of Psychology

Edelma D. Huntley

Dean, Research and Graduate Studies 


\section{Copyright by Dagmara K. Pawlowska 2011}

\section{All Rights Reserved}

Permission is hereby granted to the Appalachian State University Belk Library and to the Department of Psychology to display and provide access to this thesis for appropriate academic and research purposes. 


\section{FOREWORD}

This thesis is written in accordance with the style of the Publication Manual of the American Psychological Association (6th Edition) as required by the Department of Psychology at Appalachian State University. 


\section{ACKNOWLEDGEMENTS}

I would like to thank my thesis chair, Dr. Jim Westerman, for his patience, guidance, and mentorship throughout the thesis process. I would also like to thank my thesis committee members, Dr. Shawn Bergman and Dr. Tim Huelsman, for their assistance and enthusiasm in this project. Finally, I would like to thank my parents, Jan and Lidia Pawlowski. Their never ending support has made my graduate experience possible. 
Student Personality, Classroom Environment, and Student Outcomes: A Person-Environment Fit Analysis

Dagmara Pawlowska

Appalachian State University 


\begin{abstract}
The purpose of the study was to examine whether classroom environment moderates the relationship between student personality and student outcomes. Generally, researchers agree that congruence between persons and their environments leads to better outcomes for the individual (e.g., Ehrhart, 2006; Feldman, Smart, \& Ethington, 2004). Therefore, I hypothesized that the congruence between classroom environment and student personality would have a positive impact on student satisfaction and performance. The sample included 732 undergraduate students enrolled in Introductory Psychology courses. Data was collected at three different times during the semester. Student personality was operationalized using the Five Factor Model and measured via the NEO-FFI Form S (McCrae \& Costa, 2004) during the first two weeks of the semester. A measure was used to assess the various dimensions of the classroom environment in weeks ten through twelve. Student satisfaction was assessed during the last two weeks of the semester using a four item measure. Final percentage grades for each participant were obtained in order to assess student performance. Data were analyzed using polynomial regression analysis and surface response methodology. Results indicate that classroom environment is a strong predictor of student satisfaction, and personality is a strong predictor of performance. Structure and focus and student competition seem to be important classroom environment dimensions that increase both satisfaction and performance. Some personality and classroom environment combinations were found to increase satisfaction, performance, or both. These combinations should be further studied and developed to determine if higher education classrooms would benefit from interventions based on these factors.
\end{abstract}


Student Personality, Classroom Environment, and Student Outcomes:

\section{A Person-Environment Fit Analysis}

Many say that a bachelor's degree is the new high school diploma. And with the challenges of finding satisfactory employment and maintaining a sufficient quality of life, it is readily apparent why higher education has become increasingly popular in the U.S. However, although enrollment rates have been rising, graduation rates have been stagnating ("US College Dropout Rates Spark Concern," 2006). A study performed by American College Testing (ACT) revealed that one in every four college students drops out before finishing his or her sophomore year (Whitbourne, 2010). Research conducted by the National Center for Education Statistics correlates these findings. In the 2001 - 2002 academic year, their research indicated that slightly over half of first-time college students attending fouryear institutions full-time completed a bachelor's degree or equivalent at that institution within six years (U.S. Department of Education, National Center for Education Statistics, 2010). Many of these students borrow to pay tuition costs, but after failing to graduate, many may be worse off financially than if they had never attempted to earn a degree. It is imperative that we explore this misalignment if we intend to remain socially and intellectually competitive in an ever-more globalizing and diversifying environment.

Relatively little research has been done in higher education that parallels the research that has been performed on elementary and secondary school levels in regards to predictors of academic success (Joiner, Malone, \& Haimes, 2002). Although initial research has shown that students learn in different ways, at different rates, and in different environments (Weisstein \& Jacobson, 2009), we have disregarded this information when it comes to establishing educational structure (Tomlinson \& Kalbfleisch, 1998). Understanding the 
range of individual differences in the student population may guide educators towards developing and implementing effective interventions in teaching and towards understanding why current interventions and practices do not work (Peeke, Steward, \& Ruddock, 1998). Because there is a vast amount of variation in individual differences among students in postsecondary education, we must develop a better understanding of the interaction between individual factors and the environment in the learning process in order to improve student outcomes. There is a need for guidance in the higher education community in examining the interaction of differences within the student population with the current structure of higher education.

This research focuses on the concept of person-environment fit in the higher education classroom. This research stream suggests that diverse attributes of the individual and characteristics of the environment interact to produce important outcomes (Swanson \& Fouad, 1999). However, the relevance of person-environment fit to an academic context remains underexamined. This study examines the effects of variation in student personality classroom environment - student outcome relationships. Specifically, I examine whether the relationship between student personality and student outcomes is moderated by classroom environment to determine if fit between personality and environment leads to positive student outcomes.

The One-Size-Fits All Approach to Higher Education: Problems and Limitations Currently, there is a predominance of a "one-size-fits-all" educational theory and approach (Davis, 2010). Assessment generally measures a single form of intelligence and supports a single definition of excellence as well as only provides periodic feedback. Standards are generally uniform, from teaching approach, assignment options, textbook 
options, grading standards, and forms of assessment. This type of approach clearly disregards individual differences and provides a very rigid structure to which students must conform. Traditional higher education may be best suited for only a limited subset of individual characteristics. Students without those characteristics may need to work harder to achieve, while many may perform poorly and become disengaged.

Educational researchers support this notion by suggesting that the fault of a "one-sizefits-all" approach is that student differences are masked and not taken into consideration during educational planning (Tomlinson \& Kalbfleisch, 1998). Thus, a "one-size-fits-all" approach provides little flexibility in accommodating variation between students. For example, in higher education, students are often taught in a teacher-centered, lecture style fashion where they passively receive information and recall it on an examination that requires only a simple or rudimentary understanding of the material (Tan, Aris, \& Abu, 2006). This type of uniform approach to education is likely to serve only a minority of students (Gardner, 1995), while being ineffective for a majority of students and potentially harmful to some (Tomlinson \& Kalbfleisch, 1998). For example, Joiner et al. (2002), found in a review of research on college mathematics that many students did not respond positively to the traditional lecture approach.

In order for students to accomplish learning objectives more efficiently, pedagogical practices and procedures need to be adapted to accommodate individual differences. Many researchers agree that in the context of a heterogeneous student body, differentiation in the classroom is clearly needed (Landrum \& McDuffie, 2010). These researchers support the implementation of a more student-centered classroom that promotes differentiated instruction that meets the needs of every student. 
From a person-environment fit standpoint, personality can provide a good example of how a uniform approach can be ineffective. As previously mentioned, the structure of a higher education classroom often involves an instructor lecturing to students while they sit quietly and absorb information. This type of format likely serves the needs of only a few students. Specifically, extraverted students lack the social interaction they require to be engaged, while students high on openness to experience may benefit from a more proactive environment. This type of classroom structure is likely best suited for introverted students who, therefore, possess a competitive advantage when compared to students with different needs. Indeed, Woszczynski, Gutherie, and Shade (2005) maintain that most students are fully capable and motivated to succeed in higher education, but many struggle with the approaches used to present material.

When using an individualized approach to education, a student's attributes are taken into consideration along with academic goals (Landrum \& McDuffie, 2010). Accommodations may include changes to information delivery method, type of student performance required, and/or method of assessment. Individualized instruction does not necessarily imply that instruction must be one-on-one. Individualized instruction can be tailored to an individual, a small group, or an entire classroom. This type of student-centered approach has been shown to increase creativity, mathematical and verbal achievement, critical thinking, student satisfaction, student participation, and student self-esteem (Freiberg \& Lamb, 2009). It has also been related to a decline in dropout rates, disruptive behavior, and absences. Clearly, providing students with options that match their individual needs can increase positive student outcomes while decreasing negative ones, although it is still unclear as to what attributes matter. 
In order to base classroom environments on individual-level attributes, research is needed to determine what individual-level attributes are important. Several personality traits have been shown to be predictive of college attrition and dropout rates (Lounsbury, Saudargas, Gibson, \& Leong, 2005). It may be that certain personality types do not fit well into the traditional college classroom, which results in negative outcomes for the student and possible attrition. For example, Feldman, Smart, \& Ethington (2004) demonstrated that students who felt dissimilar with their peers in an academic setting needed to apply more academic effort in order to sustain a level that was congruent with their peers. In the process, they also had less time for social and recreational activities and developed more personal problems. If students were better matched with suitable educational environments, these negative outcomes would presumably decline. Principles of person-environment fit theory may be helpful in assessing whether student personality and dimensions of classroom environments are important predictors in the process.

\section{The Promise of Fit Research in Higher Education}

Several positive outcomes have been found to be byproducts of person-environment fit, suggesting that the theory has the potential to provide useful information in educational research. Congruence between individuals and their environment has been shown to increase academic performance, persistence in college, job satisfaction, and stability of occupational choice (Jagger \& Neukrug, 1992), which would all be beneficial outcomes for higher education students. Among other things, academic failure is associated with an inability to become financially self-sufficient (Peeke et al., 1998). Therefore, increased academic achievement through person-environment congruence may also increase student self-esteem and quality of life. Aside from economic benefits associated with increased academic 
achievement through congruence, student populations could also have the potential to gain beneficial knowledge, skills, and abilities as well as enjoy greater satisfaction and reduced stress as a result of fit.

Although fit research has examined some positive outcomes at the individual-level, there is potential to discover outcomes that are applicable to higher education in general and therefore translate more seamlessly into real-world situations. For example, a link between personality traits, classroom environments, and positive outcomes would be beneficial for colleges and universities. It might assist higher education institutions in developing better tools for assessing what types of individuals would prosper on their campuses (Farsides \& Woodfield, 2003), which may also lead to the development of more effective recruitment strategies. As individuals select certain organizations and institutions, in part because they perceive them to fit well with their own needs (Harms, Roberts, \& Winter, 2006), colleges and universities could also gain information on how to increase their applicant pools. These institutions might enjoy the benefit of increased retention if more positive student academic performance is a consequence of congruence between personality traits and classroom environments. This research has the potential to be beneficial to education and society in a broad spectrum, as enhancing positive student outcomes could help to reestablish a culture of learning. By contrast, maintaining a traditional "one-size-fits-all" approach to higher education will allow the current culture of low expectations to persist which ultimately leads to an undereducated population with little variation in knowledge, skills, and abilities.

Because of the potential relationship to future outcomes of education, results may have the ability to contribute to a better prepared workforce. We need to dramatically increase the amount of young adults gaining valuable skills and credentials necessary in the 
$21^{\text {st }}$ century economy (Weisstein \& Jacobson, 2009). It has been reported that degreecompletion rates in the U.S. are lower than those of other nations ("Higher Education Stats Stir New Concerns in USA," 2006) signaling that we are less competitive in the global market. In response, researchers have proposed that establishing multiple pathways with a variety of postsecondary options is the most efficient way to ensure that the U.S. remains intellectually competitive (Weisstein \& Jacobson). Essentially, the results from the proposed research could provide information on how to better meet potentially diverse student needs in preparing them for the working world. Results from this study may provide needed guidance in regards to how to structure higher education to produce positive learning outcomes for all students. In addition to producing a more competitive workforce, more positive learning outcomes may also increase earnings, as people with advanced degrees have been found to earn four times as much as people without a high school diploma ("Statistics about Higher Education," 2008).

The results from this research also have the potential to translate into and benefit workplace environments. Similarities have been found between traditional organizational environments and higher-level educational classrooms (Westerman \& Vanka, 2005). For example, instructors have similarities with managers in that they decide on communication and feedback methods, provide the necessary resources and inputs to complete tasks, control work progress, and rate performance. It is essential for managers to understand how to most effectively communicate with their teams to attain goals and objectives and maintain high performance and productivity. The effects of this research could be most readily applied to training or skill development situations where a manager must be aware of the learning needs and preferences of a diverse group of trainees in order for the training to be effective. 
Understanding how personality interacts with environment to produce learning outcomes would be beneficial for managers in a variety of settings including performance assessment and developmental feedback. Results concerning how student personality affects studentclassroom environment fit may provide valuable insights into how employee personality affects person-environment fit in organizations.

\section{Review of the Literature}

The following review will begin with an examination of the theory behind personenvironment fit, what assumptions it presumes, and its potential application to educational settings. This review will then examine the two descriptions of fit under examination in this study, personality and classroom environment. I begin with an assessment of personality, how it applies to educational research, and the most appropriate operationalization of the construct of personality. Then, I appraise whether classroom environment is a meaningful factor in educational research. Finally, I conclude the review of the literature with an exploration of whether personality and classroom environment interact to produce meaningful outcomes in traditional higher education settings.

\section{Person-Environment Fit.}

In order to understand how personality and classroom environment can interact to produce meaningful outcomes, a review of person-environment theory is necessary. Personenvironment fit theory is rooted in several other theories including need-press theory (Murray, 1938), Holland's $(1973,1996)$ theory of vocational behavior, the theory of work adjustment (Dawis \& Lofquist, 1984), and theories of interactional psychology (Schneider, Smith, \& Goldstein, 2000; Terborg, 1981). These theories explore the role of both the person 
and the situation in behavior and conclude that fit or congruence between persons and their environments produces positive consequences (Ehrhart, 2006).

Arguably, most influential to the contemporary theory of person-environment fit is Holland's $(1973,1996)$ theory of vocational behavior. Holland believed that "human behavior is a function of the interaction between individuals and their environments" (Feldman et al., 2004, p. 528). The theory advocates assessing individuals, environments, and the interaction between the two to determine fit or congruence. Holland describes three components upon which his theory is based: that environments tend to reward and reinforce different patterns of interests and abilities of people, that individuals have a tendency to choose environments compatible with their personalities, and that individuals tend to excel in environments that are congruent with or that "fit" their personality. Feldman et al. (2004) suggest that although Holland's theory was aimed at understanding vocational behavior, it is easily applied to higher education environments. In a longitudinal study on college and university students, he found supporting evidence for Holland's three components.

Based on Holland's original postulations, person-environment (P-E) fit assumes that (a) meaningful and reliable differences can be assessed between individuals and (b) between environments and (c) considers that matching individuals and environments will increase the likelihood of positive outcomes (Chartrand, 1991). P-E fit theory also supports the notion that people seek out environments that are congruent with their attributes and assumes that PE fit is ongoing and reciprocal.

Since individuals and environments differ in meaningful and reliable ways, P-E fit theory allows us to recognize important patterns and utilize them to organize individuals and environments to achieve optimal outcomes (Chartrand, 1991). Congruence between 
individuals and their environments can be measured along a continuum with greater fit leading to more positive outcomes (Swanson \& Fouad, 1999). These outcomes can include achievement, performance, satisfaction, tenure, retention, and stability, and can be associated with both individuals and environments. Poorer congruence is likely to lead to more negative outcomes such as poor performance, dissatisfaction, and stress (Hampton, 1991).

Although the concept of person-environment fit theory can be applied to many situations, studying individual and environmental patterns in an academic setting could provide information concerning the possibility of enhanced performance and satisfaction. Research has shown that aligning learning environments with the needs of hyperactive children is very beneficial to their development and learning (Flynn \& Rapoport, 1976), suggesting that perhaps aligning learning environments to the personality dimensions of students would have the same effect. Fraser and Fisher (1983) suggest that providing greater attention to person-environment fit is a key determinant of a student's classroom achievement and functioning. They found that congruence between a student's preferred classroom environment and actual classroom environment can be as significant as the nature of the actual environment when predicting achievement. Person-environment fit research shows promise in benefitting education, but determining what specific factors will have the most influence has yet to be examined and discussed.

Personality as the "Person" Factor of P-E Fit.

The impact of two components of the person-environment equation proposed in this research (personality and classroom environment) must be investigated and discussed in order to ensure sound rationale. The main question to be examined here is whether 
personality should be considered in the person side of the debate, particularly in educational research. If so, the most appropriate operationalization of personality must be identified.

Personality is seen as a generally stable individual characteristic (Nijhuis, Segers, \& Gijselaers, 2007) and can be conceptualized as the preferences each individual has that direct his or her interaction with the world (Davis, 2010). Although seldom used to study personenvironment fit (Ehrhart, 2006), personality as an independent and direct factor has been found to be a useful tool in educational settings. Research that spans five decades has shown that personalities relate systematically and predictably to a range of educational outcomes (Furnham, Christopher, Garwood, \& Martin, 2008). For example, personality has been generally related to academic performance (Caspi, Chajut, Saporta, \& Beyth-Marom, 2006). Specifically, conscientiousness, openness to experience, and emotional stability all relate positively to academic achievement. Personality traits have also been related to classroom behaviors including amount of participation, oral expression, written expression, motivation, work habits, and grasp of subject matter. Personality can have both positive and negative effects on student outcomes which supports the notion that traditional higher education classrooms are structured to produce positive outcomes for certain personality dimensions while producing negative outcomes for others.

Personality has also been related to learning styles in meaningful ways (Zhang, 2006). Learning styles are the ways an individual understands and maintains information and finds it most easy to learn (Wang, Wang, Wang, \& Huang, 2006). Learning styles remain stable across time (Salter, Evans, \& Forney, 2006) and have been shown to correlate strongly with academic performance (Diaz-Grandados, Dominguez, Ricardo, Ballesteros, \& Fontalvo, 2009). Learning styles and personality have been found to overlap, and some argue that 
learning styles are a sub-set of personality (Zhang, 2006). Personality, across multiple studies, has been found to be predictive of learning styles suggesting that it may be beneficial to study education in terms of personality. While some may argue that learning styles are the more appropriate factor to study, research suggests that learning style constructs and measures are not as fully developed as conceptualizations and measures of personality; specifically the Five Factor Model. Learning styles are still researched under various conceptualizations and instruments measuring them have been criticized for low reliability, validity, and response bias (Martin, 2010). While assessing learning styles in the proposed study may be a viable option in the future, studying personality is the more robust option in the present.

Personality has also been related to student preference in regard to grading or evaluation method in educational settings (Furnham et al., 2008). Specifically, extraverts have been shown to prefer multiple choice, group work, and oral assessment. Students high on openness to experience favored oral exams and essays, while disliking group work and multiple choice assessment. Conscientious students preferred continuous assessment while agreeable students preferred essays. If personality traits are related to a preference for certain forms of assessment, it is likely they will have a relation with broader manifestations of their learning environment.

Students' personality traits have also been related to residence hall placement, orientation, leadership development, and advising (Lounsbury et al., 2005). Personality information may be useful in nearly every college situation where a student has to make a choice concerning commitment, involvement, membership, and/or participation including major, course load, course format, student organizations, study habits, degree pacing, career 
planning, and many others. In summary, the research to date on the effect of personality on educational preferences and outcomes indicates a relatively strong relationship with broadbased effects.

Essentially, personality is an important factor to consider in educational research. Personality research has vast potential to provide researchers and educators information on why so many students fail to succeed in the current educational system (Woszczynski et al., 2005).

In regards to the measurement of personality, there exists general agreement on the most useful and accepted operationalization of personality as a construct. Five factors of personality have consistently emerged across major personality inventories (Lievens, Decaesteker, Coetsier, \& Geirnaert, 2001), leading to a parsimonious model of personality structure that includes five fundamental dimensions (extraversion, neuroticism, openness to experience, agreeableness, and conscientiousness) referred to as the Five Factor Model (Barrick \& Mount, 1991). This model has been shown to possess substantial heritability, stability across the life span, consistency across data sources, and replicability across languages and cultures, as well as little to no adverse impact on national origin, ethnic, or gender subgroups (Lounsbury et al., 2005). This study will employ the generally accepted Five-Factor Model of personality to determine the outcomes produced by the interaction of personality and classroom environment.

\section{Classroom Environment as the "Environment" Factor of P-E Fit.}

Westerman and Simmons (2007) suggest that research has disproportionately focused on a direct link between personality and outcomes and has neglected to examine the strong impact of one's environment. The research foundations examining the effects of 
environment on learning include Kirtz and Moos (1974), who assert that dimensions of environmental stimuli are distinct and have distinguishing effects on physiological processes. Kirtz and Moos suggest the use of environmental measurement to predict environments that may be beneficial (or disadvantageous) to particular groups of people. These environmental effects can translate into higher education since environments may carry great influence in student collegiate learning (Feldman et al., 2004).

The environmental component in the person-environment equation proposed in this research is the classroom. Classroom environments are both psychological and social in nature (Joiner et al., 2002) and many student outcome variables may be affected by this psychosocial environment. However, although a wealth of evidence exists concerning the influence of personality on educational outcomes, the empirical research on the effects of classroom environment is less well established. In one of the few such studies, Fry and Addington (1984) examined the effects of open versus traditional classrooms. They found that participants in open classrooms exhibited higher achievement in social problem-solving cognitions as well as higher ego-strength and self-esteem over participants in traditional classrooms. Fraser and Fisher (1983) found that when students had a higher preference for their environment, they exhibited greater achievement than students who had a lower preference for their environment. Nielsen and Moos (1978) examined high exploration classroom environments and found that students who preferred high exploration classroom environments were better adjusted and more satisfied than students who preferred low exploration classroom environments. Although based on limited research, some researchers such as Dorman (2001) feel strongly enough about the research to conclude that student outcomes are significantly impacted by the quality of classroom environment. Enhancing the 
level of research on environmental effects is necessary to improve our level of understanding, with the hope that it may allow us to predict student outcomes beyond those understood by personality research and allow for more effective environmental adjustments to meet diverse student needs.

\section{Interaction between Personality and Classroom Environment.}

Although personality and classroom environment are important as independent factors, there is a gap in research examining whether their interaction would produce meaningful outcomes beyond those they can produce individually. Much of the research in this area has focused on preference as determined by personality and how it affects choice of environment. In a study of choice of specialty area among medical students, students who matched each other in personality profile had a tendency to enter similar domains of medical practice (Hartung, Borges, \& Jones, 2005). Research has also found that individuals are attracted to organizations that reflect a culture that is in line with their personality (Judge \& Cable, 1997; Lievens et al., 2001). However, these studies fail to determine whether such personality-based choices actually produce beneficial individual and environmental-level outcomes. Further, these studies focus solely on preference, not fit. For the purpose of informing personality-classroom environment fit research, a more relevant study was conducted by Chamorro-Premuzic, Furnham, and Lewis (2007) who found that students high in neuroticism disliked small groups and group discussions, while agreeable and open students had a preference for these types of environments. While this study provides limited evidence that a relationship exists between personality and classroom environment, it (again) is framed in terms of student preference, and a more holistic exploration of the fit between these two factors and the specific outcomes fit may produce is needed. 
Student outcomes have been examined in research on personality-environment fit in distance/online learning formats versus traditional classroom formats. Schniederjans and Kim (2005) developed a highly accurate regression model using personality as a variable that predicted student outcomes in online course formats as opposed to traditional classroom formats. This tool aided students in deciding whether they should participate in online formats or opt for more traditional formats. Further, Williamson and Watson (2007) found that students who demonstrate positive educational outcomes in distance or online course formats have different personality profiles than students who are successful in traditional college classrooms. This research stream provides additional evidence that personality and classroom environment interact to produce meaningful outcomes for students but is limited to comparing traditional classrooms to distance/online classrooms. Although distance/online course formats are increasing in popularity, it is important to explore this principle in traditional classroom formats, as the majority of higher education settings are composed of these learning environments.

Hence, the ultimate goal of the proposed research is to determine if personality and classroom environment interact in meaningful ways in order to produce student outcomes in traditional higher education environments. Woszczynski et al. (2005) suggest that personality traits and the circumstances in which an individual is placed both play a part in how that individual behaves. Likewise, Westerman, Nowicki, and Plante (2002) have suggested that matching individual differences to preferences in learning environment would result in beneficial outcomes. Although there has been a call for research on the topic of personality and learning environment interaction and the outcomes it produces, relatively little research has been done. The proposed research answers this call by examining the interaction of 
personality and classroom environment in terms of fit and meaningful individual-level factors that are produced as a result of either congruence or incongruence.

\section{Summary.}

Although some research has been performed on the relationships between student personalities, classroom environments, and student outcomes, there remains a distinct need to determine if and how classroom environment moderates the relationship between student personality and student outcomes in traditional classroom environments. Evidence from this research could support differentiating instruction for students along personality and classroom environment dimensions to produce better performing and more satisfied students. Such information would aid in our ability to be more proactive in assuring that each student in higher education receives a positive, rewarding, and valuable experience. Understanding personality profiles may also allow teachers to tailor strategies to foster greater success for each student. Ultimately, the goal of the proposed research is to give educators enhanced tools needed to optimize learning and performance for all higher education students.

\section{The Five Factor Model and Classroom Environment Dimensions}

A review of the research indicated that personality influences perceptions of and preferences for learning environments, and students with a preference for their environment exhibit greater academic achievement. Essentially, student preferences, influenced by personality, interact with the environment to produce either positive or negative outcomes.

While this research generally supports the congruence hypothesis in academic settings, further study is needed to determine if the personality-environment congruence hypothesis holds in the traditional college classroom and for more widely accepted personality conceptualizations such as the Five Factor Model (Barrick \& Mount, 1991). In 
the following sections, I review the Five Factor Model and important dimensions of the classroom environment in order to describe the two primary tools that will be used to measure personality and classroom environment. I then assess each personality dimension (as established by the FFM) on its empirical relation to certain dimensions of classroom environments.

\section{The Big Five Personality Dimensions.}

Researchers have generally agreed that there exist five core dimensions of personality (Barrick \& Mount, 1991; Costa \& McCrae, 1995; McCrae \& Costa, 1987). The traits identified in the Five Factor Model are the result of decades of factor analytic research (Zhang, 2006). The robustness of these dimensions has been evaluated across different measures, cultures, theoretical frameworks, and various samples (Costa \& McCrae, 1994). The five personality dimensions included in the Five Factor Model are extraversion, neuroticism, openness to experience, agreeableness, and conscientiousness (Barrick \& Mount, 1991). Features of these dimensions are represented in Table 1.

\section{Classroom Environment Dimensions.}

In order to determine which dimensions of the classroom environment are important to study, the Classroom Environment Scale developed by Trickett and Moos (1973), was examined (see Appendix A). This scale is based on a high school classroom environment and was developed in order to assess the psychosocial environment of the classroom by asking students and teachers to report about their perception of various facets of the classroom. A factor analysis of this scale produced the following factors: structure and focus, participative learning, classroom involvement, instructor support, and student competition. See Table 2 for a description of these factors. Although these factors are not the same as the dimensions 
described in the original scale, the factors found may be more appropriate and effective to use in a contemporary, higher education classroom environment. The conceptualizations of the dimensions in the proposed research reflect an exploration of the original measure that may prove to be more useful in modern college classrooms. Further information concerning the factor analysis can be found in the Methods section. Appendix A provides a reference of the original scale used in the factor analysis, and Table 3 provides a description of the original factors. Appendix B provides a description of the item loadings for the factors that were used in this study.

\section{Conceptualization of Fit}

Fit has been conceptualized in various ways including supplementary fit, complementary fit, needs-supplies fit, and demands-abilities fit (Piasentin \& Chapman, 2006). The following research will examine person-environment fit in a supplementary fit framework which measures the similarity between characteristics of individuals and environments. This research will also employ indirect measures of fit, meaning individuals will not be asked about their direct perceptions of fit with their environment, but rather variables within the person and within the environment will be measured and compared in order to examine similarity. It has been suggested that this type of measurement is more representative of fit because it does not confound the two variables being measured and allows for their independent contributions to be assessed (Kristof, 1996). In this case, the dimensions of personality and classroom environment will be measured and compared to asseşs similarity and to determine fit. 


\section{Hypotheses}

Based on a review of the literature, the following provides an overview of what has been found concerning the relationship between each dimension of the Big Five and certain dimensions of the classroom environment. Inferential leaps are made in order to propose hypotheses that are based on current and available research. These hypotheses are exploratory in nature. Although all hypotheses are framed from a congruence standpoint, some hypotheses are framed in a bidirectional approach while others are framed in the traditional unidirectional approach. Decisions as to whether specific hypotheses should be framed in a unidirectional or bidirectional approach were made based on synthesis of the current literature available as well as logical inferences. Please reference Appendix C for a list of all hypotheses.

\section{Extraversion.}

As stated previously, extraversion is associated with ambition, sociability, gregariousness, talkativeness, assertiveness, impulsivity, and vigor. Because extraverts crave interpersonal interaction, it has been suggested that they seek environments with a high degree of relationship orientation (Westerman \& Simmons, 2007) and affiliation (Buunk, Nauta, \& Molleman, 2005) and also have a preference for working in groups (Furnham \& Chamorro-Premuzic, 2005). This research indicates that extraverts may respond positively to environments with high participative learning, while people low on extraversion will likely respond more positively to environments low on this dimension. Further, in educational settings, extraversion has been found to be positively related to appropriate assessment, clear goals, and good teaching (Nijhuis et al., 2007). This indicates that extraversion may be positively associated with environments providing high structure and focus as well as 
instructor support. Finally, Westerman and Simmons found that extraversion is a significant predictor of preference for goal orientation environments. These environments provide opportunities for challenge, success, accomplishment, and maintaining task orientation. Given that the dimension of extraversion includes facets such as ambition, assertiveness, and vigor, it is clear to see why this link was found. This research stream suggests a possible positive relationship between extraverts and environments with high levels of student competition, while introverted individuals will likely display a positive relationship with environments providing low student competition. Due to these empirical linkages, I hypothesize the following:

Hypothesis 1 (a): As extraversion increases and structure and focus increases, course satisfaction and course performance will increase.

Hypothesis 1 (b): As congruence between extraversion and participative learning increases, course satisfaction and course performance will increase.

Hypothesis 1 (c): As extraversion increases and instructor support increases, course satisfaction and course performance will increase.

Hypothesis 1 (d): As congruence between extraversion and student competition increases, course satisfaction and course performance will increase.

\section{Neuroticism.}

The personality dimension of neuroticism is associated characteristics of depression, anxiety, anger, emotion, embarrassment, insecurity, and worry. Students high in neuroticism have demonstrated higher level of achievement in structured classrooms (Nielson \& Moos, 1978), indicating that they may associate positively with an environment high in structure and focus. Neuroticism has also been found to be negatively related to group discussion and 
small group participation (Chamorro-Premuzic et al., 2007) and affiliation (Buunk et al., 2005). In educational settings, students high in neuroticism have been shown to perform better in classrooms that involve less participation (Nielson \& Moos; Williams, 1971). This research indicates that students high in neuroticism may respond negatively to environments with high participative learning and classroom involvement, while students who are more emotionally stable may experience the opposite effect. Due to these empirical linkages, I hypothesize the following:

Hypothesis 2 (a): As neuroticism increases and structure and focus increases course satisfaction and course performance will increase.

Hypothesis 2 (b): As congruence between neuroticism and participative learning increases, course satisfaction and course performance will increase.

Hypothesis 2 (c): As congruence between neuroticism and classroom involvement increases, course satisfaction and course performance will increase.

\section{Openness to Experience.}

The personality dimension of openness to experience is associated with imagination, curiosity, culture, broad-mindedness, originality, artistic sensitivity, and intelligence. It has been suggested that openness to experience may have an inverse relationship with organization, order, and control (Westerman \& Simmons, 2007). If true, openness to experience may be negatively related to the environmental dimension of structure and focus. Openness to experience has also been suggested to be positively related to relationshiporiented environments that provide high levels of social interaction (Westerman \& Simmons). In an educational setting, Williams (1971) found that individuals who participated actively in the classroom were shown to have higher levels of creativity and originality of 
thought - which are characteristics of openness to experience. The preceding research suggests that openness to experience may be positively related to environments that provide high participative learning and classroom involvement, while low openness to experience may be positively related to environments that provide low participative learning and classroom involvement. Openness to experience has also been negatively related to social comparison (Buunk et al., 2005), suggesting that students high in openness to experience will not respond well to environments high in student competition. Due to these empirical linkages, I hypothesize the following:

Hypothesis 3 (a): As openness to experience increases and structure and focus decreases, course satisfaction and course performance will increase.

Hypothesis 3 (b): As congruence between openness to experience and participative learning increases, course satisfaction and course performance will increase.

Hypothesis 3 (c): As congruence between openness to experience and classroom involvement increases, course satisfaction and course performance will increase.

Hypothesis 3 (d): As openness to experience increases and student competition decreases, course satisfaction and course performance will increase.

\section{Agreeableness.}

The personality dimension of agreeableness is associated with flexibility, courteousness, good-nature, trust, forgiveness, cooperation, tolerance, and soft-heartedness. Agreeableness has been found to have a positive relationship with system maintenance (which refers to organization, order, and clear expectations). This suggests that students high in agreeableness may respond positively to classroom environments high in structure and focus. Agreeableness has also been found to be related positively with affiliation (Buunk et 
al., 2005) and with environments that reinforce relationships (Westerman \& Simmons, 2007). More specifically, agreeable students prefer group discussion and participation in small groups (Chamorro-Premuzic et al., 2007; Furnham et al., 2005). This research suggests that students high in agreeableness may respond well to environments that offer high participative learning, while student low in agreeableness may respond positively to environments that offer low participative learning. Due to these empirical linkages I hypothesize the following: Hypothesis 4 (a): As agreeableness increases and structure and focus increases, course satisfaction and course performance will increase.

Hypothesis 4 (b): As congruence between agreeableness and participative learning increases, course satisfaction and course performance will increase.

\section{Conscientiousness.}

The personality dimension of conscientiousness is associated with dependability, thoroughness, carefulness, organization, responsibility, achievement-orientation, hard work, and perseverance. Conscientiousness has been related to being orderly, goal-oriented, having a need for continuous improvement (Westerman \& Simmons, 2007), and having a preference for clear goals (Nijhuis et al., 2007). Chamorro-Premuzic et al. (2007) have found that conscientious students are achievement-oriented, ambitious, organized, and hard-working. These conclusions suggest that conscientious students may respond more effectively to environments that offer high structure and focus and student competition while students low in conscientiousness may respond more positively to environments low on these dimensions. As a result, I hypothesize the following:

Hypothesis 5 (a): As congruence between conscientiousness and structure and focus increases, course satisfaction and course performance will increase. 
Hypothesis 5 (b): As congruence between conscientiousness and student competition increases, course satisfaction and course performance will increase.

\section{Method}

\section{Participants and Procedures}

The data used for the proposed research is archival in nature and does not provide any identifiers and cannot be linked to identifiable information and therefore does not require International Review Board approval. The original study that collected the data was IRB approved. The sample was drawn from a medium-sized university in the southeastern United States. All participants were undergraduate students enrolled in Introductory Psychology courses. Students in forty-one separate classrooms were asked to participate in the study yielding a sample size of 732 participants.

Students were assessed at three different times in the semester. These times are referred to as initial, interim, and final. In the initial measurement, occurring within the first two weeks of the semester, students completed the measure to assess their personalities. At the interim measurement, occurring in weeks ten through twelve of the semester, students completed the measure to assess each student's perceptions of his or her classroom environment. At the final measurement, occurring within the last two weeks of the semester, students completed the course satisfaction assessment. Final grades for each consenting participant were collected from instructors in order to assess student performance. Assessments at all three times were completed outside of class using an online survey program. Students received course credit for their participation. Data were collected and aggregated across three semesters. 


\section{Measures}

Personality. Personality was assessed using the NEO-Five Factor Inventory (NEOFFI) Form S. This inventory uses self-report to assess the Big Five personality dimensions, including extraversion, neuroticism, openness to experience, agreeableness, and conscientiousness (McCrae \& Costa, 2004). The NEO-FFI Form S is a 60-item inventory where each item is rated on a 5-point scale ranging from "strongly disagree" to "strongly agree" (see Appendix D). The validity of the five factors assessed by the NEO-FFI has been specified by a number of studies (Costa \& McCrae, 1995; McCrae \& Costa, 1987). The NEO-FFI has also been used to assess personality in several studies concerning the relationship between personality and environment (Chamorro-Premuzic et al., 2007; Westerman et al., 2002; Westerman \& Simmons, 2007).

Classroom Environment. The classroom environment was assessed using a shortened and adapted version of the Classroom Environment Scale developed by Trickett and Moos (1973; see Appendix A). The measure was shortened and adapted by researching several studies that examined the factor structure of the CES (see Deemer, 2004; Trickett \& Quinlan, 1979). Initially, all items with high factor loadings were selected to be included in the measure. The measure was further shortened by removing items that were not applicable to a college classroom environment. The measure was then changed from a true/false format to a 5-point scale format in order to provide consistency between the scale used to measure personality and the scale used to measure classroom environment. The measure used consisted of 32 items, some reverse coded, that evaluated the dimensions of involvement, affiliation, teacher support, task orientation, order and organization, rule clarity, innovation, 
and student competition. Four items were originally used to assess each dimension along a 5point scale that ranged from "not at all like my classroom" to "exactly like my classroom."

The original scales used provided poor reliabilities (see Table 4). For this reason, an exploratory factor analysis was performed in order to develop more parsimonious predictors. Principal Axis Factoring with an oblimin rotation was used. An iterative process was employed with items loadings higher than .35 on multiple factors being removed in each iteration until only a distinct set of factors remained. Items in each factor were examined for common themes, and scale dimensions were developed. The following factors were extracted: structure and focus, participative learning, classroom involvement, instructor support, and student competition. Please reference Figure 1 for the pattern matrix and Table 5 for scale reliabilities. Descriptions of the new factors are available in Table 2.

Student Performance. Student performance was determined by examining each student's final percentage grade for the course. Course grades were obtained from each student's instructor with the student's consent.

Student Satisfaction. Student satisfaction was assessed using four questions including, "Overall, I rate this course as excellent," "I am really excited about this class," "I think what we are studying in this class will be useful to know," and "I think what we are studying in this class will be important to know" (see Appendix E). Each item was rated on a 5-point scale ranging from "strongly disagree" to "strongly agree."

\section{Results}

\section{Data Aggregation}

Data were aggregated to the classroom-level. $r_{w g}$ (James, Demaree, \& Wolf, 1984) calculations were examined for the classroom environment subscales of structure and focus, 
participative learning, classroom involvement, instructor support, and student competition. These calculations provided average agreement indices of $.89, .77, .75, .75$, and .85 , respectively. The averages $r_{w g}$ demonstrated that agreement indices were high among students in the various classrooms and, therefore, provided evidence to aggregate to the classroom level.

\section{Descriptive Statistics}

Table 6 presents the means, standard deviations, correlations, and reliability (Cronbach's alpha) estimates of the research variables. Reliability estimates were generally high but fell below the general .70 cut-off score in the classroom involvement, instructor support, and student competition subscales of the classroom environment measure. Although these specific reliabilities are lower than the general .70 cut-off, they are higher than the reliabilities the original subscales produced. Table 4 provides the reliability estimates for the subscales of the original classroom environment measure used in the data collection. Table 5 provides the reliability estimates for the subscales derived from the exploratory factor analysis. Clearly, the reliability estimates for the new subscales are more robust than those for the original subscales.

\section{Examining Congruence Relationships}

Testing the impact of the congruence between personality dimensions and characteristics of the classroom environment on the outcomes in the study would have been simple and straightforward if the congruence terms were single variables. However, since person-environment fit is composed of two variables (i.e., personality dimension and classroom environment dimension), estimating the effects that fit has on an outcome requires 
techniques that can appropriately examine the simultaneous effect that individual and environmental characteristics have on student performance and satisfaction.

The most popular technique for assessing the fit between two entities is use of a bivariate congruence index such as an algebraic $(\mathrm{X}-\mathrm{Y})$, absolute $(|\mathrm{X}-\mathrm{Y}|)$, or squared difference $(\mathrm{X}-\mathrm{Y})^{2}$. However, a number of researchers have criticized the use of these methods for a wide variety of reasons (see Cronbach, 1958; Edwards, 1991; Johns, 1981; Nunnally, 1962). Thus, this study uses a polynomial regression procedure to examine the fit that exists between student personality characteristics and the classroom environment (see Edwards, 1994; Edwards \& Parry, 1993). This procedure does not collapse individual and environmental variables into a single index; rather, it examines the effect that congruence between student personality and classroom environment has on satisfaction and performance using the following equation:

$$
Z=b_{0}+b_{1} X+b_{2} Y+b_{3} X^{2}+b_{4} X Y+b_{5} Y^{2}+e
$$

(where $Z$ represents either satisfaction or performance, $X$ represents the students score on the personality dimension, and $Y$ represents the aggregated classroom environment score).

This procedure also assumes that the relationship between congruence and an outcome should be considered in three dimensions. As a result, a surface response methodology (Edwards \& Parry, 1993; Kutner, Nachtsheim, Neter, \& Li, 2005) was employed to interpret the joint relationship personality and classroom environment have on course satisfaction and course performance.

\section{Mixed Modeling}

As students were nested within classrooms, and relationships were introduced between participants, the independence of data assumption that underlies traditional 
ordinary-least-squares regression (OLS) regression was violated. For this reason, a maximum likelihood random effects modeling (ML-REM) procedure was used to examine if congruence between student personality and classroom environment had an impact on course satisfaction and course performance beyond that which could be attributed to the class from which the student was sampled.

The ML-REM procedure first compared the -2 log likelihood from models with no random effects (i.e., regression models in which the intercepts and predictor slopes were not allowed to vary across classrooms), against the models which used the grand mean of the outcome as their only predictor. Next, the models with no random effects were compared against the random intercepts models (i.e., regression models in which the intercepts were allowed to vary across classrooms). Finally, the random intercepts models were compared against the random slopes and intercepts models (i.e., regression models in which the both intercepts and predictor slopes were allowed to vary across classrooms).

As can be seen in Tables 7 and 8, the random intercepts model improved the prediction of course satisfaction over the no random effects model in seven of the fifteen hypothesis testing models and improved the prediction of the course performance in all fifteen models. The random intercept and slopes models failed to converge for all fifteen models predicting course satisfaction and thirteen of the fifteen models predicting course performance, indicating no additional variance was explained by estimating the slopes for these classrooms. The two random intercepts and slopes models that did converge failed to improve the prediction of course performance over the random intercepts models. Although not all of the random intercepts models were significant in predicting the study's outcomes 
over the models with no random effects, the random intercepts models for both outcomes were used to test the study's hypotheses for comparability purposes.

\section{Hypothesis Testing}

Course Satisfaction. Table 9 shows that for each hypothesis, the random intercepts model significantly predicted course satisfaction better than the null base model. The table also provides a summary of the results for the hypothesis testing for the course satisfaction outcome.

Hypothesis 1(a) proposed that as extraversion and structure and focus increases, course satisfaction would also increase. As can be seen in the surface plot in Figure 2, course satisfaction was maximized when both extraversion and structure and focus were high, as denoted by circle $\mathrm{A}$ in the plot. Additionally, course satisfaction was minimized when extraversion and structure and focus were low, as denoted by circle B on the plot. These results provide support for Hypothesis 1(a) for this outcome.

Hypothesis 1(b) proposed that as congruence between extraversion and participative learning increases, course satisfaction would also increase. As can be seen in the surface plot in Figure 3, course satisfaction was maximized when both extraversion and participative learning were high, as denoted by circle $\mathrm{A}$ in the plot. Course satisfaction was minimized, rather than maximized, when extraversion and participative learning were low, as denoted by circle B on the plot. Although the data does not represent a traditional fit relationship where an outcome is maximized everywhere along the line of perfect fit, it does reflect a positive fit relationship. Thus, these results provide partial support for Hypothesis 1(b) for this outcome.

Hypothesis 1(c) proposed that as extraversion and instructor support increases, course satisfaction would also increase. As can be seen in the surface plot in Figure 4, course 
satisfaction was maximized when both extraversion and instructor support are high, as denoted by circle $\mathrm{A}$ in the plot. Additionally, course satisfaction was minimized when extraversion and instructor support were low, as denoted by circle B on the plot. These results provide support for Hypothesis 1(c) for this outcome.

Hypothesis 1(d) proposed that as congruence between extraversion and student competition increases, course satisfaction would also increase. As can be seen in the surface plot in Figure 5, there is no fit relationship between the variables. Course satisfaction was not maximized along the line of fit; however, there was a main effect for environment. As denoted by oval A in the plot, course satisfaction generally increased as student competition increased, regardless the students' level of extraversion. Thus, Hypothesis 1(d) was not supported for this outcome.

Hypothesis 2(a) proposed that as neuroticism and structure and focus increases, course satisfaction will also increase. As can be seen in the surface plot in Figure 6, there is no fit relationship between the variables. Course satisfaction was not maximized when both neuroticism and structure and focus were high; however, there was a main effect for environment. As denoted by oval A in the plot, course satisfaction generally increased as structure and focus increased, regardless of the students' level of neuroticism. Thus, Hypothesis 2(a) was not supported for this outcome.

Hypothesis 2(b) proposed that as congruence between neuroticism and participative learning increases, course satisfaction will also increase. As can be seen in the surface plot in Figure 7, there is no fit relationship between the variables. Course satisfaction was not maximized when both neuroticism and participative learning were high; however, there was a main effect for the individual. As denoted by oval $\mathrm{A}$ in the plot, course satisfaction 
generally increased as neuroticism increased, regardless of the environment's level of participative learning. Thus, Hypothesis 2(b) was not supported for this outcome.

Hypothesis 2(c) proposed that as congruence between neuroticism and classroom involvement increases, course satisfaction will also increase. As can be seen in the surface plot in Figure 8, there is no fit relationship between the variables. Course satisfaction was not maximized along the line of fit; however, there was a main effect for the individual. As denoted by oval A in the plot, course satisfaction generally increased as neuroticism increased, regardless of the environment's level of classroom involvement. Thus, Hypothesis 2(c) was not supported for this outcome.

Hypothesis 3(a) proposed that as openness to experience increases and structure and focus decreases, course satisfaction will increase. As can be seen in the surface plot in Figure 9, there is no fit relationship between the variables. Course satisfaction was not maximized when openness to experience was high and structure and focus was low; however, there was a main effect for environment. As denoted by oval $\mathrm{A}$ in the plot, course satisfaction generally increased as structure and focus increased, regardless of students' level of openness to experience. Thus, Hypothesis 3(a) was not supported for this outcome.

Hypothesis 3(b) proposed that as congruence between openness to experience and participative learning increases, course satisfaction would also increase. As can be seen in the surface plot in Figure 10, there is no fit relationship between the variables. Course satisfaction was not maximized along the line of fit; however, there was a main effect for the individual and the environment. As denoted by oval $\mathrm{A}$ in the plot, course satisfaction generally increased as openness to experience decreased, regardless of the environment's level of participative learning. As denoted by oval B, course satisfaction generally increased 
as participative learning increased, regardless of students' level of openness to experience. Thus, Hypothesis 3(a) was not supported for this outcome.

Hypothesis 3(c) proposed that as congruence between openness to experience and classroom involvement increases, course satisfaction would also increase. As can be seen in the surface plot in Figure 11, course satisfaction was maximized when both openness to experience and classroom involvement were high, as denoted by circle A in the plot. Course satisfaction was minimized, rather than maximized, when openness to experience and classroom involvement were low, as denoted by circle B on the plot. Although the data does not represent a traditional fit relationship where an outcome is maximized everywhere along the line of perfect fit, it does reflect a positive fit relationship. Thus, these results provide partial support for Hypothesis 3(c) for this outcome.

Hypothesis 3(d) proposed that as openness to experience increases and student competition decreases, course satisfaction will increase. As can be seen in the surface plot in Figure 12, there is no fit relationship between the variables. Course satisfaction was not maximized at significantly different points along openness to experience. Course satisfaction was minimized when openness to experience was high and student competition was low, as denoted by circle $\mathrm{A}$ in the plot. This represents the opposite result of what was expected. However, there was a main effect for environment. As denoted by oval B, course satisfaction generally increased as student competition increased, regardless of students' level of openness to experience. Thus, Hypothesis 3(d) was not supported for this outcome.

Hypothesis 4(a) proposed that as agreeableness and structure and focus increase, course satisfaction would also increase. As can be seen in the surface plot in Figure 13, course satisfaction is maximized when both agreeableness and structure and focus are high, 
as denoted by circle $\mathrm{A}$ in the plot. Course satisfaction is minimized when agreeableness and structure and focus are low, as denoted by circle B on the plot. Thus, Hypothesis 4(a) was supported for this outcome.

Hypothesis 4(b) proposed that as congruence between agreeableness and participative learning increases, course satisfaction would also increase. As can be seen in the surface plot in Figure 14, course satisfaction is maximized when both agreeableness and participative learning are high, as denoted by circle $\mathrm{A}$ in the plot. Course satisfaction is minimized, rather than maximized, when agreeableness and participative learning are low, as denoted by circle B on the plot. Although the data does not represent a traditional fit relationship where an outcome is maximized everywhere along the line of perfect fit, it does reflect a positive fit relationship. Thus, these results provide partial support for Hypothesis 4(b) for this outcome.

Hypothesis 5(a) proposed that as congruence between conscientiousness and structure and focus increases, course satisfaction will increase. As can be seen in the surface plot in Figure 15, there is no fit relationship between the variables. Course satisfaction was not maximized along the line of fit; however, there was a main effect for the environment. As denoted by oval A, course satisfaction generally increased as structure and focus increased, regardless of students' level of conscientiousness. Thus, Hypothesis 5(a) was not supported for this outcome.

Hypothesis 5(b) proposed that as congruence between conscientiousness and student competition increases, course satisfaction would also increase. As can be seen in the surface plot in Figure 16, course satisfaction was maximized when both conscientiousness and student competition were high, as denoted by circle $A$ in the plot. Course satisfaction was minimized, rather than maximized, when conscientiousness and student competition were 
low, as denoted by circle B on the plot. Although the data does not represent a traditional fit relationship where an outcome is maximized everywhere along the line of perfect fit, it does reflect a positive fit relationship. Thus, these results provide partial support for Hypothesis 5(b) for this outcome.

Course Performance. Table 10 shows that for each hypothesis, the random intercepts model significantly predicted course performance better than the null base model. The table also provides a summary of the results for the hypothesis testing for the course performance outcome.

Hypothesis 1(a) proposed that as extraversion and structure and focus increased, course performance would also increase. As can be seen in the surface plot in Figure 17, there is no fit relationship between the variables. Course performance was not maximized when extraversion and structure and focus were both high; however, there was a main effect for the individual. As denoted by oval A, course performance generally increased as extraversion increased, regardless of the environment's level of structure and focus. Thus, Hypothesis 1(a) was not supported for this outcome.

Hypothesis 1(b) proposed that as congruence between extraversion and participative learning increases, course performance would also increase. However, the model did not reveal a fit relationship. That is, after accounting for the random intercepts, none of the predictors of fit (i.e., $X, Y, X^{2}, X Y, Y^{2}$ ) were significant predictors (Figure 18). Therefore, Hypothesis 1(b) was not supported for this outcome.

Hypothesis 1(c) proposed that as extraversion and instructor support increases, course satisfaction would also increase. However, the model did not reveal a fit relationship. That is, after accounting for the random intercepts, none of the predictors of fit (i.e., $X, Y, X^{2}, X Y, Y^{2}$ ) 
were significant predictors (Figure 19). Therefore, Hypothesis 1(c) was not supported for this outcome.

Hypothesis 1(d) proposed that as congruence between extraversion and student competition increases, course performance would also increase. As can be seen in the surface plot in Figure 20, course performance was maximized when both extraversion and student competition were high, as denoted by circle A. Course performance was minimized, rather than maximized, when extraversion and student competition were low, as denoted by circle B on the plot. Although the data does not represent a traditional fit relationship where an outcome is maximized everywhere along the line of perfect fit, it does reflect a positive fit relationship. Thus, these results provide partial support for Hypothesis 1(d) for this outcome.

Hypothesis 2(a) proposed that as neuroticism and structure and focus increases, course performance will also increase. As can be seen in the surface plot in Figure 21, there is no fit relationship between the variables. Course performance was not maximized when neuroticism and structure and focus were both high; however, there was a main effect for environment. As denoted by oval A, course satisfaction generally increased as structure and focus increased, regardless of students' level of neuroticism. Thus, Hypothesis 2(a) was not supported for this outcome.

Hypothesis 2(b) proposed that as congruence between neuroticism and participative learning increases, course performance will also increase. However, the model did not reveal a fit relationship. That is, after accounting for the random intercepts, none of the predictors of fit (i.e., $X, Y, X^{2}, X Y, Y^{2}$ ) were significant predictors (Figure 22). Therefore, Hypothesis 2(b) was not supported for this outcome. 
Hypothesis 2(c) proposed that as congruence between neuroticism and classroom involvement increases, course performance will also increase. However, the model did not reveal a fit relationship. That is, after accounting for the random intercepts, none of the predictors of fit (i.e., $X, Y, X^{2}, X Y, Y^{2}$ ) were significant predictors (Figure 23). Therefore, Hypothesis 2(c) was not supported for this outcome.

Hypothesis 3(a) proposed that as openness to experience increases and structure and focus decreases, course performance will increase. As can be seen in the surface plot in Figure 24, course performance was maximized when openness to experience was low and structure and focus was low, as denoted by circle A. Course performance was minimized when openness to experience and structure and focus were high, as denoted by circle B on the plot. These results represent a negative fit relationship that was not hypothesized. Thus, Hypothesis 3(a) was not supported for this outcome.

Hypothesis 3(b) proposed that as congruence between openness to experience and participative learning increases, course performance would also increase. As can be seen in the surface plot in Figure 25, there is no fit relationship between the variables. Course performance was not maximized along the line of fit; however, there was a main effect for the individual and the environment. Course performance was maximized when openness to experience was moderate and participative learning was high, as denoted by circle $\mathrm{A}$ in the plot. Thus, Hypothesis 3(a) was not supported for this outcome.

Hypothesis 3(c) proposed that as congruence between openness to experience and classroom involvement increases, course performance would also increase. As can be seen in the surface plot in Figure 26, course performance was maximized when both openness to experience and classroom involvement were high, as denoted by circle A in the plot. Course 
performance was minimized, rather than maximized, when openness to experience and classroom involvement were low, as denoted by circle B on the plot. Although the data does not represent a traditional fit relationship where an outcome is maximized everywhere along the line of perfect fit, it does reflect a positive fit relationship. Thus, these results provide partial support for Hypothesis 3(c) for this outcome.

Hypothesis 3(d) proposed that as openness to experience increases and student competition decreases, course performance will increase. As can be seen in the surface plot in Figure 27, there is no fit relationship between the variables. Course performance was not maximized along the line of perfect fit; however, there was a main effect for the individual. As denoted by oval A, course performance generally increased as student competition increased, regardless of the students' level of openness to experience. Thus, Hypothesis 3(d) was not supported for this outcome.

Hypothesis 4(a) proposed that as agreeableness and structure and focus increases, course performance would also increase. As can be seen in the surface plot in Figure 28, course performance is maximized when both agreeableness and structure and focus are high, as denoted by circle $\mathrm{A}$ in the plot. Course performance is minimized when agreeableness and structure and focus are low, as denoted by circle B on the plot. Thus, Hypothesis 4(a) was supported for this outcome.

Hypothesis 4(b) proposed that as congruence between agreeableness and participative learning increases, course performance would also increase. As can be seen in the surface plot in Figure 29, course performance is maximized when both agreeableness and participative learning are high, as denoted by circle A in the plot. Course performance is minimized, rather than maximized, when agreeableness and participative learning are low, as 
denoted by circle B on the plot. Although the data does not represent a traditional fit relationship where an outcome is maximized everywhere along the line of perfect fit, it does reflect a positive fit relationship. Thus, these results provide partial support for Hypothesis 4(b) for this outcome.

Hypothesis 5(a) proposed that as congruence between conscientiousness and structure and focus increases, course performance will increase. As can be seen in the surface plot in Figure 30, there is no fit relationship between the variables. Course performance was not maximized along the line of fit; however, there were main effects for both the individual and the environment. As denoted by oval A, course performance generally increased as structure and focus increased, regardless of the students' level of conscientiousness. As denoted by oval B, course performance generally increased as conscientiousness increased regardless of the environment's level of structure and focus. Thus, Hypothesis 5(a) was not supported for this outcome.

Hypothesis 5(b) proposed that as congruence between conscientiousness and student competition increases, course performance would also increase. As can be seen in the surface plot in Figure 31, there is no fit relationship between the variables. Course performance was not maximized along the line of fit; however, there was a main effect for the individual and the environment. As denoted by oval A, course performance generally increased as student competition increased, regardless of the students' level of conscientiousness. As denoted by oval B, course performance generally increased as conscientiousness increased regardless of the environment's level of student competition. Thus, Hypothesis 5(b) was not supported for this outcome. 


\section{Discussion}

The results of the study reveal an interesting pattern of relationships. Given that classroom environment was a strong predictor of student satisfaction, this study provides support for restructuring instruction for students along classroom environment dimensions to produce more satisfied students. Personality dimensions were the predominant predictors of performance in this study, lending support to the view that personality traits have remarkable impacts on academic achievement. Interestingly, only those personality dimensions framed in a "positive" direction were related to course performance suggesting that these "positive" traits have an important relation to success in psychology courses. Unexpectedly, higher levels of neuroticism were related to increases in student satisfaction (the opposite direction generally found in prior research), and neuroticism was not related to academic performance. Structure and focus and student competition seem to be the primary classroom environment dimensions that are associated with increases in student satisfaction and performance. Some personality and classroom environment combinations were also found to increase satisfaction, performance, or both. All but one of these relationships were in the positive direction. These results are discussed in the following sections.

\section{Main Effects}

When considering the performance outcome, most hypotheses have a significant main effect for personality, demonstrating that personality disproportionately predicted student classroom performance. My results specifically indicate that extraversion, openness to experience, agreeableness, and conscientiousness have significant relationships with course performance. These findings support previous research that suggests that personality has a remarkable effect on academic achievement (Trapmann, Hell, Hirn, \& Schuler, 2007). 
Specifically, Chamorro-Premuzic and Furnham (2003) found that extraversion, conscientiousness, and neuroticism were significant predictors of academic performance. Although their meta-analysis only found conscientiousness to be a significant predictor of academic performance in higher education, in their review, Trapmann et al. cited correlations of $.40, .42$, and .70 respectively for conscientiousness, openness to experience, and extraversion with academic achievement. Additionally, in his meta-analysis, Poropat (2009) found significant correlations with academic performance and conscientiousness, agreeableness, and openness to experience. Though prior findings on the personalityclassroom performance linkage are somewhat varied, the results from the present study suggest that personality is a significant predictor of academic performance.

While four of the five personality traits studied were significant predictors of performance, neuroticism was not. Additionally, the other personality traits are framed in a positive direction, suggesting that "positive" personality traits are related to academic success in psychology courses. This finding may be due to the demands required by psychology courses. More specifically, psychology courses often involve a great amount of discussion and group interaction suggesting that individuals with a positive orientation in extraversion may have an advantage in these types of courses. In addition, topics covered in psychology courses represent theoretical ideas and are often abstract. Being positively oriented on openness to experience and agreeableness may give individuals an advantage with this type of course material since these individuals would be more imaginative, creative, flexible, tolerant, and cooperative. Finally, psychology courses (as well as most higher education courses) require students to be organized, hardworking, and achievement-oriented, suggesting that being on the positive end of the spectrum in conscientiousness would be 
beneficial to performance in these courses. These results may not transfer to other fields, such as hard sciences, mathematics, or accounting, which may not emphasize the same "positive" characteristics, particularly when considering extraversion, openness to experience, and agreeableness. Courses in these fields may be less socially interactive and may contain more applied course material.

Another interesting pattern demonstrated in the performance outcome involves the environmental dimensions of structure and focus and student competition. These were the only environmental dimensions that significantly predicted student classroom performance. These findings suggest that providing both structure and focus and student competition in the classroom environment is disproportionately and consistently critical to academic success. Providing structure and focus in a classroom provides clarity, predictability, and encourages students to concentrate on their performance. For example, classrooms rated high on structure and focus in this study were generally well-organized, provided clearly and carefully planned lectures, activities, and assignments, provided a clear set of rules, and had an instructor that focused on the course material. In addition to structure and focus, providing student competition in the classroom has been shown to increase performance by enhancing student motivation (Shui-fong, Pui-shan, Law, \& Cheung, 2004).

In contrast to the personality-dominated predictors of student performance, student satisfaction was disproportionately predicted by environment. The effect of environment was so strong that nearly all of the hypotheses had significant main effects for environment when predicting satisfaction. These results demonstrate that satisfaction has a separate and distinct predictor from performance and that environment is a strong predictor of student attitudes. These results are consistent with other recent research. For example, Sell and Cleal (2011) 
found that psychosocial factors of the work environment significantly impacted levels of job satisfaction. In addition, Trapmann et al. (2007) found that only one of the Big Five personality traits, neuroticism, was significantly correlated with satisfaction. These findings suggest that environment has a more substantial effect on student attitudes than does personality. Such conclusions may have important implications for teaching assessments.

Since attitudes are more strongly influenced by environments, this may suggest that providing satisfying classroom environments would perhaps be more beneficial for instructors than affording higher grades in terms of positive teaching evaluations.

The pattern of results concerning the two outcome variables reveals several important findings. In summation, the environmental dimensions of structure and focus and student competition seem to be the only environmental components that transcend both outcomes. These results demonstrate the importance of structure and focus and student competition in psychology courses and perhaps other higher education courses as well. Secondly, attitudes and performance are predicted by different characteristics. The higher education community would benefit from considering these results when attempting to effect change in student performance and satisfaction.

\section{Fit Relationships}

In terms of personality, most of the significant fit results support existing research. Extraversion had the most fit relationships suggesting that people high on extraversion tend to be more outgoing, sociable, and active in their environments. This conclusion is evidenced by the fact that all of the hypotheses for extraversion were partially supported with positive fit relationships. More specifically, individuals high on extraversion increased in their satisfaction or performance if the corresponding environmental dimension was also high. 
These results are supported by previous research. Srivastava, Angelo, and Vallereux (2008) found that extraverts participate in more social interactions and actively engage with the environment more than do introverts.

Neuroticism did not demonstrate any fit relationships and only provided main effects in the satisfaction outcome. However, these main effects suggested that as neuroticism increases, satisfaction also increases. Neuroticism has generally been found to be a significant predictor of satisfaction (Trapmann et al., 2007), but not in the direction of the current results. Unlike this study, neuroticism has also generally been found to be a significant predictor of performance (Chamorro-Premuzic \& Furnham, 2003). However, other research results on this association are less clear. For example, Garfinkel et al. (2001) found that neuroticism was not a significant predictor of personal or professional satisfaction. Further, Trapmann et al. found that neuroticism was not related to academic achievement. The net effect of these conflicting results suggests that future research is needed to further examine neuroticism's relationship with both satisfaction and performance.

Openness to experience was related to increased satisfaction and performance when students were provided with the opportunity to engage in the classroom activities. This finding suggests that as individuals high on openness to experience become more interested and are given more say in classroom activities, their satisfaction and performance increase. These results may speak to the creative and imaginative nature of the openness to experience trait. Specifically, openness to experience is related strongly to motivation for behavioral variation meaning that individuals high on this trait have a need to participate in different kinds of behaviors (Joy, 2004). This may explain why individuals high on openness to experience produce positive outcomes when given an opportunity to provide input on what 
they will be doing in the classroom. In addition, openness to experience has been related to a preference for more active involvement in shared decision making concerning health care (Flynn \& Smith, 2007). Individuals high on openness to experience prefer to offer input and deliberate with others when determining their health care needs. These results indirectly support the finding in this study that individuals high on openness to experience will produce more positive outcomes when given the opportunity to participate in decision-making in the classroom.

Agreeableness was related to increased satisfaction and performance when students were provided with an organized and focused classroom and when students were provided with social learning opportunities. The findings provide support for the notion that agreeableness is related to system maintenance which encompasses organization, order, and expectations (Westerman \& Simmons, 2007). These results relate to the cooperative nature of individuals high on agreeableness and provide support for the belief that agreeableness is related to relationship orientation. This is evidenced by several studies where agreeableness has been related to interpersonal interaction (Nikolaou, 2003) and social participation (Stevens \& Ash, 2001).

Conscientiousness was related to satisfaction when individuals high on this trait were placed in environments with high student competition. This outcome relates to the finding that individuals high on conscientiousness have a need for continuous improvement and have achievement and goal orientations (Chamorro-Premuzic et al., 2007, Westerman \& Simmons, 2007). In terms of performance, congruence with environment may not play an important role since conscientiousness on its own has been related to high performance and achievement across several studies. In particular, in their meta-analysis, Trapmann et al. 
(2007) found it to be the only personality trait that was a significant predictor of academic achievement in higher education. These results suggest that conscientious individuals will perform well in most environments although they may not be as satisfied in most environments.

Overall, the results indicate some variations in performance and satisfaction with different combinations of personality and environmental dimensions. The study provides evidence that personality types are more satisfied and perform better in varying classroom environments. The higher education community needs to further explore these results in the interest of better serving their students, with the cautionary note that these results should be replicated and examined further.

More generally, in terms of the fit analyses, the results indicated that all but one of the significant fit relationships were in the positive direction, i.e. both predictor variables needed to be high in order to produce a significant outcome. These results suggest that if individuals are expecting certain characteristics from their environments that are indeed present, their outcomes will likely increase. Conversely, if individuals are not expecting certain characteristics from their environments, then it does not seem to make a difference in terms of student satisfaction and performance whether the characteristics are present or not.

\section{Implications}

In the broader scope of education, the results point to several interesting conclusions. In terms of one-size-fits-all education, the findings are inconclusive. Providing structured and focused environments as well as environments that encourage student competition are aspects that seem to hold true for most students in both satisfaction and performance outcomes. These conclusions lend support to the idea that certain environmental dimensions 
should be present in all psychology classrooms. However, evidence from this research also suggests that different personality types do seem to be more satisfied and perform better in varying environments lending support to the notion that one size may not fit all. This result was found more consistently for the student satisfaction outcome. Considering that student satisfaction is related to retention (Elliot \& Healy, 2001), this finding may have important implications for the higher education community. More specifically, universities are becoming more aware that they are in a service industry. They are emphasizing more the importance of meeting student needs and expectations. The general finding from this study, that environments are important predictors of student satisfaction, may be critical to the future success of universities. As student satisfaction leads to both retention and recommendations about the university to others, enhancements in classroom environments may provide for more successful recruitment efforts in such universities.

If, as indicated by the research, personality significantly predicts performance, universities may benefit from assessing personality in admissions processes. Research indicates that personality has incremental validity over typical measures used in college admittance such as the Scholastic Aptitude Test (Trapmann et al., 2007). Several researchers have supported the concept of using personality assessments in admissions processes in higher education institutions. This support is present, in part, because personality measures would reduce adverse impact for gender and race. The current study provides support for the use of personality measures in admission processes since four of the five personality traits measured were significant predictors of academic performance. Using personality measures may become a viable option for universities with large numbers of applicants and stringent competition for admittance. 
When considering the world of work, organizations might also benefit from the results of this study. As stated previously, the findings suggest that environments impact satisfaction. Employee satisfaction has been related to workplace safety, retention, profit, productivity, and customer satisfaction (Harter, Schmidt, \& Hayes, 2002). In addition, job satisfaction has been related to organizational commitment (Mathieu \& Zajac, 1990), job involvement (Spector, 1997), and many other attitudinal outcomes (Jex \& Britt, 2008). Organizations could use the results from this study to structure their environments to optimize employee satisfaction and reap the benefits of related outcomes.

These findings also relate to organizational training and development. Individual differences have important implications for training. In the case of personality, conscientiousness is an important predictor of training success as it has been strongly correlated to both motivation to learn (Colquitt, Le Pine, \& Noe, 2000) and transfer of training (Blume, Ford, Baldwin, \& Huang, 2010). Additionally, extraversion, agreeableness, and openness to experience have also been related positively to training achievement (Barrick \& Mount, 1991). Some research suggests that neuroticism is negatively related to training success (Campbell, Castaneda, \& Pulos, 2010). This finding does not fall in line with the results of the current study, advocating the need for future research to not only study further neuroticism's relationship with performance but more specifically with training success. Ultimately, personality is an important predictor of success in training programs. The current research supports these findings and suggests that organizations may benefit from assessing personalities not only for selection purposes but also for training and development intentions. 
Additionally, this study suggests that the environmental dimensions of structure and focus and student competition may also be important predictors of performance in organizational training and development programs. Providing trainees with structure and focus gives them clarity and predictability in the training environment and allows them to concentrate on their performance. The environmental dimension of student competition may be even more predictive of performance in an organizational setting as opposed to an educational setting. As the organizational culture and training environment encourage more competition among employees, employees will perhaps more readily seek development opportunities and be more motivated to perform well in these training initiatives. The organization may, therefore, benefit from a more talented workforce through the use of this tactic.

The study's findings also add support to the view that satisfaction is not a significant predictor of performance. The idea that employee satisfaction leads to increased performance has been debated greatly, but the current study suggests that a happy worker is not necessarily a productive worker. Past research has found low (Iaffaldano \& Muchinsky, 1985) to moderate (Judge, Thoresen, Bono, \& Patton, 2001) correlations between job satisfaction and job performance. These results are varied, but the current research suggests that these two variables have little relation. Evidence for this argument is provided when examining the fit relationships found as most of the personality-environment combinations that significantly predicted satisfaction did not predict performance. This pattern suggests that satisfaction and performance are different concepts, one being attitudinal and the other being behavioral. The research cited above and the current findings suggest that these concepts are predicted by different constructs and produce different outcomes. 


\section{Limitations}

Limitations to the study include that the nature of the measure used to assess perceived classroom environment was altered from its original state. Trickett and Moos' (1973) Classroom Environment Scale is a 90 item true/false measure that assesses high school classrooms along nine dimensions. This measure was altered in that low factor loading items were removed, items not related to a college classroom environment were removed, and the scale was changed to a 5-point Likert scale in order to provide consistency between the scale used to measure personality and the scale used to measure classroom environment. Changing the scale may have made the measure consistent with the personality measure, but it also removed Trickett and Moos' (1973) forced choice approach. This may have altered the factors and classroom environment dimensions significantly.

The study was also limited in that it only used participants from Introductory Psychology courses. These courses may produce significantly different classroom environments than other fields. These courses also may demand different characteristics of their students in order for students to have positive outcomes.

Finally, the study was limited by sample size. Although the sample size was large enough to find significant effects, a larger sample would have provided more variation. A larger sample may have also been more representative of the population.

\section{Suggestions for Future Research}

Future research should test these findings in different academic fields. Doing so may be able to determine if "positive" traits still predict performance, and if environment still predicts attitudes. It is possible that different academic fields require different characteristics 
of students, and may also provide different classroom environments. Therefore, results may vary from the findings in the current study.

Additionally, future research needs to further explore the relationship between neuroticism and the outcomes of satisfaction and performance. Although research generally suggests that neuroticism is a significant predictor of satisfaction and performance, some studies have not found this to be the case. This study adds to this conflicting evidence as neuroticism predicted satisfaction in the opposite direction than is generally found and did not predict performance. Further exploration is needed to determine how this personality trait is related to satisfaction and performance.

Finally, several personality-environment fit relationships predicted increased satisfaction, performance, or both. These relationships need to be explored further and results replicated if they are to be used as a basis for tailoring classroom environments. The higher education community has a vested interest to see if these results hold for other disciplines.

\section{Conclusion}

Evidence from this research supports restructuring instruction for students along classroom environment dimensions to produce more satisfied students. In particular, structure and focus and student competition seem to be important classroom environment dimensions that increase both satisfaction and performance. Personality dimensions were the predominant predictors of performance in this study lending support to the view that personality traits have remarkable impacts on academic achievement. More specifically, this study suggests that positive personality traits are important to success in psychology courses. Unexpectedly, neuroticism was positively related to student satisfaction and had no significant relation to student performance suggesting that the relationship between 
neuroticism and these outcomes should be examined further. Some personality and classroom environment combinations were found to increase satisfaction, performance, or both. Most of these relationships were in the positive direction. These combinations should be further studied and developed to determine if higher education classrooms would benefit from interventions based on these factors. 


\section{References}

Barrick, M. R., \& Mount, M. K. (1991). The big five personality dimensions and job performance: A meta-analysis. Personnel Psychology, 44, 1-26.

Blume, B. D., Ford, J., Baldwin, T. T., \& Huang, J. L. (2010). Transfer of training: A metaanalytic review. Journal of Management, 36, 1065-1105.

doi: $10.1177 / 0149206309352880$

Buunk, B. P., Nauta, A., Molleman, E. (2005). In search of the true group animal: The effects of affiliation orientation and social comparison orientation upon group satisfaction. European Journal of Personality, 19, 69-81.

Campbell, J. S., Castaneda, M., \& Pulos, S. (2010). Meta-analysis of personality assessments as predictors of military aviation training success. International Journal of Aviation Psychology, 20, 92-109. doi:10.1080/10508410903415872

Caspi, A., Chajut, E., Saporta, K., \& Beyth-Marom, R. (2006). The influence of personality on social participation in learning environments. Learning and Individual Differences, 16, 129-144.

Chamorro-Premuzic, T., \& Furnham, A. (2003). Personality predicts academic performance: Evidence from tow longitudinal university samples. Journal of Research in Personality, 37, 319-338.

Chamorro-Premuzic, T., Furnham, A., \& Lewis, M. (2007). Personality and approaches to learning predict preference for different teaching methods. Learning and Individual Differences, 17, 241-250. doi: 10.1016/j.lindif.2006.12.001

Chartrand, J. M. (1991). The evolution of trait-and-factor career counseling: A person x environment fit approach. Journal of Counseling \& Development, 69, 518-524. 
Colquitt, J. A., LePine, J. A., \& Noe, R. A. (2000). Toward an integrative theory of training motivation: A meta-analytic path analysis of 20 years of research. Journal of Applied Psychology, 85, 678-707.

Costa, P., \& McCrae, R. (1994). Stability and change in personality from adolescence through adulthood. In: Halverson, C. F. Jr, Kohnstamm, G. A., and Martin, R. P. (Eds.), The Developing Structure of Temperament and Personality from Infancy to Adulthood, Erlbaum, Hillsdale, NJ, pp. 139-155.

Costa, P. T., \& McCrae, R. R. (1995). Domains and facets: Hierarchical personality assessment using the revised NEO Personality Inventory. Journal of Personality Assessment, 64, 21-50.

Cronbach, L. J. (1958). Proposals leading to analytic treatment of social perception scores. In R. Tagiuri \& L. Petrullo (Eds.), Person Perception and Interpersonal Behavior (pp. 353-379). Stanford, CA: Stanford University Press.

Dawis, R.V., \& Lofquist, L.H. (1984). A psychological theory of work adjustment: An individual differences model and its application. Minneapolis, MN: University of Minnesota Press.

Davis, M. (2010). Personality and its effect on relationships and teaching and learning styles. International Schools Journal, 29, 22-29.

Deemer, S. A. (2004). Classroom goal orientation in high school classrooms: revealing links between teacher beliefs and classroom environments. Educational Research, 46, 7390. 
Diaz-Grandados, F. I., Dominguez, E., Ricardo, C., Ballesteros, B., \& Fontalvo, H. (2009). Effects of a centered virtual teaching environment on learning styles in the academic performance of college students. iJET, 4, 59-63.

Dorman, J. P. (2001). Associations between classroom environment and academic efficacy. Learning Environments Research, 4, 243-257.

Edwards, J. R. (1991). Person-job fit: A conceptual integration, literature review, and methodological critique. In C. L. Cooper \& I. T. Robertson (Eds.), International Review of Industrial and Organizational Psychology (Vol. 6, pp. 283-357). Chichester, UK: Wiley.

Edwards, J. R. (1994). Alternatives to difference scores as dependent variables in the study of congruence in organizational research. Organizational Behavior and Human Decision Processes, 64, 307-324.

Edwards, J. R., \& Parry, M. E. (1993). On the use of polynomial regression equations as an alternative to difference scores in organizational research. Academy of Management Journal, 36, 1577-1613.

Ehrhart, K. H. (2006). Job characteristics beliefs and personality as antecedents of subjective person-job fit. Journal of Business and Psychology, 21, 193-226.

Elliot, K. M., \& Healy, M. A. (2001). Key factors influencing student satisfaction relate to recruitment and retention. Journal of Marketing for Higher Education, 10, 1-11.

Farsides, T., \& Woodfield, R. (2003). Individual differences and undergraduate academic success: The roles of personality, intelligence, and application. Personality and Individual Differences, 34, 1225-1243. 
Feldman, K. A., Smart, J. C., \& Ethington, C. A. (2004). What do college students have to lose? Exploring the outcomes of differences in person-environment fits. The Journal of Higher Education, 75, 528-555.

Flynn, N. M., \& Rapoport, J. L. (1976). Hyperactivity in open and traditional classroom environments. The Journal of Special Education, 10, 285-290.

Flynn, K. E., \& Smith, M. A. (2007). Personality and health care decision-making style. The Journals of Gerontology: Series B: Psychological Sciences and Social Sciences, 62, 261-267.

Fraser, B. J., \& Fisher, D. L. (1983). Use of actual and preferred classroom environment scales in person-environment fit research. Journal of Educational Psychology, 75, 303-313.

Freiberg, H. J., \& Lamb, S. M. (2009). Dimensions of person-centered classroom management. Theory Into Practice, 48, 99-105.

Fry, P. S., \& Addington, J. (1984). Comparison of social problem solving of children from open and traditional classrooms: A two-year longitudinal study. Journal of Educational Psychology, 76, 318-329.

Furnham, A., \& Chamorro-Premuzic, T. (2005). Individual differences in students' preferences for lecturers' personalities. Journal of Individual Differences, 26, 176184. doi: $10.1027 / 1614-0001.26 .4 .176$

Furnham, A., Christopher, A., Garwood, J., \& Martin, N. G. (2008). Ability, demography, learning style, and personality trait correlates of student preference for assessment method. Educational Psychology, 28, 15-27.

Gardner, H. (1995). Reflections on multiple intelligences. Phi Delta Kappan, 77, 200-208. 
Garfinkel, P. E., Bagby, R., Schuller, D. R., Williams, C. C., Dickens, S. E., \& Dorian, B. (2001). Predictors of success and satisfaction in the practice of psychiatry: A preliminary follow-up study. The Canadian Journal of Psychiatry / La Revue canadienne de psychiatrie, $46,835-840$.

Hampton, G. (1991). Coping with person-environment incongruence. Journal of Applied Psychology, 21, 1277-1292.

Harms, P. D., Roberts, B. W., \& Winter, D. (2006). Becoming the Harvard man: Personenvironment fit, personality development, and academic success. Personality and Social Psychology Bulletin, 32, 851-865. doi: 10.1177/0146167206287720

Harter, J. K., Schmidt, F. L., \& Hayes, T. L. (2002). Business-unit-level relationship between employee satisfaction, employee engagement, and business outcomes: A metaanalysis. Journal of Applied Psychology, 87, 268-279.

Hartung, P. J., Borges, N. J., \& Jones, B. J. (2005). Using person matching to predict career specialty choice. Journal of Vocational Behavior, 67, 102-117.

"Higher Education Stats Stir New Concerns in USA." (2006, September 6). USA Today. Retrieved from http:/www.usatoday.com/news/education/2006-09-06-highereducation_x.htm.

Holland, J. L. (1973). Making vocational choices: A theory of careers. Englewood Cliffs, NJ: Prentice-Hall.

Holland, J. L. (1996). Exploring careers with a typology: What we have learned and some new directions. American Psychologist, 51, 397-406.

Iaffaldano, M. T., \& Muchinsky, P. M. (1985). Job satisfaction and job performance: A metaanalysis. Psychological Bulletin, 97, 251-273. 
Jagger, L. \& Neukrug, E. (1992). Congruence between personality traits and chosen occupation as a predictor of job satisfaction for people with disabilities. Rehabilitation Counseling Bulletin, 36, 53-61.

James, L.R., Demaree, R.G., \& Wolf, G. (1984). Estimating within-group interrater reliability with and without response bias. Journal of Applied Psychology, 69, 85-98.

Jex, S. M., \& Britt, T. W. (2008). Organizational psychology: A scientist-practitioner approach. Hoboken, NJ: John Wiley \& Sons, Inc.

Johns, G. (1981). Difference score measures of organizational behavior variables: A critique. Organizational Behavior and Human Performance, 27, 443-463.

Joiner, K. F., Malone, J. A., \& Haimes, D. H. (2002). Assessment of classroom environments in reformed calculus education. Learning Environments Research, 5, 51-76.

Joy, S. (2004). Innovation motivation: The need to be different. Creativity Research Journal, 16, 313-330. doi:10.1207/s15326934crj1602\&3_13

Judge, T. A., \& Cable, D. M. (1997). Applicant personality, organizational culture, and organization attraction. Personnel Psychology, 50, 359-394.

Judge, T. A., Thoresen, C. J., Bono, J. E., \& Patton, G. K. (2001). The job satisfaction-job performance relationship: A qualitative and quantitative review. Psychological Bulletin, 127, 376-407.

Kirtz, S., \& Moos, R. H. (1974). Physiological effects of social environments. Psychosomatic Medicine, 36, 96-114.

Kristof, A. L. (1996). Person-organization fit: An integrative review of its conceptualizations, measurement, and implications. Personnel Psychology, 49, 1-49. doi:10.1111/j.1744-6570.1996.tb01790.x 
Kutner, M. H., Nachtsheim, C. J., Neter, J., \& Li, W. (2005). Applied Linear Statistical Models (5th ed.). Boston, MA: McGraw-Hill Irwin.

Landrum, T. J., \& McDuffie, K. A. (2010). Learning styles in the age of differentiated instruction. Exceptionality, 18, 6-17.

Lievens, F., Decaesteker, C., Coetsier, P., \& Geirnaert, J. (2001). Organizational attractiveness for prospective applicants: A person-organisation fir perspective. Applied Psychology: An International Review, 50, 30-51.

Lounsbury, J. W., Saudargas, R. A., Gibson, L. W., \& Leong, F. T. (2005). An investigation of broad and narrow personality traits in relation to general and domain-specific life satisfaction of college students. Research in Higher Education, 46, 707-729.

Martin, S. (2010). Teachers using learning styles: Torn between research and accountability. Teaching and Teacher Education, 26, 1583-1591.

Mathieu, J. E., \& Zajac, D. M. (1990). A review and meta-analysis of the antecedents, correlates, and consequences of organizational commitment. Psychological Bulletin, $108,171-194$.

McCrae, R. R., \& Costa, P. T. (1987). Validation of the five-factor model of personality across instruments and observers. Journal of Personality and Social Psychology, 52, 81-90.

McCrae, R. R., \& Costa, P. T. (2004). A contemplated revision of the NEO Five-Factor Inventory. Personality and Individual Differences, 36, 587-596.

Murray, H. (1938). Explorations in personality. New York: Oxford University Press. 
Nielsen, H. D., \& Moos, R. H. (1978). Exploration and adjustment in high school classrooms: A study of person-environment fit. The Journal of Educational Research, $72,52-57$.

Nijhuis, J., Segers, M., \& Gijselaers, W. (2007). The interplay of perceptions of the learning environment, personality, and learning strategies: A study amongst international business studies students. Studies in Higher Education, 32, 59-77, doi: $10.1080 / 03075070601099457$

Nikolaou, I. (2003). Fitting the person to the organization: Examining the personality-job performance relationship from a new perspective. Journal of Managerial Psychology, 18, 639-648.

Nunnally, J. C. (1962). The analysis of profile data. Psychological Bulletin, 59, 311-319. Peeke, P. A., Steward, R. J., \& Ruddock, J. A. (1998). Urban adolescents' personality and learning styles: Required knowledge to develop effective interventions in schools. Journal of Multicultural Counseling and Development, 26, 120-136.

Piasentin, K. A., \& Chapman, D. S. (2006). Subjective person-organization fit: Bridging the gap between conceptualization and measurement. Journal of Vocational Behavior, 69, 202-221. doi:10.1016/j.jvb.2006.05.001

Poropat, A. E. (2009). A meta-analysis of the five-factor model of personality and academic performance. Psychological Bulletin, 135, 322-338. doi:10.1037/a0014996

Salter, D. W., Evans, N. J., \& Forney, D. S. (2006). A longitudinal study of learning style preference on the Myers-Briggs Type Indicator and Learning Style Inventory. Journal of College Student Development, 47, 173-184. 
Schneider, B., Smith, D. B., \& Goldstein, H. W. (2000). Attraction-selection-attrition: Toward a person-environment psychology of organizations. In W. B. Walsh, K. H. Craik \& R. H. Price (Eds.), Person-environment psychology: New directions and perspectives (pp. 61-85). Mahwah, NJ: Lawrence Erlbaum Associates.

Schniederjans, M. J., \& Kim, E. B. (2005). Relationship of student undergraduate achievement and personality characteristics in a total web-based environment: An empirical study. Decision Science Journal of Innovative Education, 3, 205-221.

Sell, L., \& Cleal, B. (2011). Job satisfaction, work environment, and rewards: Motivational theory revisited. Labour, 25, 1-23.

Shui-fong, L., Pui-shan, Y., Law, J. F., \& Cheung, R. Y. (2004). The effects of competition on achievement motivation in Chinese classrooms. British Journal of Educational Psychology, 74, 281-296.

Spector, P. E. (1997). Job satisfaction: Application, assessment, causes, and consequences. Thousand Oaks, CA: Sage.

Srivastava, S., Angelo, K. M., \& Vallereux, S. R. (2008). Extraversion and positive affect: A day reconstruction study of person-environment transactions. Journal of Research in Personality, 42, 1613-1618.

"Statistics about Higher Education." (2008, January 12). The San Diego Union-Tribune. Retrieved from http://www.signonsandiego.com/uniontrib/20080112/news_ lzln12list.html.

Stevens, C., \& R. Ash. (2001). Selecting employees for fit: Personality and preferred managerial style. Journal of Managerial Issues, 13, 500-517. 
Swanson, J. L., \& Fouad, N. A. (1999). Applying theories of person-environment fit to the transition from school to work. The Career Development Quarterly, 47, 337-347.

Tan, W.C., Aris, B., \& Abu, S. (2006). GLOTT Model: A pedagogically enriched design framework of learning environment to improve higher order thinking skills. $A A C E$ Journal, 14(2), 139-153.

Terborg, J. R. (1981). Interactional psychology and research on human behavior in organizations. Academy of Management Review, 6, 569-576.

Tomlinson, C. A., \& Kalbfleisch, M. L. (1998). Teach me, teach my brain, a call for differentiated classrooms. Educational Leadership, 52-55.

Trapmann, S., Hell, B., Hirn, J. O. W., \& Schuler, H. (2007). Meta-analysis of the relationship between the big five and academic success at university. Journal of Psychology, 215, 132-151.

Trickett, E. J., \& Moos, R. H. (1973). Social environment of junior high and high school classrooms. Journal of Educational Psychology, 65, 93-102.

Trickett, E. J. \& Quinlan, D. M. (1979). Three domains of classroom environment: Factor analysis of the classroom environment scale. American Journal of Community Psychology, 7, 279-291.

"US College Dropout Rates Spark Concern." (2006, September 27). Associated Press. Retrieved from http://diverseeducation.com/article/6422/. U.S. Department of Education, National Center for Education Statistics. (2010). The Condition of Education 2010 (NCES 2010-028). Retrieved from http://nces.ed.gov/fastfacts/display.asp?id=40. 
U.S. Department of Education, National Center for Education Statistics. (2010). The Condition of Education 2010 (NCES 2010-028). Retrieved from http://nces.ed.gov/fastfacts/display.asp?id=40.

Wang, K. H., Wang, T. H., Wang, W. L., \& Huang, S. C. (2006). Learning styles and formative assessment strategy: enhancing student achievement in web-based learning. Journal of Computer Assisted Leaning, 22, 207-217.

Weisstein, E., \& Jacobson, D. (2009). Many sizes fit all: Considering multiple pathways to higher learning. The New England Journal of Higher Education, 15-17.

Westerman, J. W., Nowicki, M. D., \& Plante, D. (2002). Fit in the classroom: Predictors of student performance and satisfaction in management education. Journal of Management Education, 26, 5-18. doi: 10.1177/105256290202600102

Westerman, J. W., \& Simmons, B. L. (2007). The effects of work environment on the personality-performance relationship: An exploratory study. Journal of Managerial Issues, 19, 288-305.

Westerman, J. W., \& Vanka, S. (2005). A cross-cultural empirical analysis of personorganization fit measures as predictors of student performance in business education: Comparing students in the United States and India. Academy of Management Learning \& Education, 4, 409-420.

Whitbourne, J. (2010). The dropout dilemma: One in four college freshmen drop out. What is going on here? What does it take to stay in?. Careers and College. Retrieved from http://findarticles.com/p/articles/mi_m0BTR/is_4_22/ai_84599442/pg_7/?tag $=$ content; coll 
Williams, R. L. (1971). Relationship of class participation to personality, ability, and achievement variables. The Journal of Social Psychology, 83, 193-198.

Williamson, M. F., \& Watson, R. L. (2007). Learning styles research: Understanding how teaching should be impacted by the way learners learn part III: Understanding how learners' personality styles impact learning. Christian Education Journal, 4, 62-77.

Woszczynski, A. B., Gutherie, T. C., \& Shade, S. (2005). Personality and programming. Journal of Information Systems Education, 16, 293-299.

Zhang. L. (2006). Thinking styles and the big five personality traits revisited. Personality and Individual Differences, 40, 1177-1187. 


\section{Appendix A \\ Original Classroom Environment Scale}

$\mathrm{R}$ denotes a reverse-coded item.

\section{Involvement}

1. Students are often "clock-watching" in class. (R)

2. Most students in this class really pay attention to what the instructor is saying.

3. Students frequently take part in class discussions or activities.

4. Students sometimes present something they've worked on to the class.

\section{Affiliation}

5. Students in this class get to know each other really well.

6. Students enjoy working together on projects in this class.

7. Students enjoy helping each other with homework.

8. Students don't have much of a chance to get to know each other in this class. (R)

\section{Teacher Support}

9. This instructor often spends time just talking with students.

10. The instructor takes a personal interest in students.

11. The instructor goes out of his/her way to help students.

12. This instructor wants to know what the students want to learn about.

\section{Task Orientation}

13. Almost all class time is spent on discussing the course material.

14. We often spend more time discussing outside student activities than class-related material (R)

15. This instructor often takes time out from the lesson plan to talk about other things. (R) 
16. The instructor sticks to course material and does not get sidetracked.

\section{Order and Organization}

17. This is a well-organized class.

18. Assignments are usually clear so everyone knows what to do.

19. This class hardly ever starts on time. (R)

20. Activities and lectures in this course are clearly and carefully planned.

\section{Rule Clarity}

21. There is a clear set of rules for students to follow.

22. There are very few rules to follow. (R)

23. The instructor is very strict.

24. The teacher makes a point of sticking to the rules he/she has made.

\section{Innovation}

25. New and different ways of teaching are tried very often in this course.

26. The instructor likes students to try unusual projects.

27. Students have very little to say about how class time is spent. (R)

28. Students do the same kind of work almost every day in this class. (R)

\section{Student Competition}

29. Students try hard to get the best grade.

30. Grades are not very important in this class. (R)

31. Students have to work for a good grade in this class.

32. Students usually pass even if they don't do much. (R) 
Appendix B

\section{Classroom Environment Dimensions}

\section{Structure and Focus}

1. This is a well-organized class.

2. Activities and lectures in this course are clearly and carefully planned.

3. The instructor sticks to the course material and does not get sidetracked.

4. Assignments are usually clear so everyone knows what to do.

5. The teacher makes a point of sticking to the rules he/she has made.

6. Almost all class time is spent on discussing the course material.

7. There is a clear set of rules for students to follow.

8. The instructor goes out of his/her way to help students.

\section{Participative Learning}

9. Students enjoy working together on projects in this class.

10. Students enjoy helping each other with homework.

11. Students sometimes present something they've worked on to the class

12. Students in the class get to know each other really well.

13. New and different ways of teaching are tried very often in this course.

14. The instructor likes students to try unusual projects.

\section{Classroom Involvement}

15. Students don't have much of a chance to get to know each other in this class. (R)

16. Students have very little input on how the class time is spent. (R)

17. Students do the same kind of work almost every day in this class. (R)

18. Students are often clock-watching in class. (R) 


\section{Instructor Support}

19. This instructor often spends time just talking with students.

20. This instructor often takes time out from the lesson plan to talk about other things.

21. The instructor takes a personal interest in students.

\section{Student Competition}

22. Students have to work for a good grade in this class.

23. Student usually pass even if they don't do much.

24. Students try hard to get the best grade. 


\section{Appendix C}

\section{Hypotheses}

\section{Extraversion}

Hypothesis 1 (a): As extraversion increases and structure and focus increases, student performance and course satisfaction will increase.

Hypothesis 1 (b): As congruence between extraversion and participative learning increases, student performance and course satisfaction will increase.

Hypothesis 1 (d): As extraversion increases and instructor support increases, student performance and course satisfaction will increase.

Hypothesis 1 (e): As congruence between extraversion and student competition increases, student performance and course satisfaction will increase.

\section{Neuroticism}

Hypothesis 2 (a): As neuroticism increases and structure and focus increases, student performance and course satisfaction will increase.

Hypothesis 2 (b): As congruence between neuroticism and participative learning increases, student performance and course satisfaction will increase.

Hypothesis 2 (c): As congruence between neuroticism and classroom involvement increases, student performance and course satisfaction will increase.

\section{Openness to Experience}

Hypothesis 3 (a): As openness to experience increases and structure and focus decreases, student performance and course satisfaction will increase.

Hypothesis 3 (b): As congruence between openness to experience and participative learning increases, student performance and course satisfaction will increase. 
Hypothesis 3 (c): As congruence between openness to experience and classroom involvement increases, student performance and course satisfaction will increase.

Hypothesis 3 (d): As openness to experience increases and student competition decreases, student performance and course satisfaction will increase.

\section{Agreeableness}

Hypothesis 4 (a): As agreeableness increases and structure and focus increases, student performance and course satisfaction will increase.

Hypothesis 4 (b): As congruence between agreeableness and participative learning increases, student performance and course satisfaction will increase.

\section{Conscientiousness}

Hypothesis 5 (a): As congruence between conscientiousness and structure and focus increases, student performance and course satisfaction will increase.

Hypothesis 5 (b): As congruence between conscientiousness and student competition increases, student performance and course satisfaction will increase. 


\section{Appendix D}

\section{NEO-FFI}

(R) denotes a reverse coded item.

\section{Neuroticism}

1. I am not a worrier.(R)

3. I often feel inferior to others.

11. When I'm under a great deal of stress, sometimes I feel like I'm going to pieces.

16. I rarely feel lonely or blue.(R)

21. I often feel tense and jittery,

26. Sometimes I feel completely worthless.

31. I rarely feel fearful or anxious. (R)

36. I often get angry at the way people treat me.

41. Too often, when things go wrong, I get discouraged and feel like giving up.

46. I am seldom sad or depressed. (R)

51. I often feel helpless and want someone else to solve my problems.

56. At times I have been so ashamed I just wanted to hide.

\section{Extraversion}

2. I like to have a lot of people around me.

7. I laugh easily.

12. I don't consider myself especially "light-hearted." (R)

17. I really enjoy talking to people.

22. I like to be where the action is.

32. I often feel as if I'm bursting with energy. 
27. I usually prefer to do things alone. (R)

37. I am a cheerful, high-spirited person.

42. I am not a cheerful optimist. (R)

47. My life is fast-paced.

52. I am a very active person.

57. I would rather go my own way than be a leader of others. (R)

\section{Openness to Experience}

3. I don't like to waste my time daydreaming. (R)

8. Once I find the right way to do something, I stick to it. (R)

13. I am intrigued by the patterns I find in art and nature.

18. I believe letting people hear controversial speakers can only confuse and mislead them. (R)

23. Poetry has little or no effect on me. (R)

28. I often try new and foreign foods.

33. I seldom notice the moods or feelings that different environments produce. (R)

38. I believe we should look at our religious authorities for decisions on moral issues. (R)

43. Sometimes when I am reading poetry or looking at a work of art, I feel a chill or wave of excitement.

48. I have little interest in speculating on the nature of the universe or the human condition. (R)

53. I have a lot of intellectual curiosity.

58. I often enjoy playing with theories or abstract ideas. 


\section{Agreeableness}

4. I try to be courteous to everyone I meet.

9. I often get into arguments with my family and peers. (R)

14. Some people think I'm selfish and egotistical. (R)

19. I would rather cooperate with others than compete with them.

24. I tend to be cynical and skeptical of others' intentions. (R)

29. I believe that most people will take advantage of you if you let them. (R)

34. Most people I know like me.

39. Some people think of me as cold and calculating. (R)

44. I'm hard-headed and tough-minded in my attitudes. (R)

49. I generally try to be thoughtful and considerate.

54. If I don't like people I let them know it. (R)

59. If necessary, I am willing to manipulate people to get what I want. (R)

\section{Conscientiousness}

5. I keep my belongings neat and clean.

10. I'm pretty good about pacing myself so as to get things done on time.

15. I am not a very methodical person. (R)

20. I try to perform all the tasks assigned to me conscientiously.

25. I have a clear set of goals and work toward them in an orderly fashion.

30. I waste a lot of time before settling down to work. (R)

35. I work hard to accomplish my goals.

40. When I make a commitment, I can always be counted on to follow through.

45. Sometimes I'm not as dependable or reliable as I should be. (R) 
50. I am a productive person who always gets the job done.

55. I never seem to be able to get organized. (R)

60. I strive for excellence in everything I do. 
Appendix E

\section{Course Satisfaction}

1. Overall, I rate this course as excellent.

2. I am really excited about this class.

3. I think what we are studying in this class will be useful to know.

4. I think what we are studying in this class will be important to know. 
Table 1

Five Factor Model Factor Descriptions

\begin{tabular}{ll}
\hline Dimension & Features \\
\hline Extraversion & Ambitious, sociable, gregarious, talkative, assertive, impetuous, \\
active & Depressed, anxious, angry, emotional, embarrassed, insecure, \\
Neuroticism & worried \\
Openness to Experience & $\begin{array}{l}\text { Imaginative, curious, cultured, broad-minded, original, artistically } \\
\text { sensitive, intelligent } \\
\text { Agreeableness }\end{array}$ \\
Flexible, courteous, good-natured, trusting, forgiving, cooperative, \\
tolerant, soft-hearted \\
Dependable, thorough, careful, organized, responsible, \\
achievement-oriented, hardworking, persevering
\end{tabular}


Table 2

Classroom Environment Factor Descriptions

Dimension Description

Structure and Focus

The extent to which the course material is focused on and the classroom is organized.

Participative Learning

The degree to which learning is a social activity in the classroom.

Classroom Involvement The degree to which students show interest in and provide input concerning the activities in the classroom.

Instructor Support

The extent to which the instructor takes an interest in the students and material unrelated to the course.

Student Competition The level of emphasis placed on academic competition between students within the classroom. 
Table 3

Original Classroom Environment Scale Factor Descriptions

\begin{tabular}{|c|c|}
\hline Dimension & Description \\
\hline Student Competition & $\begin{array}{l}\text { The level of emphasis placed on academic competition between } \\
\text { students within the classroom. }\end{array}$ \\
\hline Innovation & $\begin{array}{l}\text { The degree to which various methods of classroom interaction } \\
\text { and teaching are employed in the class. }\end{array}$ \\
\hline Rule Clarity & $\begin{array}{l}\text { The extent to which rules are explicitly stated and understood in } \\
\text { the classroom. }\end{array}$ \\
\hline Order and Organization & $\begin{array}{l}\text { The extent to which activities in the classroom are organized } \\
\text { well and the extent to which emphasis is placed on the } \\
\text { maintenance of order. }\end{array}$ \\
\hline Teacher Control & $\begin{array}{l}\text { The extent and amount of rules that govern student behavior in } \\
\text { the class. }\end{array}$ \\
\hline Task Orientation & $\begin{array}{l}\text { The degree to which activities are employed to accomplish } \\
\text { specific academic goals. }\end{array}$ \\
\hline Teacher Support & $\begin{array}{l}\text { The degree to which the instructor expresses an interest in } \\
\text { regard to the students. }\end{array}$ \\
\hline Affiliation & $\begin{array}{l}\text { The degree to which students interact with one another and get } \\
\text { to know one another within the class. }\end{array}$ \\
\hline Involvement & $\begin{array}{l}\text { The degree to which the students show interest in and pay } \\
\text { attention to the activities in the classroom. }\end{array}$ \\
\hline
\end{tabular}


Table 4

Reliabilities for Subscales in Original Classroom Environment Scale Used

\begin{tabular}{lcc}
\hline \multicolumn{1}{c}{ Scale } & Cronbach's Alpha & Number of Items \\
\hline Involvement & .49 & 4 \\
Affiliation & .71 & 4 \\
Teacher Support & .69 & 4 \\
Task Orientation & .59 & 4 \\
Order and Organization & .69 & 4 \\
Rule Clarity & .49 & 4 \\
Innovation & .58 & 4 \\
Student Competition & .54 & 4 \\
\hline
\end{tabular}


Table 5

Reliabilities for Subscales in New Classroom Environment Scale

\begin{tabular}{lcc}
\hline \multicolumn{1}{c}{ Scale } & Cronbach's Alpha & Number of Items \\
\hline Structure and Focus & .77 & 6 \\
Participative Learning & .80 & 6 \\
Classroom Involvement & .67 & 4 \\
Instructor Support & .56 & 3 \\
Student Competition & .56 & 3 \\
\hline
\end{tabular}


Table 6

Correlations Among Study Variables

\begin{tabular}{|c|c|c|c|c|c|c|c|c|c|c|c|c|c|c|}
\hline Variable & $\mathbf{M}$ & SD & 1 & 2 & 3 & 4 & 5 & 6 & 7 & 8 & 9 & 10 & 11 & 12 \\
\hline $\begin{array}{l}\text { 1.Personality- } \\
\text { Extraversion }\end{array}$ & 2.52 & 0.45 & $(.71)$ & & & & & & & & & & & \\
\hline $\begin{array}{l}\text { 2.Personality- } \\
\text { Neuroticism }\end{array}$ & 1.84 & 0.67 & $-.32 * *$ & $(.85)$ & & & & & & & & & & \\
\hline $\begin{array}{l}\text { 3. Personality- } \\
\text { Openness }\end{array}$ & 2.38 & 0.54 & -.03 & .02 & $(.76)$ & & & & & & & & & \\
\hline $\begin{array}{l}\text { 4.Personality- } \\
\text { Agreeableness }\end{array}$ & 2.61 & 0.49 & $.33^{* *}$ & $-.20 * *$ & .03 & $(.75)$ & & & & & & & & \\
\hline $\begin{array}{l}\text { 5.Personality- } \\
\text { Conscientiousness }\end{array}$ & 2.56 & 0.56 & $.18^{* *}$ & $-.22 * *$ & $-.18 * *$ & $.23^{* *}$ & $(.84)$ & & & & & & & \\
\hline $\begin{array}{l}\text { 6.CE- Structure } \\
\text { and Focus }\end{array}$ & 3.72 & 0.60 & $.16^{* *}$ & -.05 & .01 & $.23 * *$ & $.19 * *$ & $(.77)$ & & & & & & \\
\hline $\begin{array}{l}\text { 7.CE- Participative } \\
\text { Learning }\end{array}$ & 2.35 & 0.80 & $.12^{* *}$ & -.07 & -.02 & .04 & $.14^{* *}$ & $.26 * *$ & $(.80)$ & & & & & \\
\hline $\begin{array}{l}\text { 8.CE-Classroom } \\
\text { Involvement }\end{array}$ & 3.24 & 0.79 & .07 & -.07 & .03 & .04 & $.09 *$ & $.14^{* *}$ & $.32^{* *}$ & (.67) & & & & \\
\hline $\begin{array}{l}\text { 9.CE- Instructor } \\
\text { Support }\end{array}$ & 2.97 & 0.77 & $.15^{* *}$ & -.01 & -.01 & .05 & $.10^{* *}$ & $.15^{* *}$ & $.46^{* *}$ & $.15^{* *}$ & $(.56)$ & & & \\
\hline $\begin{array}{l}\text { 10.CE- Student } \\
\text { Competition }\end{array}$ & 3.81 & 0.63 & $.16^{* *}$ & -.02 & -.05 & $.14^{* *}$ & $.21^{* *}$ & $.41^{* *}$ & $.14^{* *}$ & $.17^{* *}$ & $.08^{*}$ & $(.56)$ & & \\
\hline $\begin{array}{l}\text { 11.Course } \\
\text { Satisfaction }\end{array}$ & 4.00 & 0.67 & $.08 * *$ & -.00 & .10 & $.15^{* *}$ & $.10^{* *}$ & $.36^{* *}$ & $.24^{* *}$ & $.21 * *$ & $.14^{* *}$ & $.26 * *$ & $(.85)$ & \\
\hline 12.Final Grade & 82.70 & 17.43 & $.07 * *$ & -.02 & -.01 & $.13 * *$ & $.11^{* *}$ & $.10^{*}$ & -.01 & .02 & .01 & $.09 * *$ & $.09 * *$ & - \\
\hline
\end{tabular}

Note. Values on main diagonal (in parentheses) represent Cronbach's coefficient alpha. CE denotes Classroom Environment. Final Grade was assessed using a single item, therefore its reliability estimate is not available. M denotes the mean and SD denotes the standard deviation. ${ }^{*} p<.05$, 2-tailed. ${ }^{* *} p<.01,2$-tailed. $\mathrm{N}=732$. 
Table 7

Percent Reduction in Residual Variance over the Null Model for Course Satisfaction

\begin{tabular}{lcccccccc}
\hline & \multicolumn{3}{c}{ No Random Effects } & \multicolumn{3}{c}{ Random Intercepts } & \multicolumn{2}{c}{ Random Intercepts and Slopes } \\
\hline Hypothesis & $\begin{array}{c}\boldsymbol{\Delta} \\
\text { Residual } \\
\text { Variance }\end{array}$ & $\begin{array}{c}\boldsymbol{\Delta - 2} \\
\text { loglikelihood }\end{array}$ & $\begin{array}{c}\boldsymbol{p} \text { - } \\
\text { value }\end{array}$ & $\begin{array}{c}\boldsymbol{\Delta} \\
\text { Residual } \\
\text { Variance }\end{array}$ & $\begin{array}{c}\boldsymbol{\Delta - 2} \\
\text { loglikelihood }\end{array}$ & $\begin{array}{c}\boldsymbol{p} \text { - } \\
\text { value }\end{array}$ & $\begin{array}{c}\boldsymbol{\Delta} \\
\text { Residual } \\
\text { Variance }\end{array}$ & $\begin{array}{c}\boldsymbol{\Delta}-\mathbf{2} \\
\text { loglikelihood } \\
\text { value }\end{array}$ \\
\hline 1A & $18.16 \%$ & 1755.82 & 0.00 & $2.08 \%$ & 2.28 & 0.13 & DNC \\
1B & $13.28 \%$ & 1723.60 & 0.00 & $4.11 \%$ & 6.87 & 0.01 & DNC \\
1C & $9.68 \%$ & 1700.99 & 0.00 & $3.81 \%$ & 5.68 & 0.02 & DNC \\
1D & $14.29 \%$ & 1730.12 & 0.00 & $1.59 \%$ & 1.13 & 0.29 & DNC \\
2A & $18.25 \%$ & 1756.45 & 0.00 & $2.58 \%$ & 3.28 & 0.07 & DNC \\
2B & $13.06 \%$ & 1722.24 & 0.00 & $4.25 \%$ & 7.24 & 0.01 & DNC \\
2C & $12.08 \%$ & 1715.97 & 0.00 & $4.60 \%$ & 8.65 & 0.00 & DNC \\
3A & $17.43 \%$ & 1767.59 & 0.00 & $2.05 \%$ & 2.12 & 0.15 & DNC \\
3B & $12.77 \%$ & 1737.57 & 0.00 & $4.09 \%$ & 6.60 & 0.01 & DNC \\
3C & $11.56 \%$ & 1730.02 & 0.00 & $4.40 \%$ & 7.86 & 0.01 & DNC \\
3D & $13.60 \%$ & 1742.79 & 0.00 & $1.21 \%$ & 0.67 & 0.41 & DNC \\
4A & $18.71 \%$ & 1759.58 & 0.00 & $2.01 \%$ & 2.19 & 0.14 & DNC \\
4B & $15.10 \%$ & 1735.40 & 0.00 & $3.94 \%$ & 6.77 & 0.01 & DNC \\
5A & $18.89 \%$ & 1760.81 & 0.00 & $2.18 \%$ & 2.44 & 0.12 & DNC \\
5B & $14.92 \%$ & 1734.26 & 0.00 & $1.69 \%$ & 1.27 & 0.26 & DNC \\
\hline
\end{tabular}

Note. Change in $-2 \log$ likelihood for no random effect model denotes change in loglikelihood from null model. Change in -2 log likelihood for random intercepts model denotes change in log likelihood from no random effects model. Change in -2 log likelihood for random intercepts and slopes model denotes change in log likelihood from random slopes model. $p$-value denotes the change in log likelihood divided by the degrees of freedom with a Chi Square distribution. DNC denotes that the model did not converge. 
Table 8

Percent Reduction in Residual Variance over the Null Model for Course Performance

\begin{tabular}{|c|c|c|c|c|c|c|c|c|c|}
\hline \multirow[b]{2}{*}{ Hypothesis } & \multicolumn{3}{|c|}{ No Random Effects } & \multicolumn{3}{|c|}{ Random Intercepts } & \multicolumn{3}{|c|}{ Random Intercepts and Slopes } \\
\hline & $\begin{array}{c}\Delta \\
\text { Residual } \\
\text { Variance } \\
\end{array}$ & $\begin{array}{c}\Delta-2 \\
\text { loglikelihood }\end{array}$ & $\begin{array}{c}p \text { - } \\
\text { value }\end{array}$ & $\begin{array}{c}\Delta \\
\text { Residual } \\
\text { Variance } \\
\end{array}$ & $\begin{array}{c}\Delta-2 \\
\text { loglikelihood }\end{array}$ & $\begin{array}{c}p \text { - } \\
\text { value }\end{array}$ & $\begin{array}{c}\Delta \text { Residual } \\
\text { Variance } \\
\end{array}$ & $\begin{array}{c}\Delta-2 \\
\text { loglikelihood }\end{array}$ & $\begin{array}{c}p- \\
\text { value }\end{array}$ \\
\hline $\mathbf{1 A}$ & $20.03 \%$ & 9335.56 & 0.00 & $55.46 \%$ & 688.06 & 0.00 & DNC & & \\
\hline $1 B$ & $19.17 \%$ & 9328.05 & 0.00 & $55.78 \%$ & 680.70 & 0.00 & DNC & & \\
\hline $1 \mathrm{C}$ & $19.25 \%$ & 9328.68 & 0.00 & $55.64 \%$ & 678.66 & 0.00 & DNC & & \\
\hline $1 D$ & $19.98 \%$ & 9335.13 & 0.00 & $54.92 \%$ & 672.77 & 0.00 & DNC & & \\
\hline 2A & $19.66 \%$ & 9332.25 & 0.00 & $55.59 \%$ & 684.59 & 0.00 & DNC & & \\
\hline $\mathbf{2 B}$ & $18.87 \%$ & 9325.44 & 0.00 & $55.84 \%$ & 676.93 & 0.00 & DNC & & \\
\hline $2 \mathrm{C}$ & $19.20 \%$ & 9328.23 & 0.00 & $55.46 \%$ & 672.77 & 0.00 & DNC & & \\
\hline $\mathbf{3 A}$ & $22.78 \%$ & 9476.34 & 0.00 & $53.12 \%$ & 659.58 & 0.00 & DNC & & \\
\hline 3B & $22.15 \%$ & 9470.68 & 0.00 & $53.22 \%$ & 650.44 & 0.00 & DNC & & \\
\hline $3 C$ & $22.23 \%$ & 9471.39 & 0.00 & $53.08 \%$ & 648.36 & 0.00 & DNC & & \\
\hline 3D & $23.49 \%$ & 9482.67 & 0.00 & $51.89 \%$ & 639.22 & 0.00 & DNC & & \\
\hline $4 A$ & $19.79 \%$ & 9333.46 & 0.00 & $55.60 \%$ & 687.41 & 0.00 & DNC & & \\
\hline $4 B$ & $19.31 \%$ & 9329.24 & 0.00 & $55.86 \%$ & 685.23 & 0.00 & DNC & & \\
\hline $5 \mathbf{A}$ & $20.58 \%$ & 9340.40 & 0.00 & $55.36 \%$ & 695.40 & 0.00 & $0.16 \%$ & 0.29 & 0.86 \\
\hline $5 B$ & $20.49 \%$ & 9339.56 & 0.00 & $55.24 \%$ & 690.01 & 0.00 & $0.28 \%$ & 0.69 & 0.71 \\
\hline
\end{tabular}

Note. Change in $-2 \log$ likelihood for no random effect model denotes change in loglikelihood from null model. Change in -2 log

likelihood for random intercepts model denotes change in log likelihood from no random effects model. Change in -2 log likelihood for random intercepts and slopes model denotes change in log likelihood from random slopes model. $p$-value denotes the change in log likelihood divided by the degrees of freedom with a Chi Square distribution. DNC denotes that the model did not converge. 
Table 9

Reduction in Error Variance of Random Intercepts Model over Null Model Predicting Grand Mean for Course Satisfaction

\begin{tabular}{lcccc}
\hline & \multicolumn{3}{c}{ Reduction in } \\
Residual & $\begin{array}{c}\Delta-2 \\
\text { Variance }\end{array}$ & $\begin{array}{l}\text { loglikelihood } \\
\text { Hypothesis }\end{array}$ & Form of Relationship & Figure \\
\hline 1A & $20.24 \%$ & $1758.10^{* * *}$ & Positive Fit & 2 \\
1B & $17.39 \%$ & $1730.47^{* * *}$ & Positive Fit & 3 \\
1C & $13.49 \%$ & $1706.67^{* * *}$ & Positive Fit & 4 \\
1D & $15.88 \%$ & $1731.25^{* * *}$ & Main Effect: Environment & 5 \\
2A & $20.83 \%$ & $1759.73^{* * *}$ & Main Effect: Environment & 6 \\
2B & $17.32 \%$ & $1729.48^{* * *}$ & Main Effect: Individual & 7 \\
2C & $16.68 \%$ & $1724.63^{* * *}$ & Main Effect: Individual & 8 \\
3A & $19.48 \%$ & $1769.71^{* * *}$ & Main Effect: Environment & 9 \\
3B & $16.86 \%$ & $1744.18^{* * *}$ & Main Effect: Individual and Environment & 10 \\
3C & $15.96 \%$ & $1737.88^{* * *}$ & Positive Fit & 11 \\
3D & $14.81 \%$ & $1743.46^{* * *}$ & Main Effect: Environment & 12 \\
4A & $20.72 \%$ & $1761.77^{* * *}$ & Positive Fit & 13 \\
4B & $19.04 \%$ & $1742.18^{* * *}$ & Positive Fit & 14 \\
5A & $21.07 \%$ & $1763.25 * * *$ & Main Effect: Environment & 15 \\
5B & $16.61 \%$ & $1735.53^{* * *}$ & Positive Fit & 16 \\
\hline
\end{tabular}

Note. Probabilities denote change in -2 loglikelihood with a Chi Square distribution of 6 degrees of freedom. Reduction in residual variance denotes the amount of residual variance explained by the random intercepts model. Reduction in residual variance was computed by subtracting the residual variance of the random intercepts model from the residual variance of the null model and dividing it by the residual variance of the null model.

${ }^{*} p<.05,2$-tailed, ${ }^{* *} p<.01,2$-tailed, ${ }^{* * *} p<.001,2$-tailed. $\mathrm{N}=732$ 
Table 10

Reduction in Error Variance of Random Intercepts Model over Null Model Predicting Grand Mean for Course Performance

\begin{tabular}{lcccc}
\hline & \multicolumn{4}{c}{ Random Intercepts Model } \\
\hline Hypothesis & $\begin{array}{c}\text { Reduction in } \\
\text { Residual Variance }\end{array}$ & $\begin{array}{c}\Delta-2 \\
\text { loglikelihood }\end{array}$ & Form of Relationship & Figure \\
\hline 1A & $75.50 \%$ & $10023.62 * * *$ & Main Effect: Individual & 17 \\
1B & $74.95 \%$ & $10008.74 * * *$ & No Significant Predictors & 18 \\
1C & $74.89 \%$ & $10007.34 * * *$ & No Significant Predictors & 19 \\
1D & $74.91 \%$ & $10007.90^{* * *}$ & Positive Fit & 20 \\
2A & $75.24 \%$ & $10016.85 * * *$ & Main Effect: Environment & 21 \\
2B & $74.71 \%$ & $10002.36 * * *$ & No Significant Predictors & 22 \\
2C & $74.65 \%$ & $10001.00^{* * *}$ & No Significant Predictors & 23 \\
3A & $75.91 \%$ & $10135.93 * * *$ & Main Effect: Individual & 24 \\
3B & $75.37 \%$ & $10121.12 * * *$ & Main Effect: Individual & 25 \\
3C & $75.31 \%$ & $10119.74 * * *$ & Positive Fit & 26 \\
3D & $75.38 \%$ & $10121.89 * * *$ & Main Effect: Environment & 27 \\
4A & $75.40 \%$ & $10020.87 * * *$ & Positive Fit & 28 \\
4B & $75.17 \%$ & $10014.47 * * *$ & Positive Fit & 29 \\
5A & $75.94 \%$ & $10035.80^{* * *}$ & Main Effect: Individual and Environment & 30 \\
5B & $75.73 \%$ & $10029.57 * * *$ & Main Effect: Individual and Environment & 31 \\
\hline
\end{tabular}

Note. Probabilities denote change in -2 loglikelihood with a Chi Square distribution of 6 degrees of freedom. Reduction in residual

variance denotes the amount of residual variance explained by the random intercepts model. Reduction in residual variance was

computed by subtracting the residual variance of the random intercepts model from the residual variance of the null model and

dividing it by the residual variance of the null model.

${ }^{*} p<.05,2$-tailed, ${ }^{* *} p<.01,2$-tailed, ${ }^{* * *} p<.001,2$-tailed. $\mathrm{N}=732$ 
Pattern Matrixa

\begin{tabular}{|c|c|c|c|c|c|}
\hline & \multicolumn{5}{|c|}{ Factor } \\
\hline & 1 & 2 & 3 & 4 & 5 \\
\hline $\begin{array}{l}\text { ACE_AFF_2 ACE_AFF } 2 \text { : Students enjoy worklng together on } \\
\text { projects in thls class (Perception of Class) }\end{array}$ & .788 & & & & \\
\hline $\begin{array}{l}\text { ACE_AFF_3 ACE AFF_3: Students enjoyhelplng each other } \\
\text { with homework (Perception of Class) }\end{array}$ & .644 & & & & \\
\hline $\begin{array}{l}\text { ACE_INV_ } 4 \text { ACE_INV } 4 \text { : Students sometimes present } \\
\text { something theyve worked on to the class (Perception of Class) }\end{array}$ & .636 & & & & \\
\hline $\begin{array}{l}\text { ACE_AFF_ } 1 \text { ACE_AFF } 1 \text { : Students in this class get to know } \\
\text { each other reaily well (Perception of Class) }\end{array}$ & .530 & & & & \\
\hline $\begin{array}{l}\text { ACE_INN_1 ACE_INN_1: Now and different ways of teaching } \\
\text { are tried very often in this course (Perception of Class) }\end{array}$ & .439 & & & & \\
\hline $\begin{array}{l}\text { ACE_INN_2 ACE_INN_2: The Instructor llkes students to try } \\
\text { unusual projects (Perception of Class) }\end{array}$ & .374 & & & & \\
\hline $\begin{array}{l}\text { ACE_OO } 1 \text { ACE OO_1: Thls is a well-organized class } \\
\text { (Perception of Class) }\end{array}$ & & .701 & & & \\
\hline $\begin{array}{l}\text { ACE OO } 4 \text { ACE_OO } 4 \text { : Activities and lectures in this course } \\
\text { are clearly and carefully planned (Perception of Class) }\end{array}$ & & .673 & & & \\
\hline $\begin{array}{l}\text { ACE TA } 4 \text { ACE TA } 4 \text { : The Instructor sticks to course material } \\
\text { and does not get sldetracked (Perception of Class) }\end{array}$ & & .647 & & & \\
\hline $\begin{array}{l}\text { ACE_OO } 2 \text { ACE_OO_2 : Asslgnments are usually clear so } \\
\text { everyone knows what to do (Perception of Class) }\end{array}$ & & .566 & & & \\
\hline $\begin{array}{l}\text { ACE_TA } 1 \text { ACE_TA 1 : Almost all class time is spent on } \\
\text { dlscussing the course material (Perception of Class) }\end{array}$ & & .516 & & & \\
\hline $\begin{array}{l}\text { ACE RC } 1 \text { ACE RC } 1 \text { : There is a clear set of rules for } \\
\text { students to follow (Perception of Class) }\end{array}$ & & .423 & & & \\
\hline $\begin{array}{l}\text { ACE_INST_3 ACE_INST_3 : The Instructor goes out of hls-her } \\
\text { wayto help students (Perception of Class) }\end{array}$ & & .405 & & & \\
\hline $\begin{array}{l}\text { ACE_AFF_4R ACE_AFF_4: Students dont have much of a } \\
\text { chance to get to know each other In thls class (Perception of } \\
\text { Class) (RECODE) }\end{array}$ & & & .832 & & \\
\hline $\begin{array}{l}\text { ACE_INN_3R ACE_INN_3 : Students have very llttle Input on } \\
\text { how class time is spent (Perception of Class) (RECODE) }\end{array}$ & & & .531 & & \\
\hline $\begin{array}{l}\text { ACE_INN_4R ACE_INN_4 : Students do the same kInd of work } \\
\text { almost every day In thls class (Perception of Class) (RECODE) }\end{array}$ & & & .495 & & \\
\hline $\begin{array}{l}\text { ACE_INV_1R ACE_INV_1: Students are often clock-watchling } \\
\text { In class (Perception of Class) (RECODE) }\end{array}$ & & & .484 & & \\
\hline $\begin{array}{l}\text { ACE_INST_1 ACE_INST_1: Thls Instructor often spends time } \\
\text { just falking with students (Perception of Class) }\end{array}$ & & & & .655 & \\
\hline $\begin{array}{l}\text { ACE_TA } 3 \text { ACE_TA_3 : Thls Instructor often takes time out } \\
\text { fom the Tesson plan to talk about other things (Perception of } \\
\text { Class) }\end{array}$ & & & & .578 & \\
\hline $\begin{array}{l}\text { ACE_INST_2 ACE_INST_2: The Instructor takes a personal } \\
\text { Interest In students's (Perception of Class) }\end{array}$ & & & & .434 & \\
\hline $\begin{array}{l}\text { ACE_SC } 3 \text { ACE_SC } 3 \text { : Students have to work for a good } \\
\text { grade in this class (Perception of Class) }\end{array}$ & & & & & .712 \\
\hline $\begin{array}{l}\text { ACE_SC_4RACE_SC_4 : Students usuallypass even If they } \\
\text { dont do much (Perception of Class) (RECODE) }\end{array}$ & & & & & .572 \\
\hline $\begin{array}{l}\text { ACE_SC } 1 \text { ACE_SC } 1 \text { : Students try hard to get the best grade } \\
\text { (Perception of CTass) }\end{array}$ & & & & & .462 \\
\hline
\end{tabular}

Extraction Method: Princlpal Axis Factoring.

Rotation Method: Oblim In with Kals er Normalization.

a. Rotation converged In 9 Iterations.

Figure 1. Exploratory Factor Analysis pattern matrix for new classroom environment factors. 


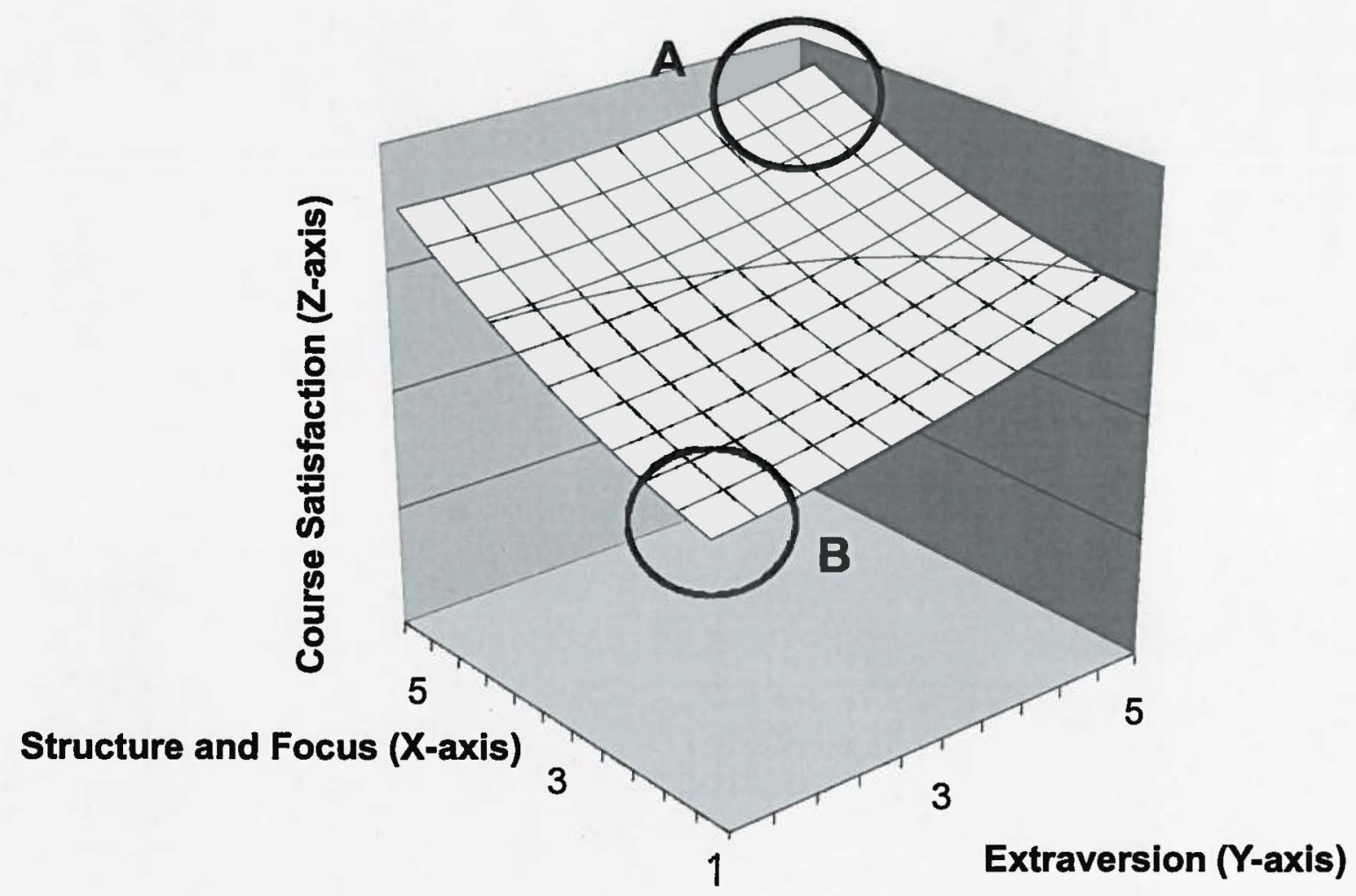

Figure 2. Functional form of objective fit between extraversion and structure and focus for the course satisfaction outcome. 


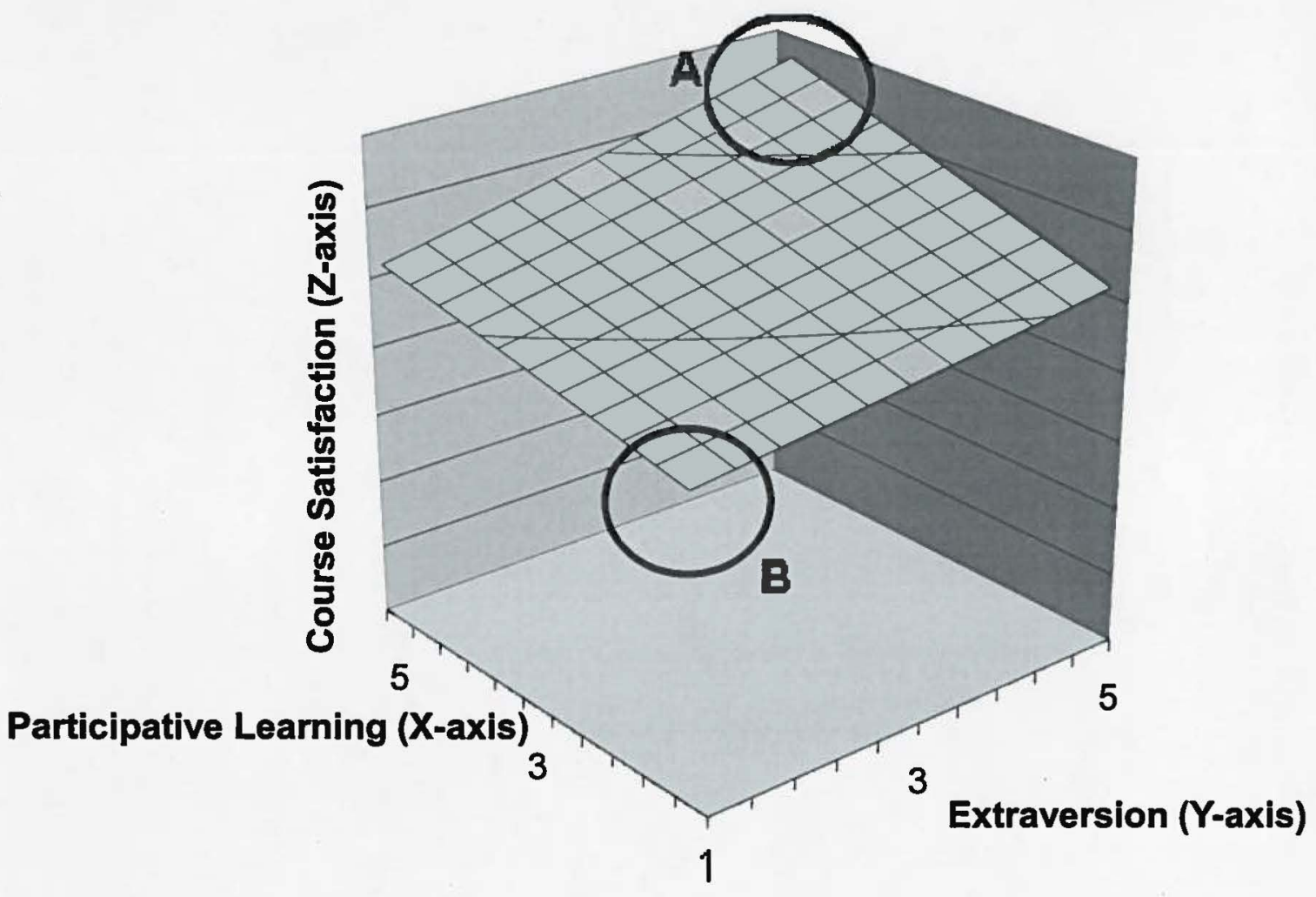

Figure 3. Functional form of objective fit between extraversion and participative learning for the course satisfaction outcome. 


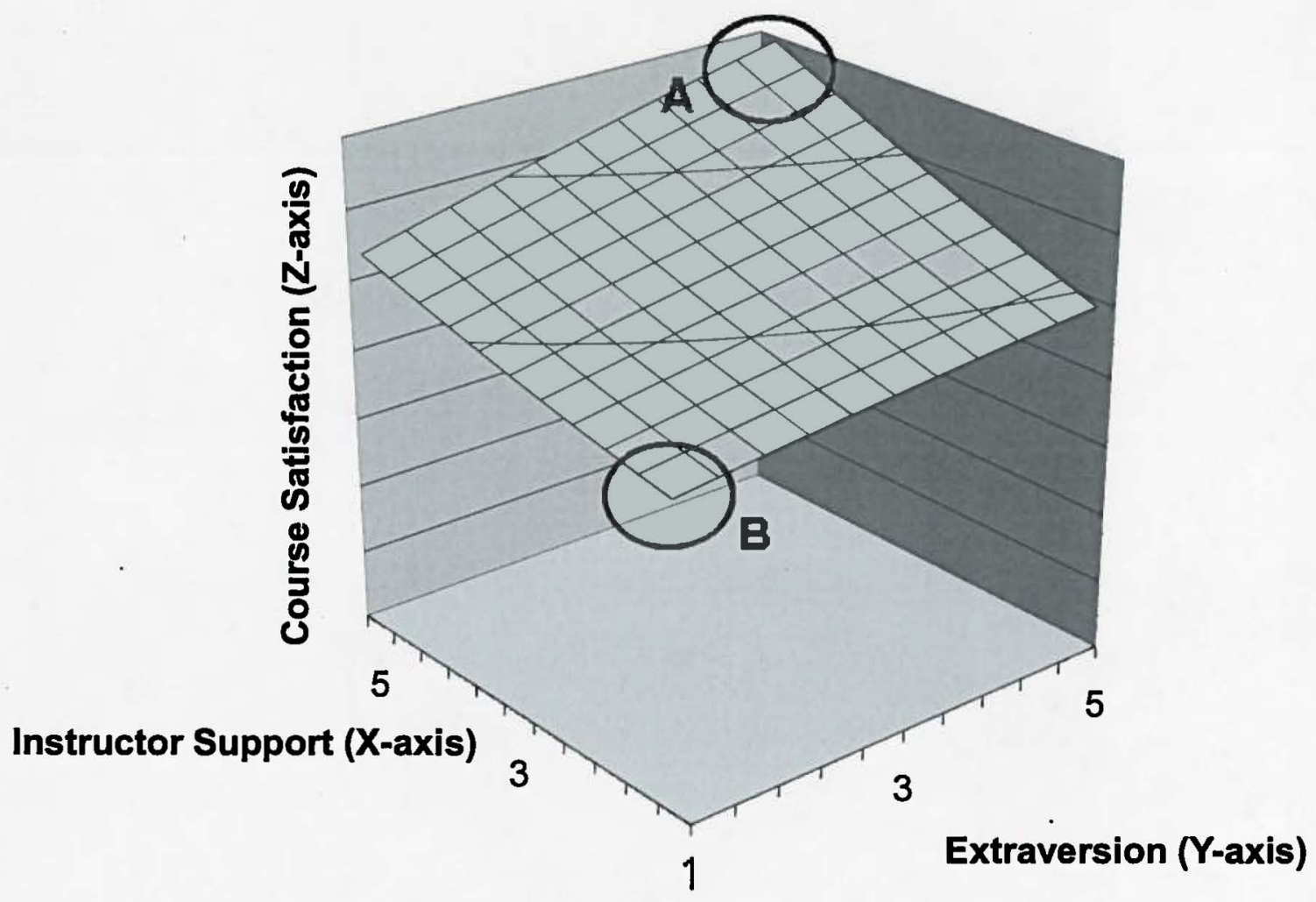

Figure 4. Functional form of objective fit between extraversion and instructor support for the course satisfaction outcome. 


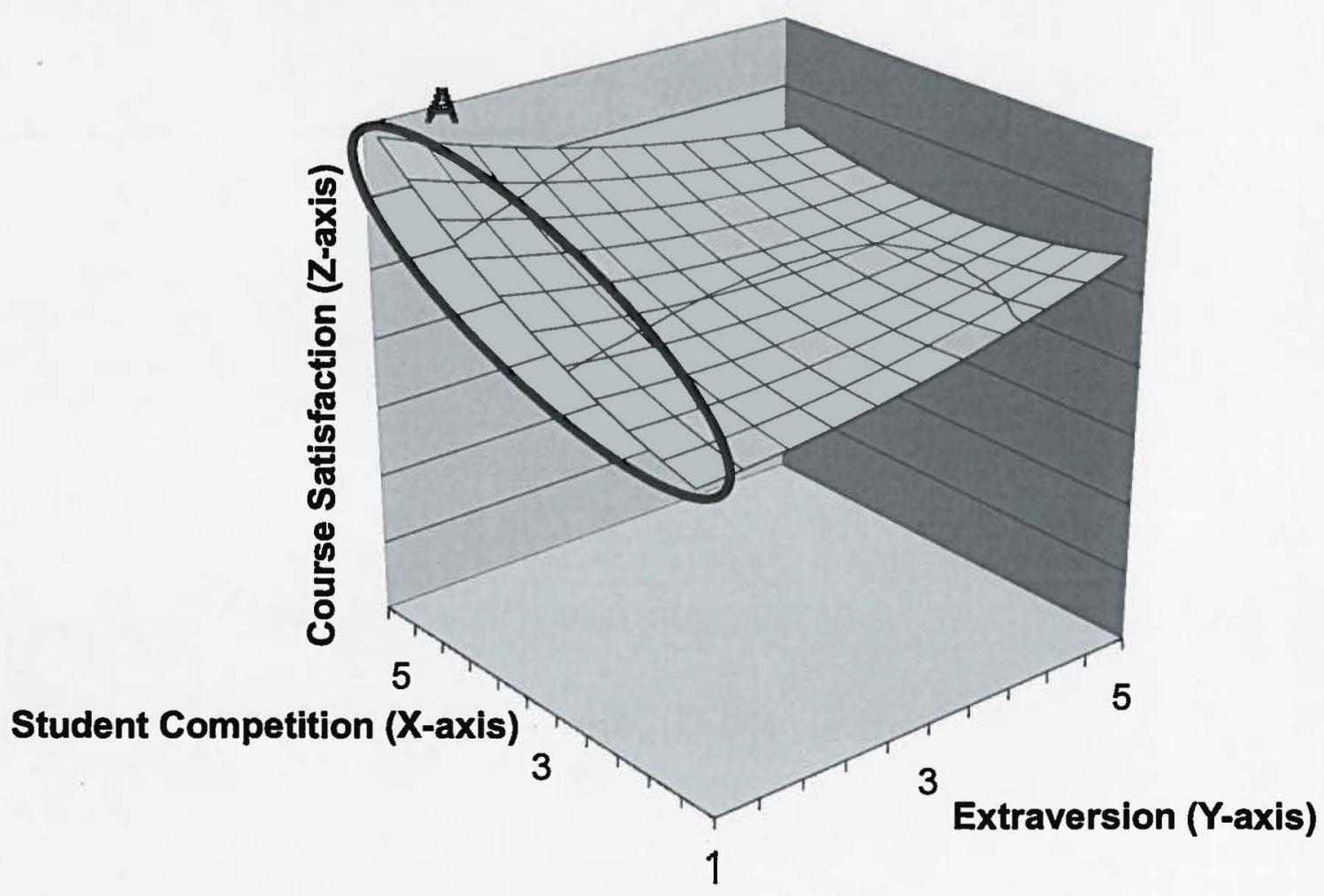

Figure 5. Functional form of objective fit between extraversion and student competition for the course satisfaction outcome. 


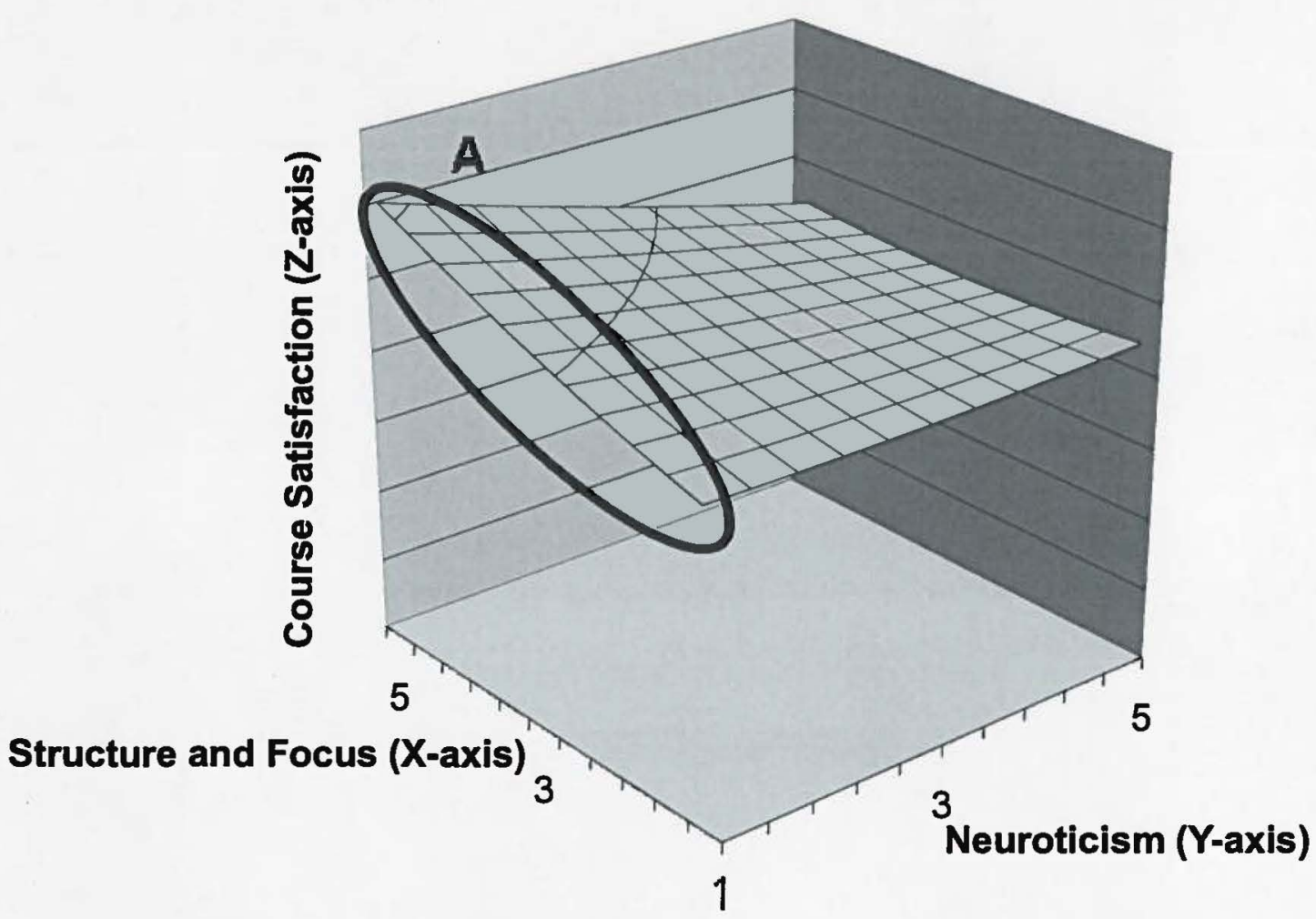

Figure 6. Functional form of objective fit between neuroticism and structure and focus for the course satisfaction outcome. 


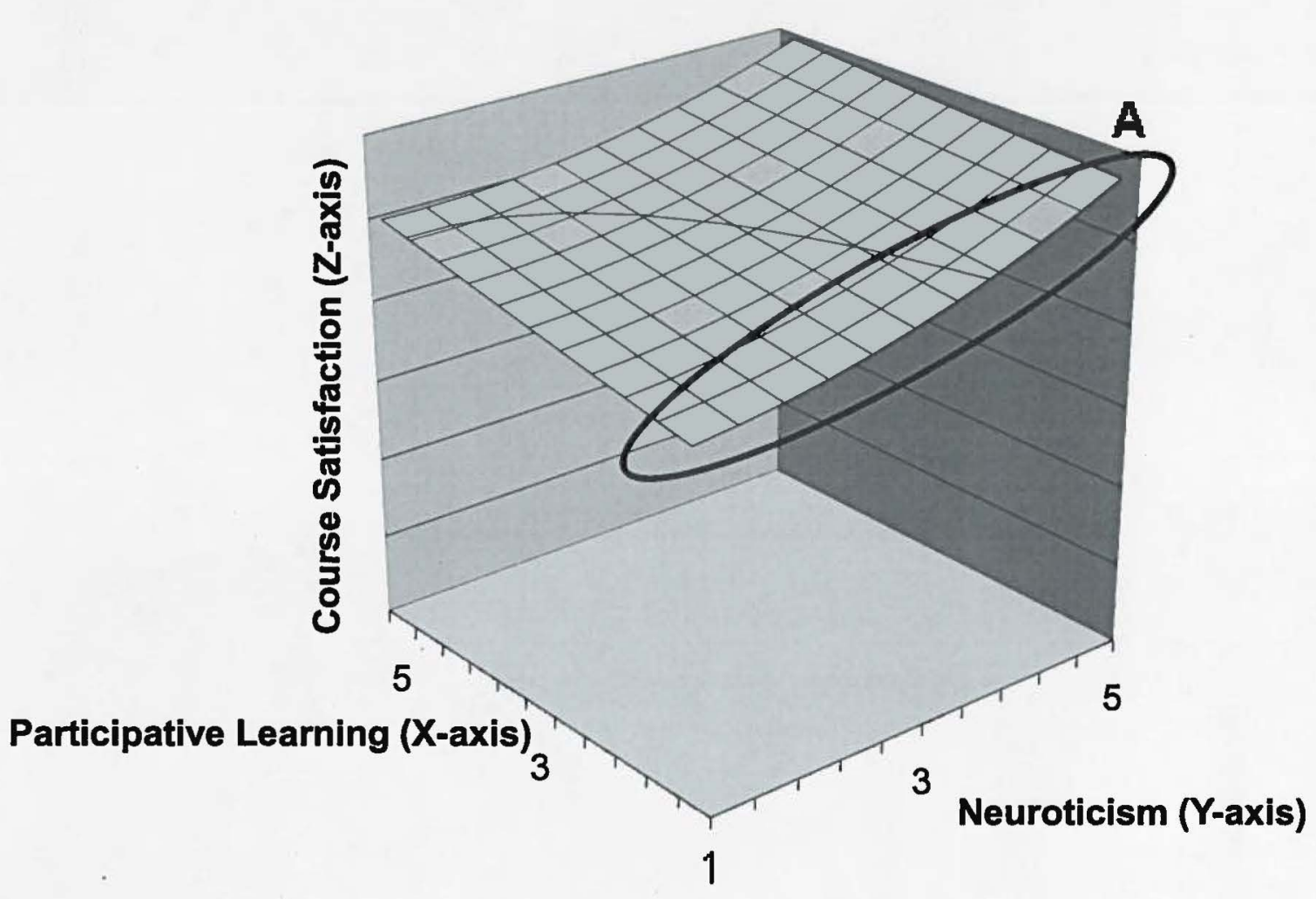

Figure 7. Functional form of objective fit between neuroticism and participative learning for the course satisfaction outcome. 


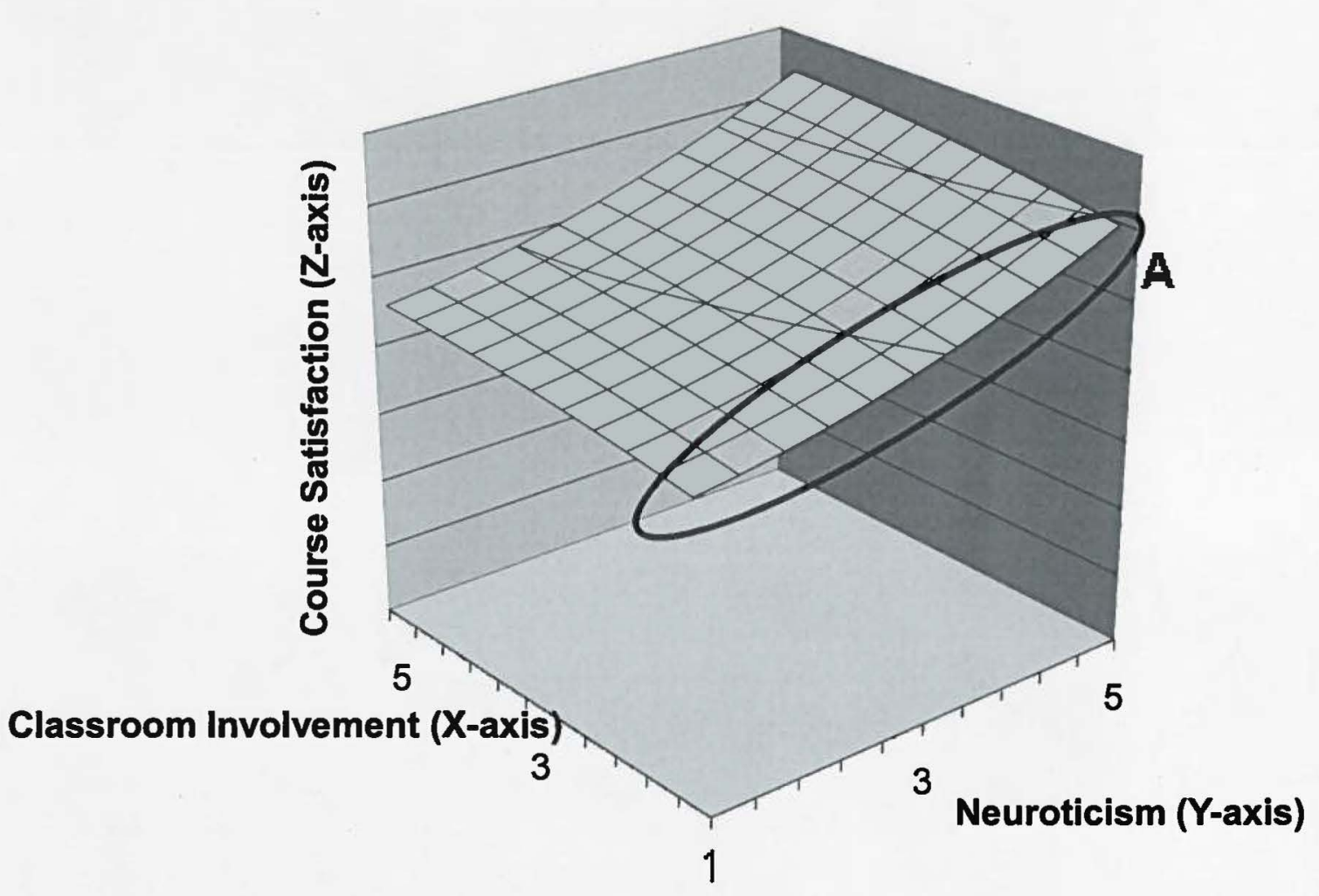

Figure 8. Functional form of objective fit between neuroticism and classroom involvement for the course satisfaction outcome. 


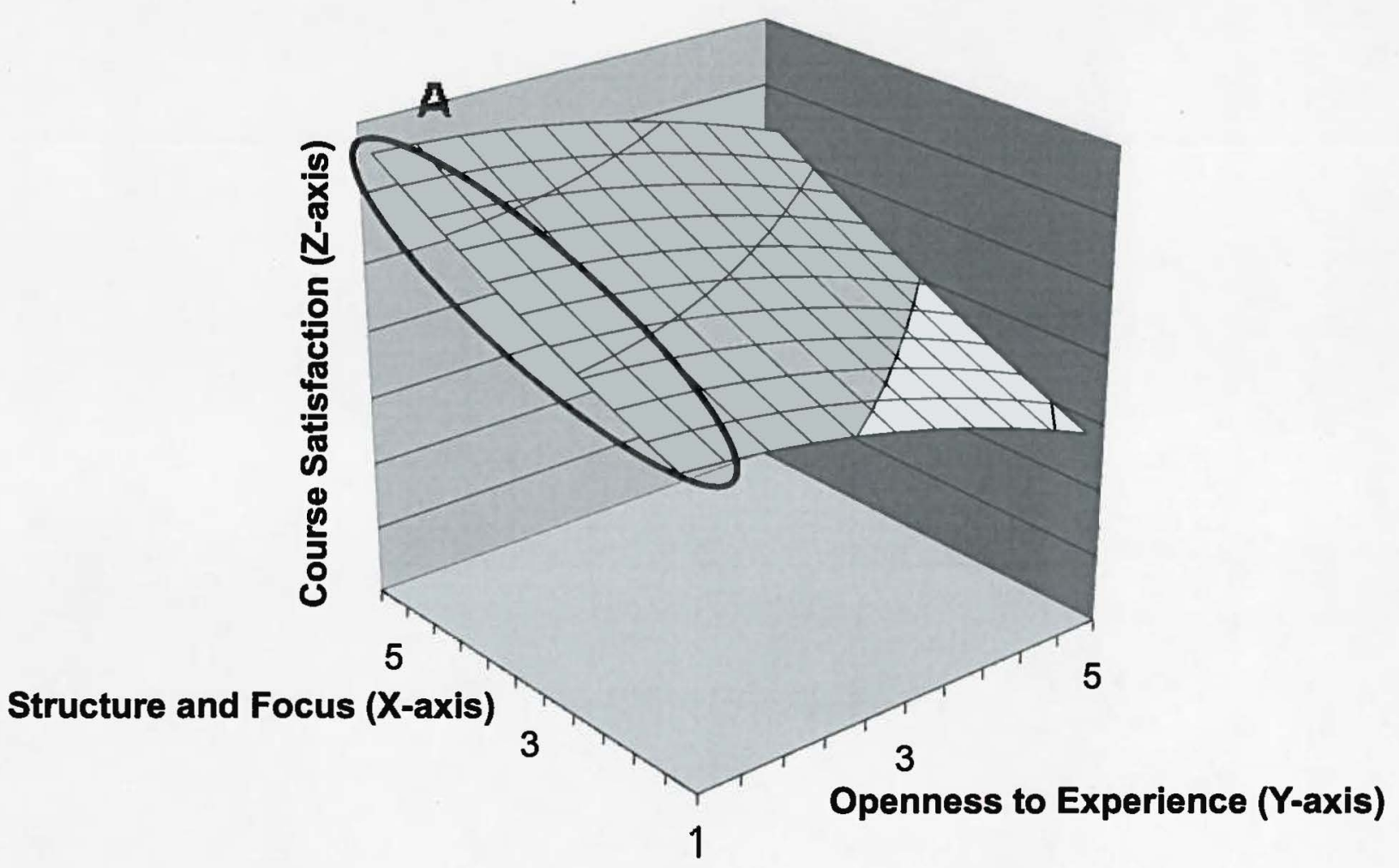

Figure 9. Functional form of objective fit between openness to experience and structure and focus for the course satisfaction outcome. 


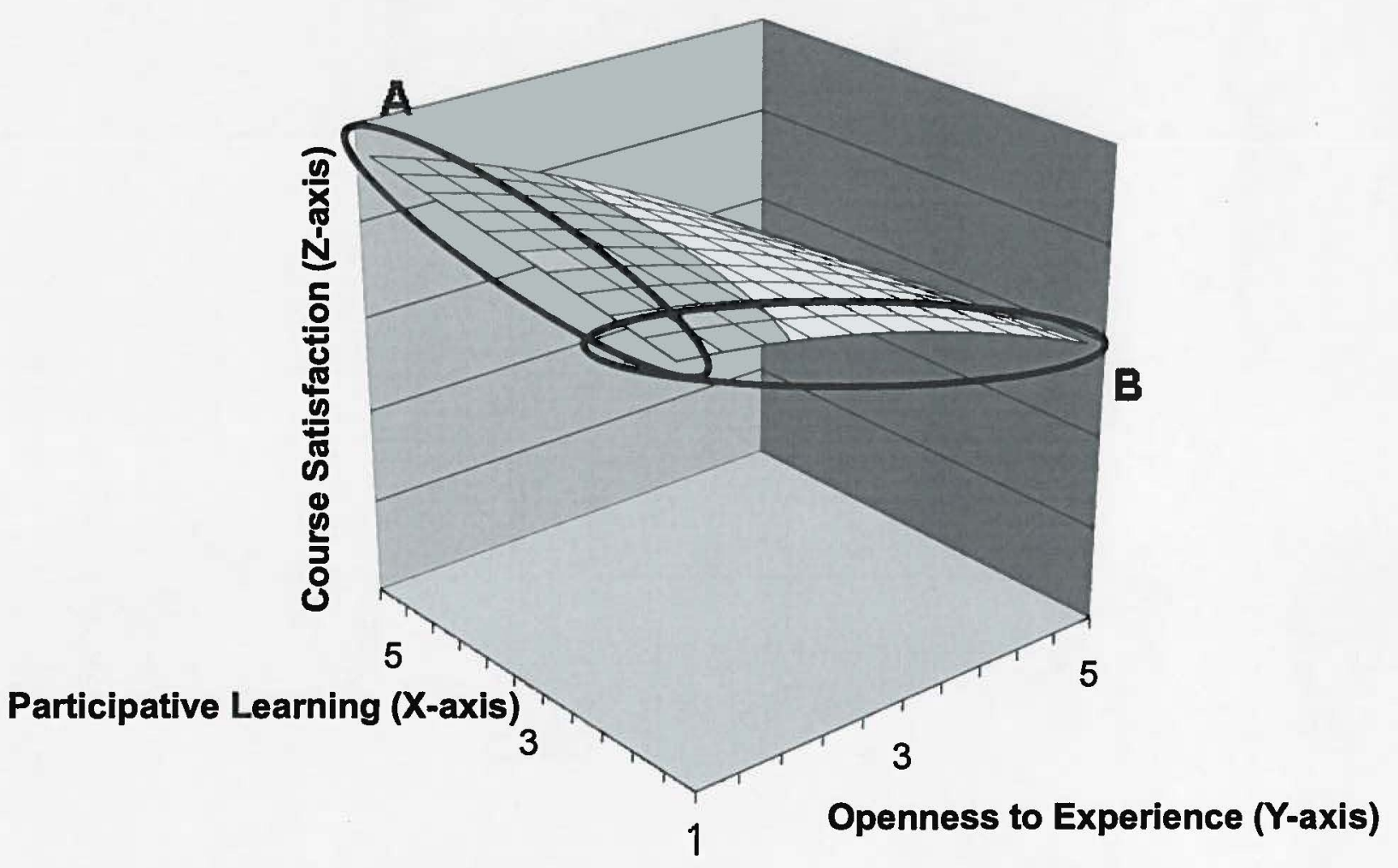

Figure 10. Functional form of objective fit between openness to experience and participative learning for the course satisfaction outcome. 


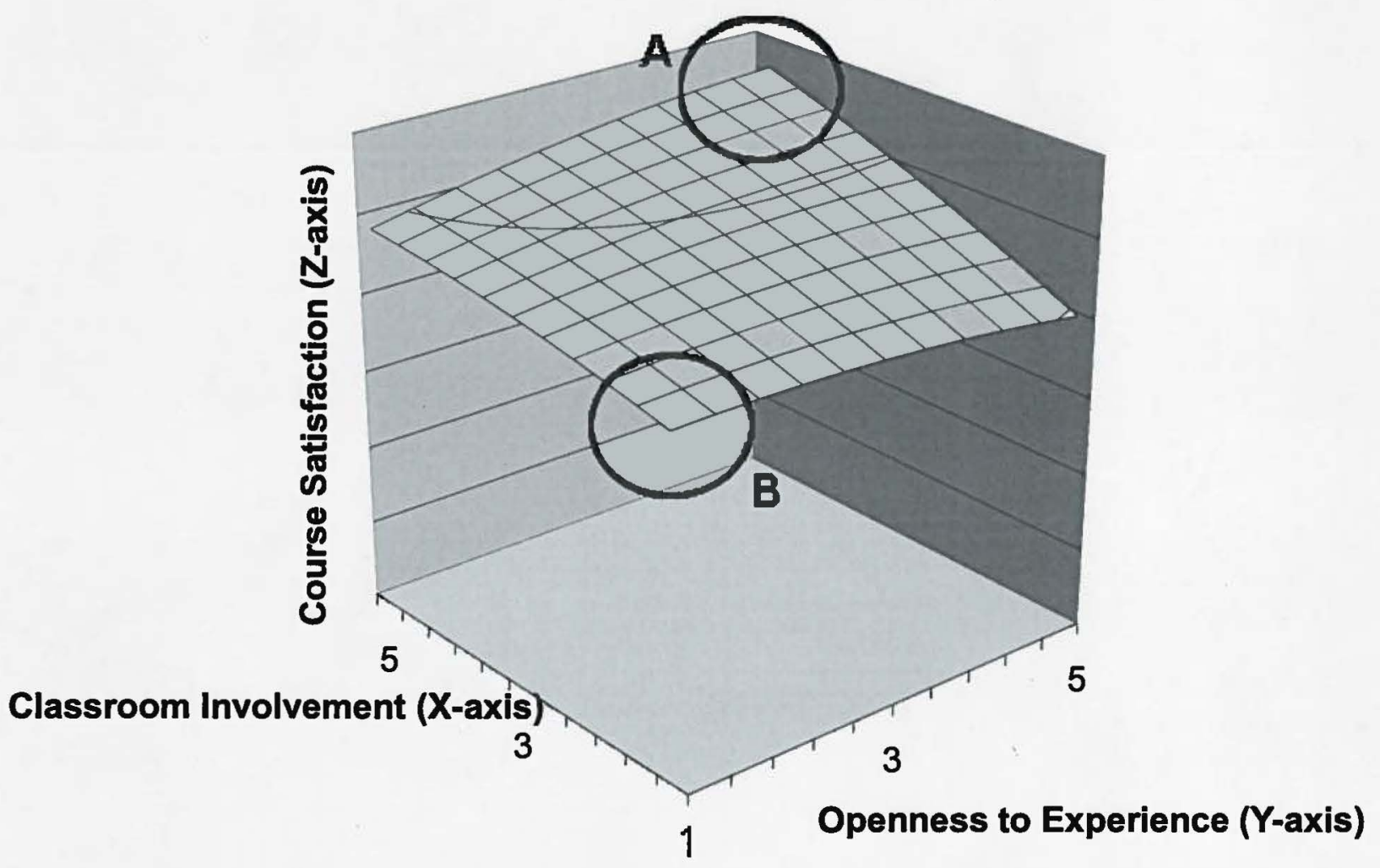

Figure 11. Functional form of objective fit between openness to experience and classroom involvement for the course satisfaction outcome. 


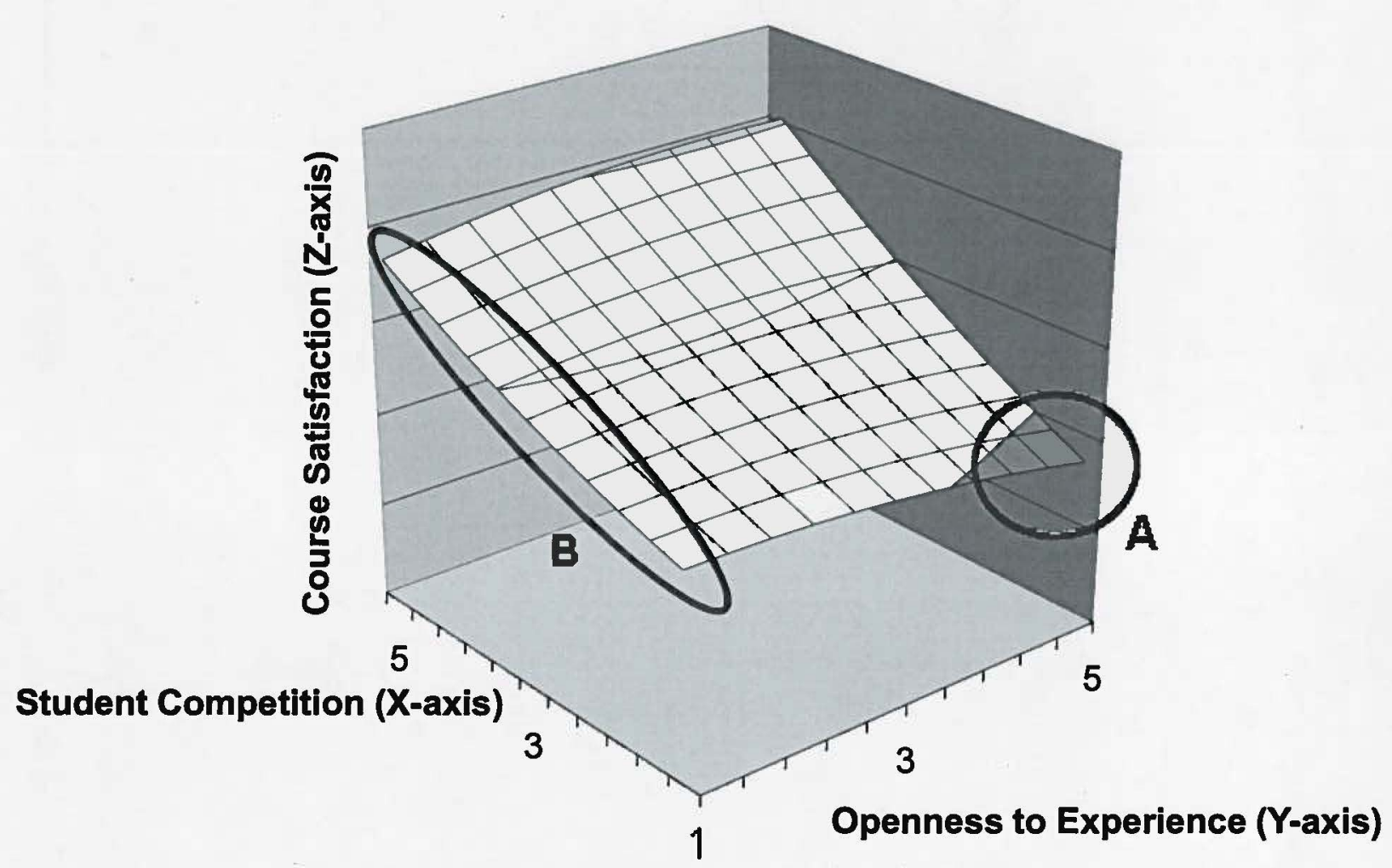

Figure 12. Functional form of objective fit between openness to experience and student competition for the course satisfaction outcome. 


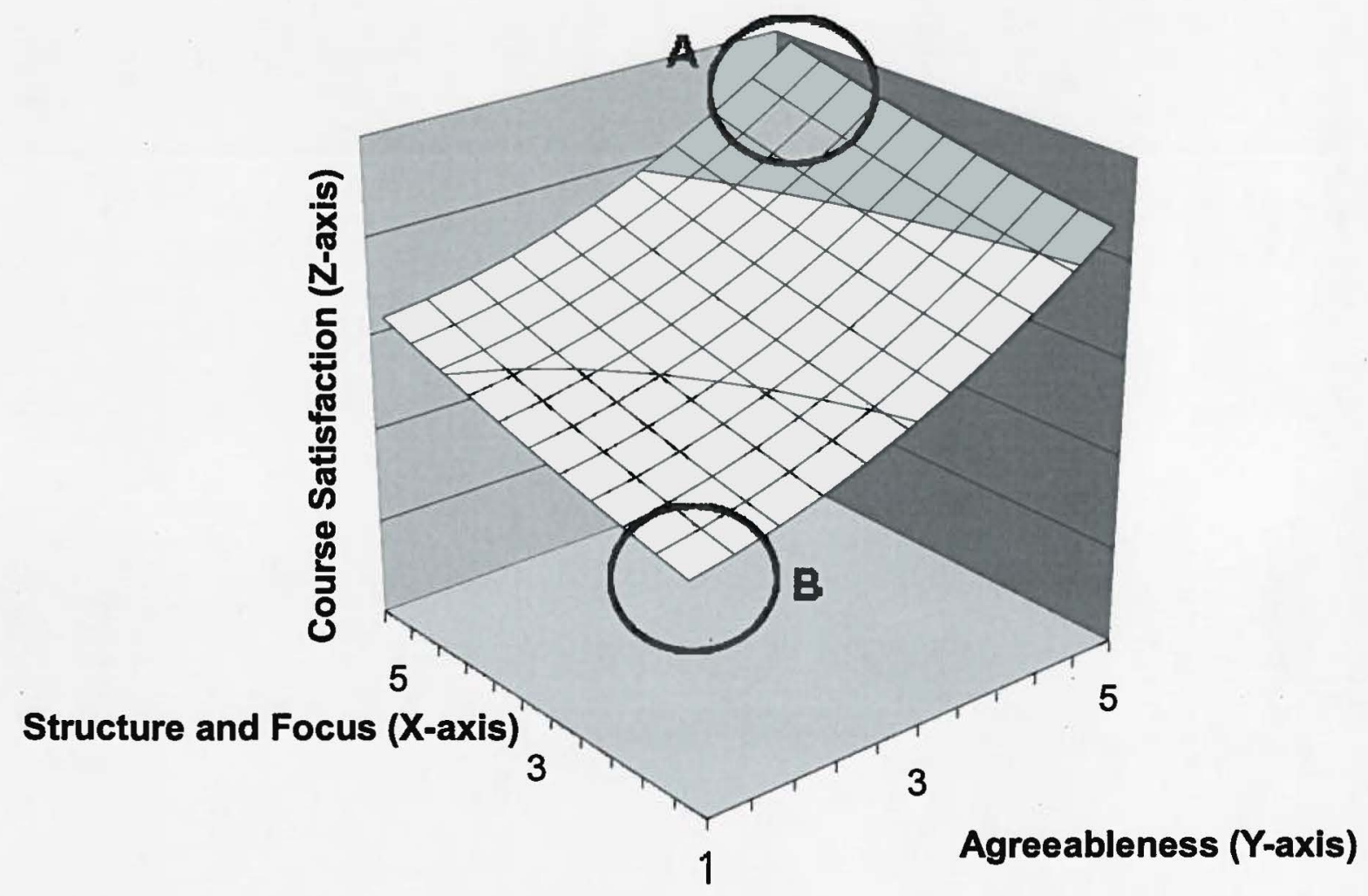

Figure 13. Functional form of objective fit between agreeableness and structure and focus for the course satisfaction outcome. 


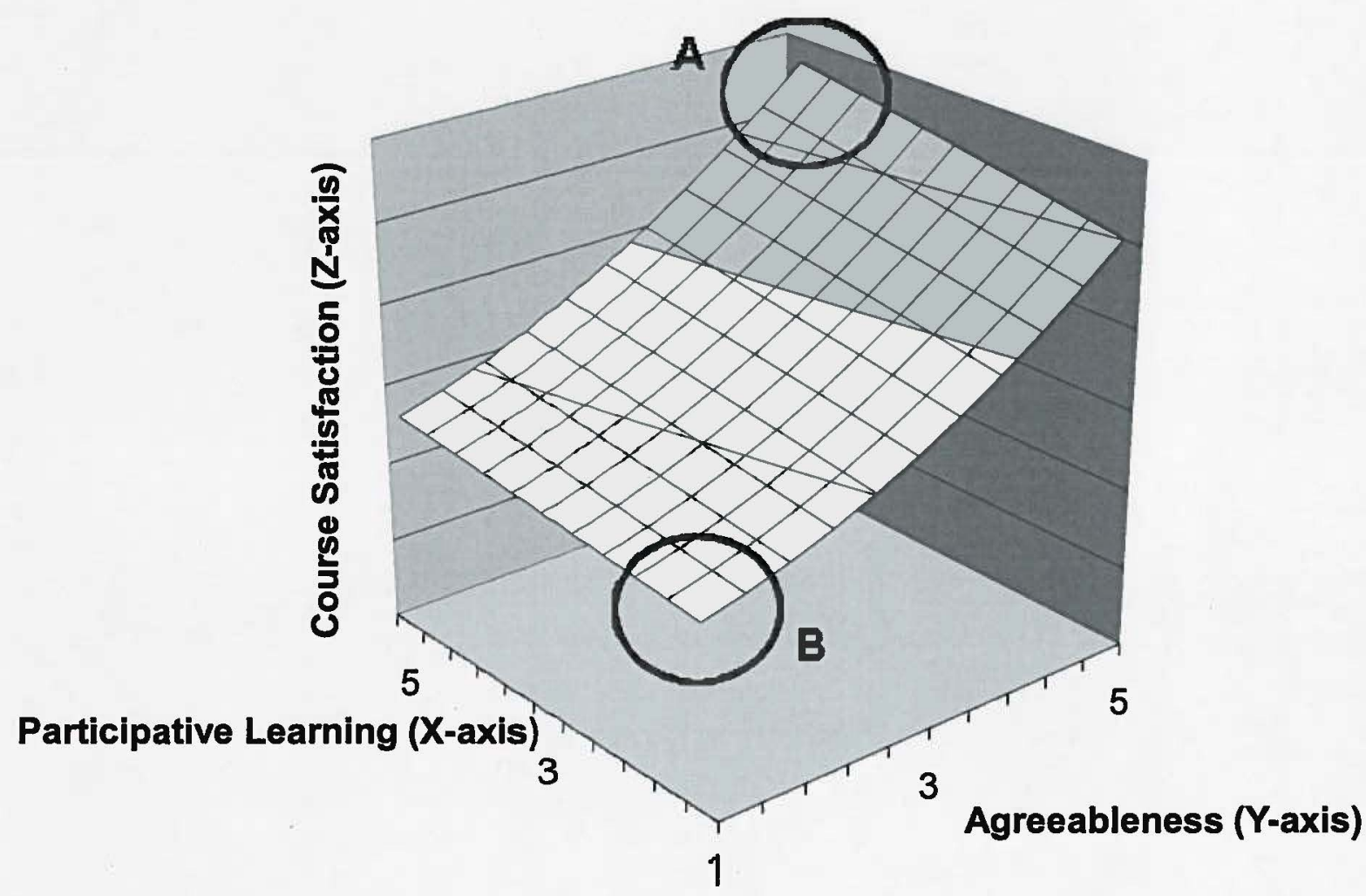

Figure 14. Functional form of objective fit between agreeableness and participative learning for the course satisfaction outcome. 


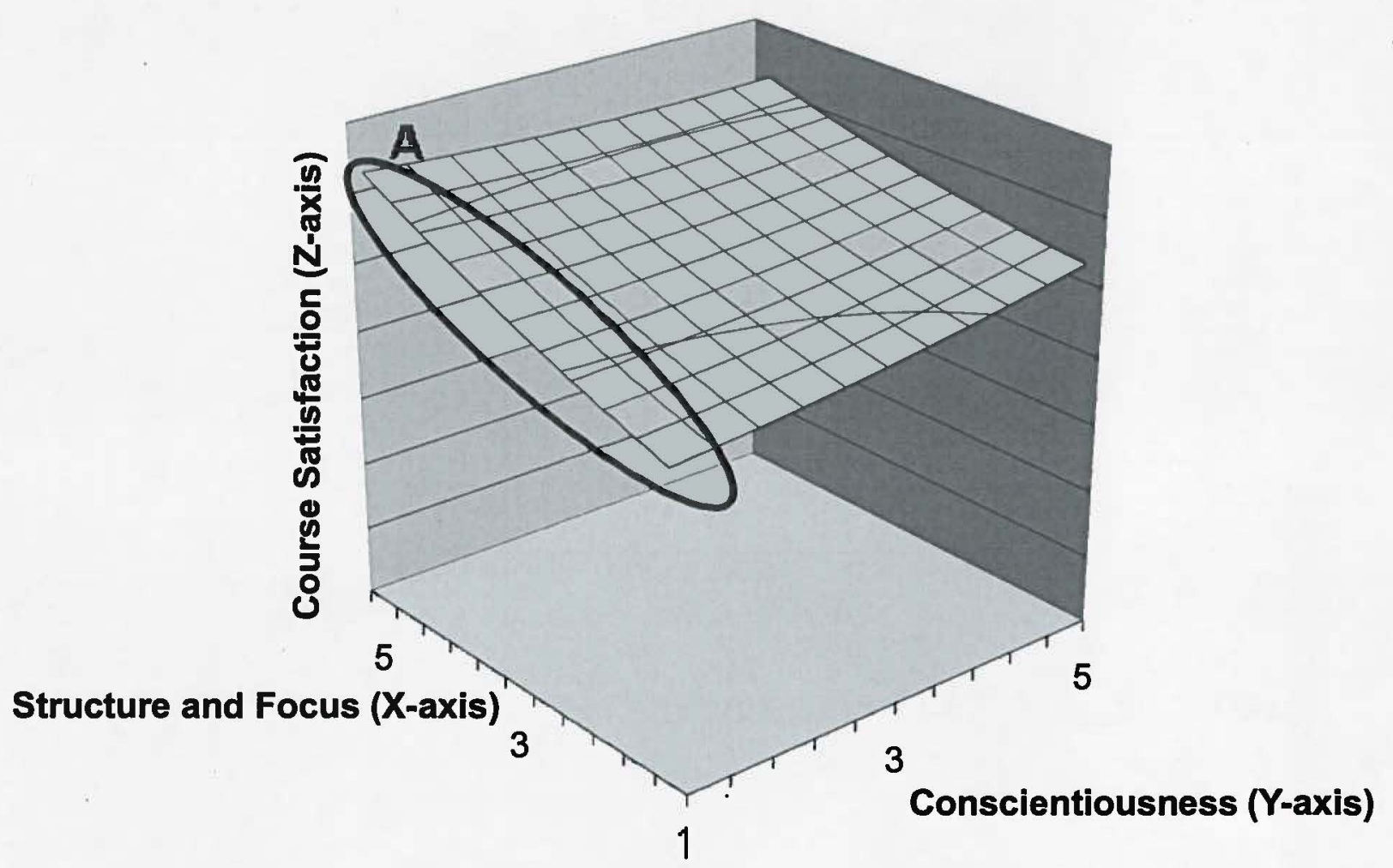

Figure 15. Functional form of objective fit between conscientiousness and structure and focus for the course satisfaction outcome. 


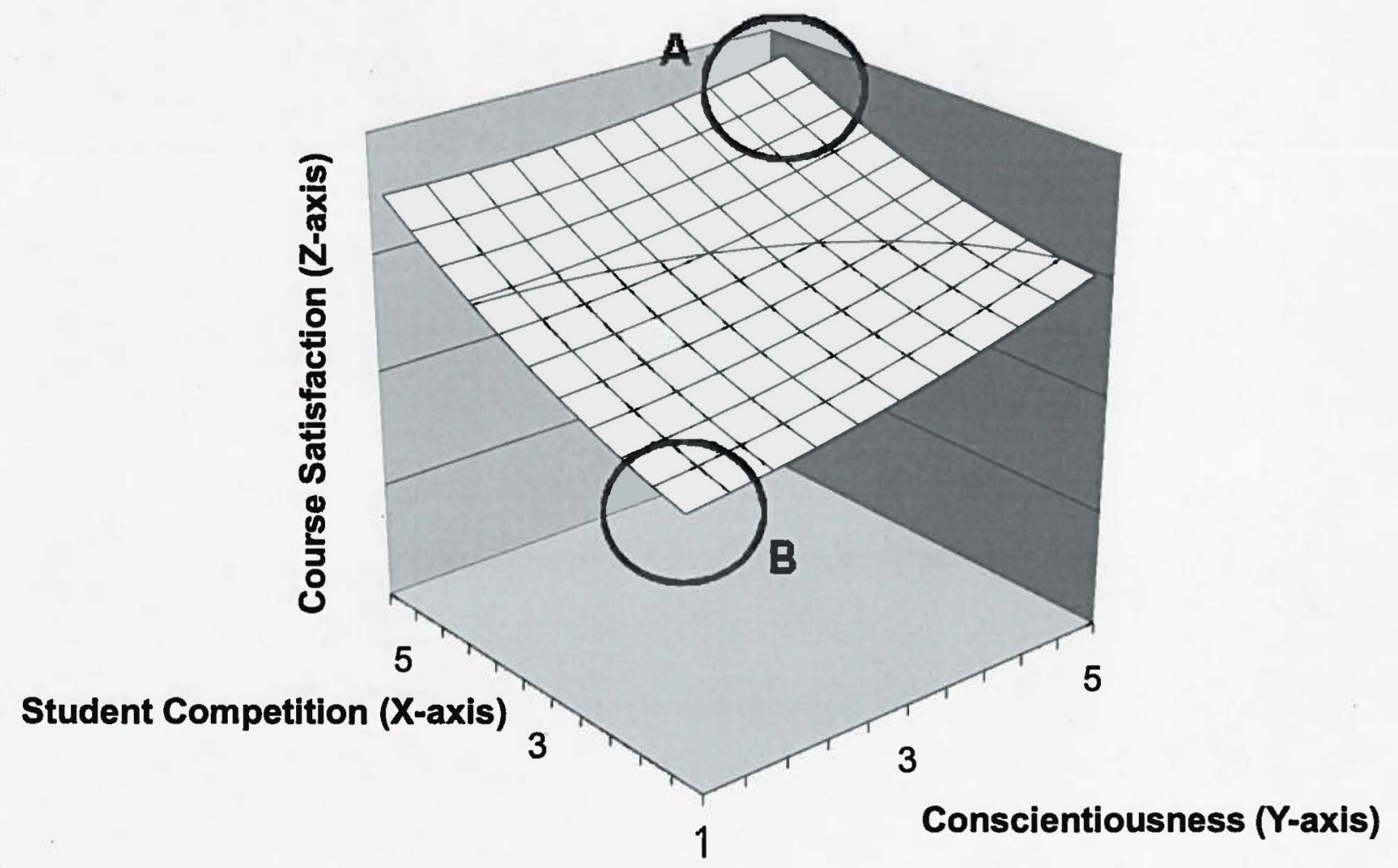

Figure 16. Functional form of objective fit between conscientiousness and student competition for the course satisfaction outcome. 


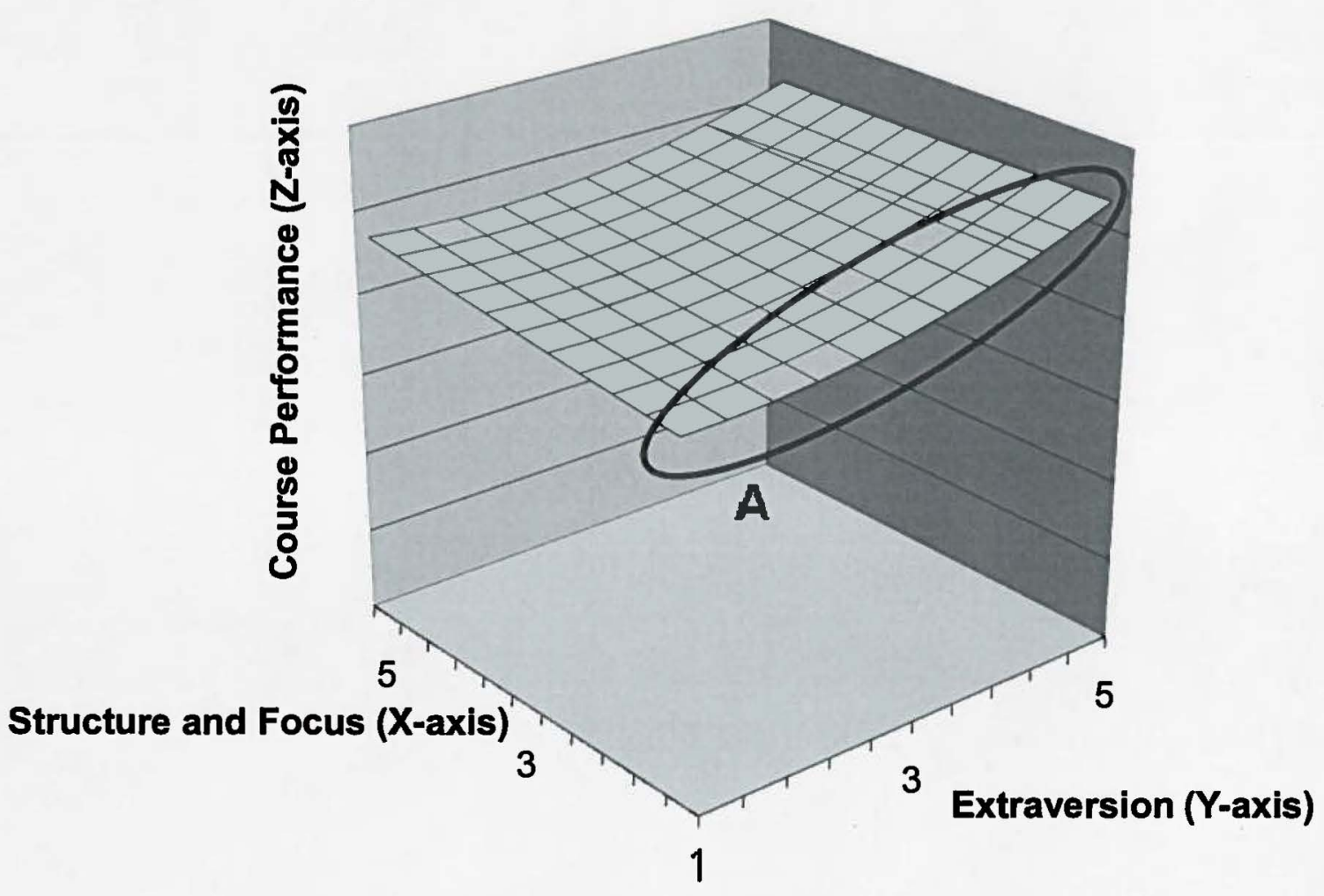

Figure 17. Functional form of objective fit between extraversion and structure and focus for the course performance outcome. 


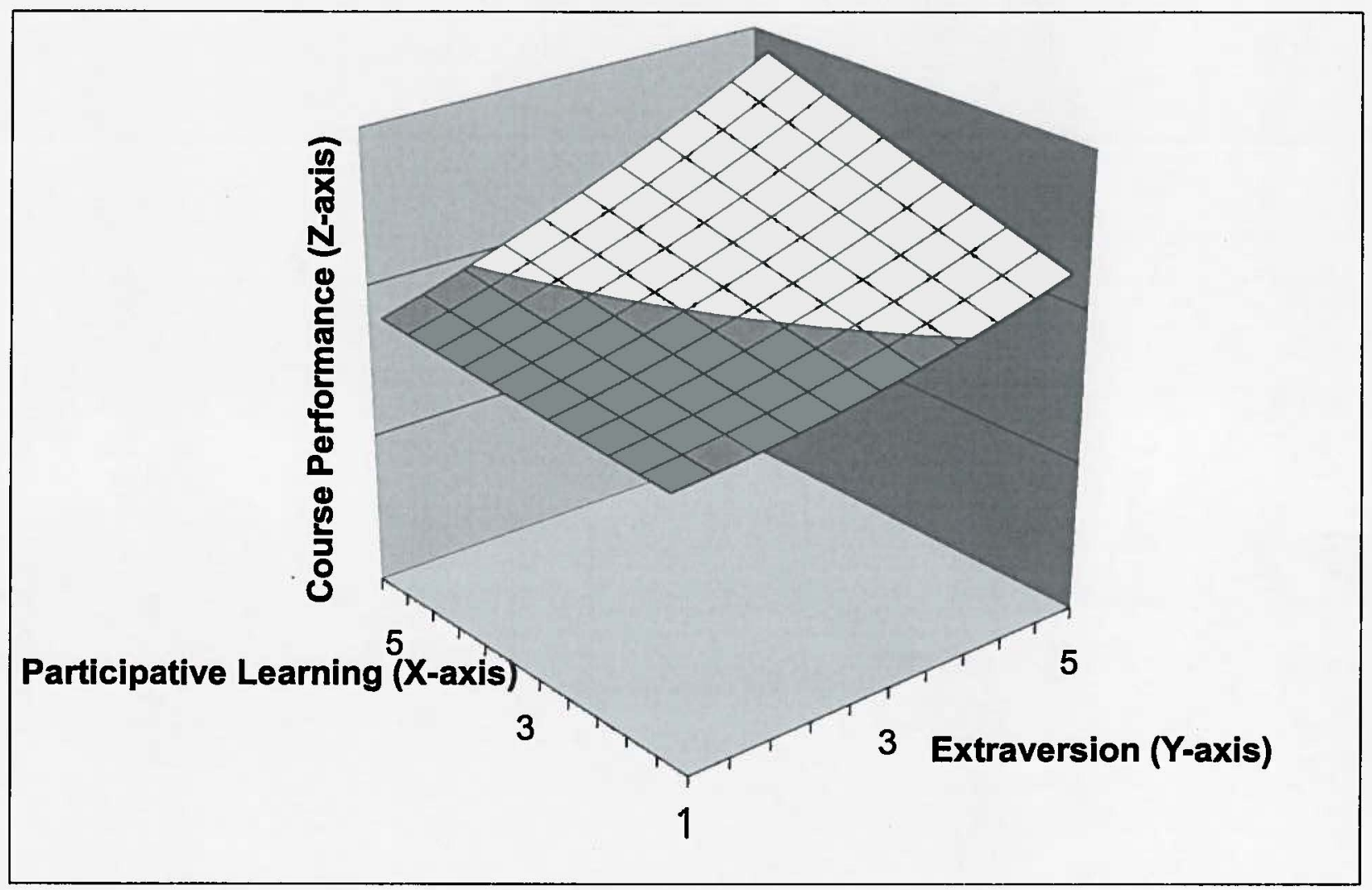

Figure 18. Functional form of objective fit between extraversion and participative learning for the course performance outcome. 


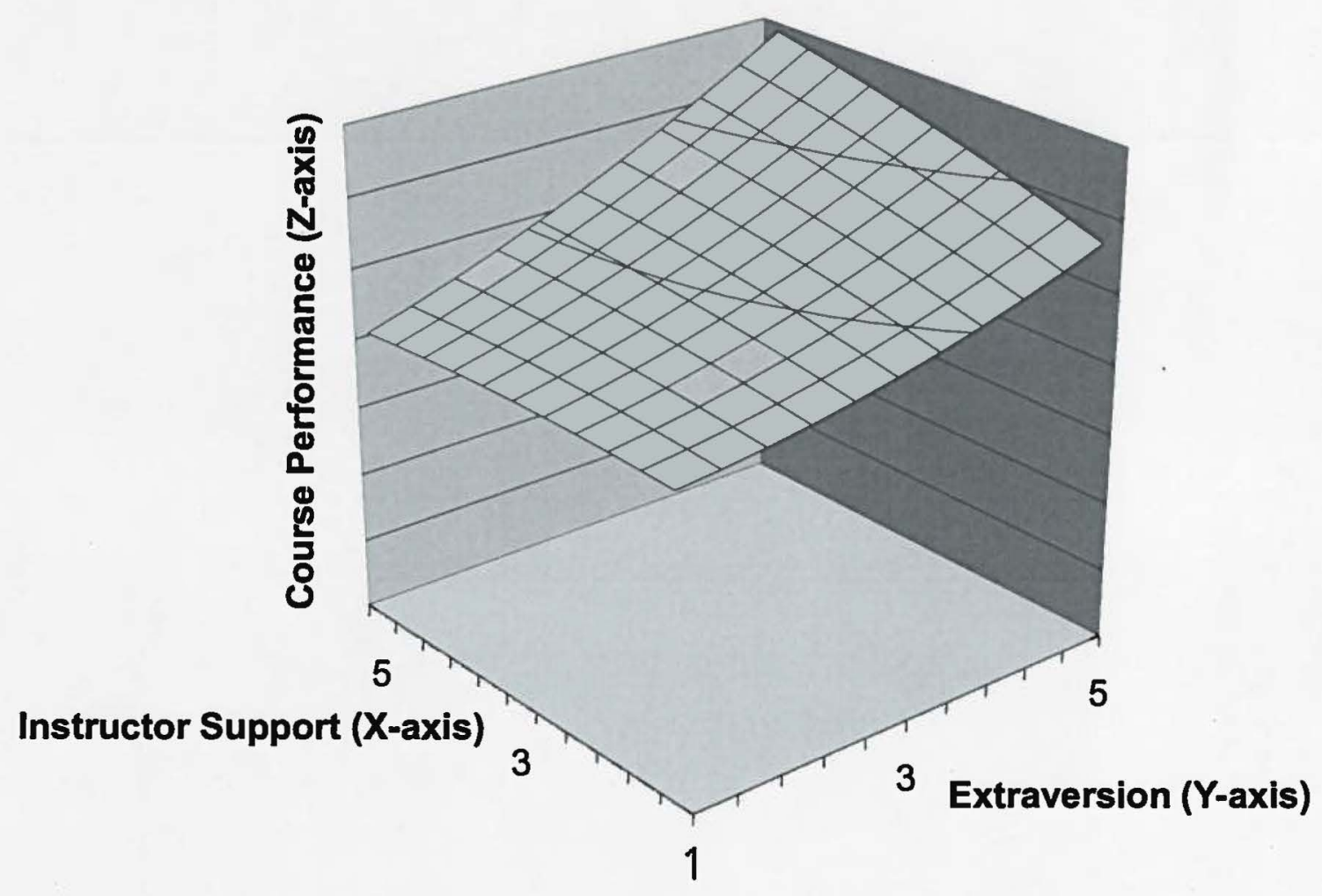

Figure 19. Functional form of objective fit between extraversion and instructor support for the course performance outcome. 


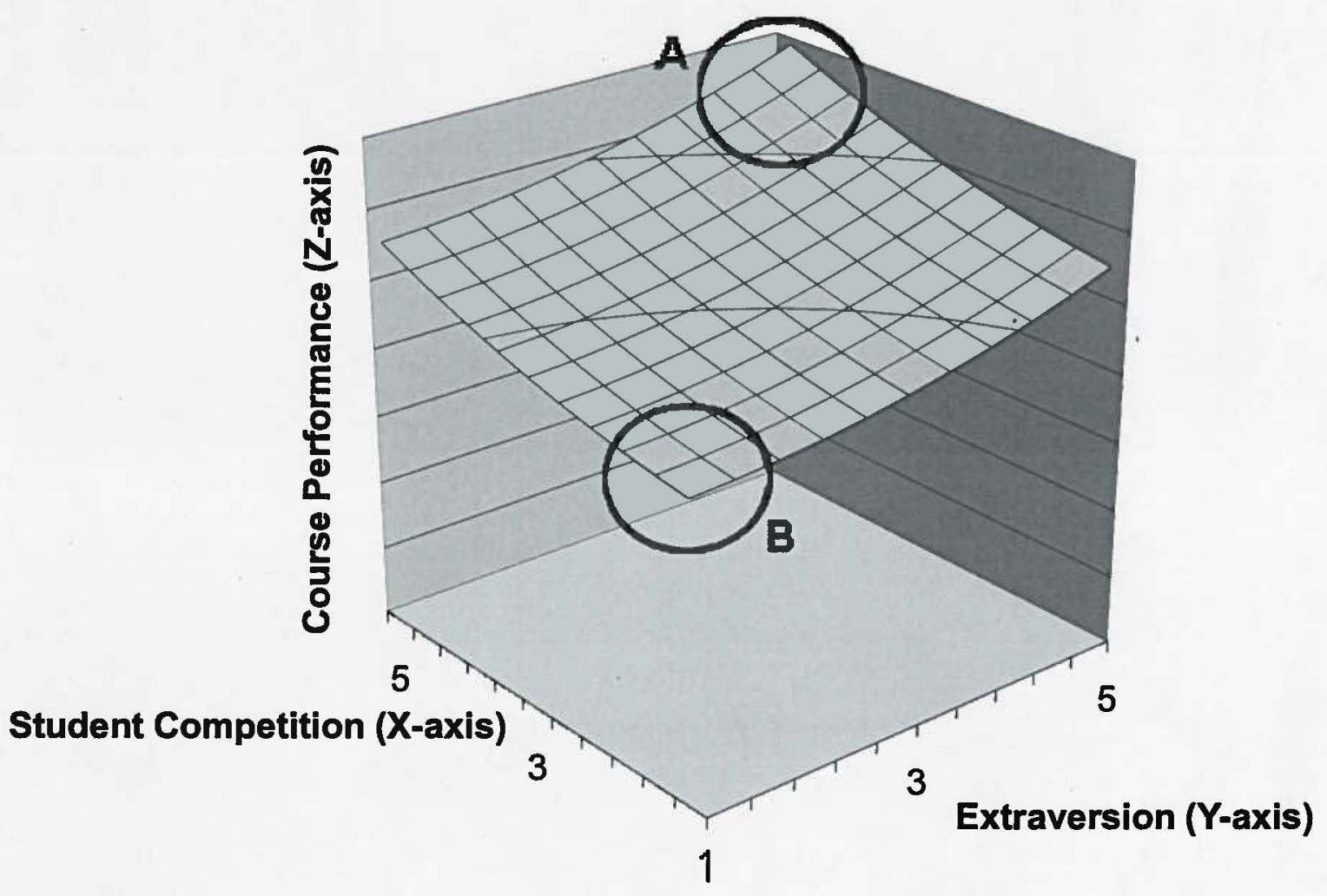

Figure 20. Functional form of objective fit between extraversion and student competition for the course performance outcome. 


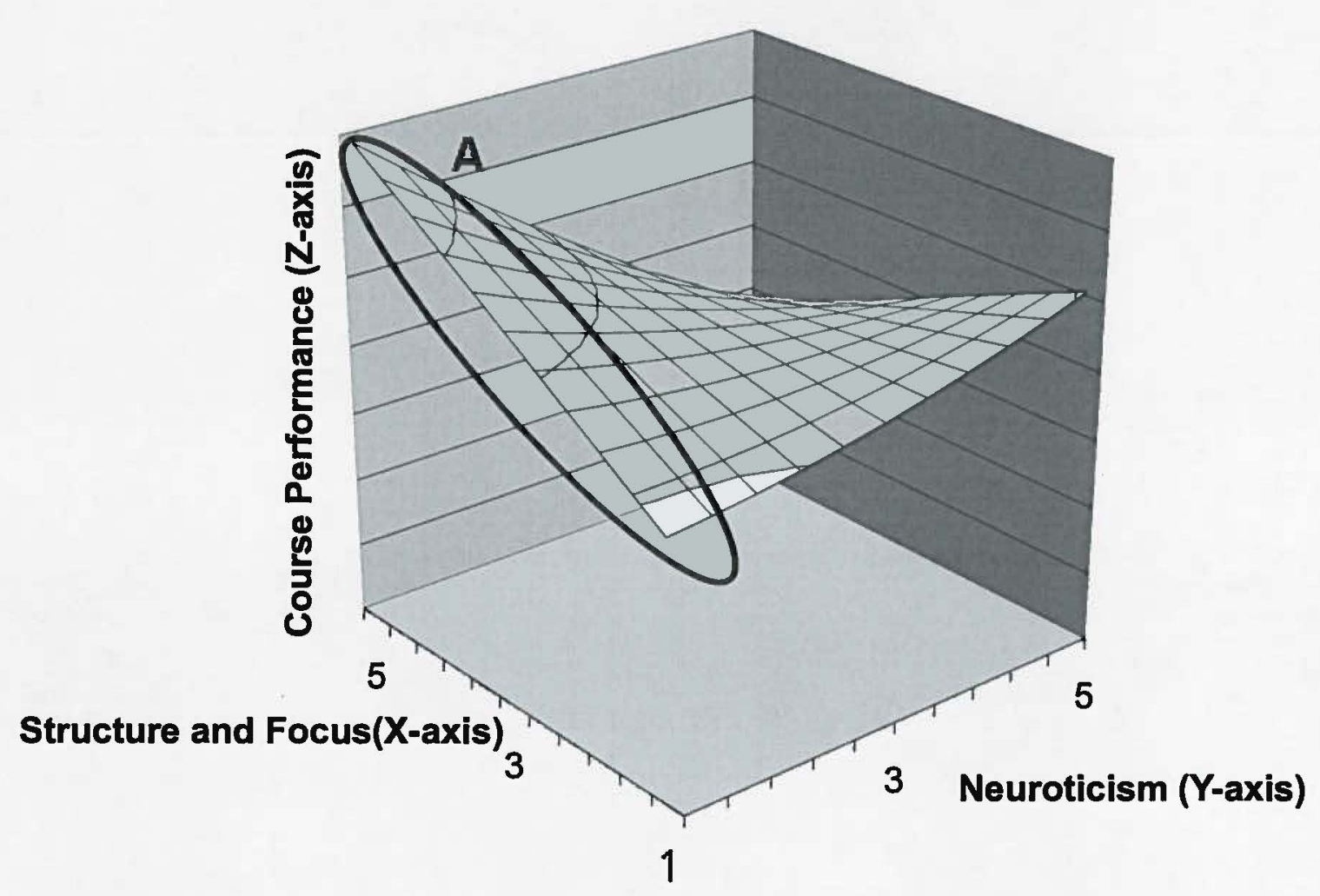

Figure 21. Functional form of objective fit between neuroticism and structure and focus for the course performance outcome. 


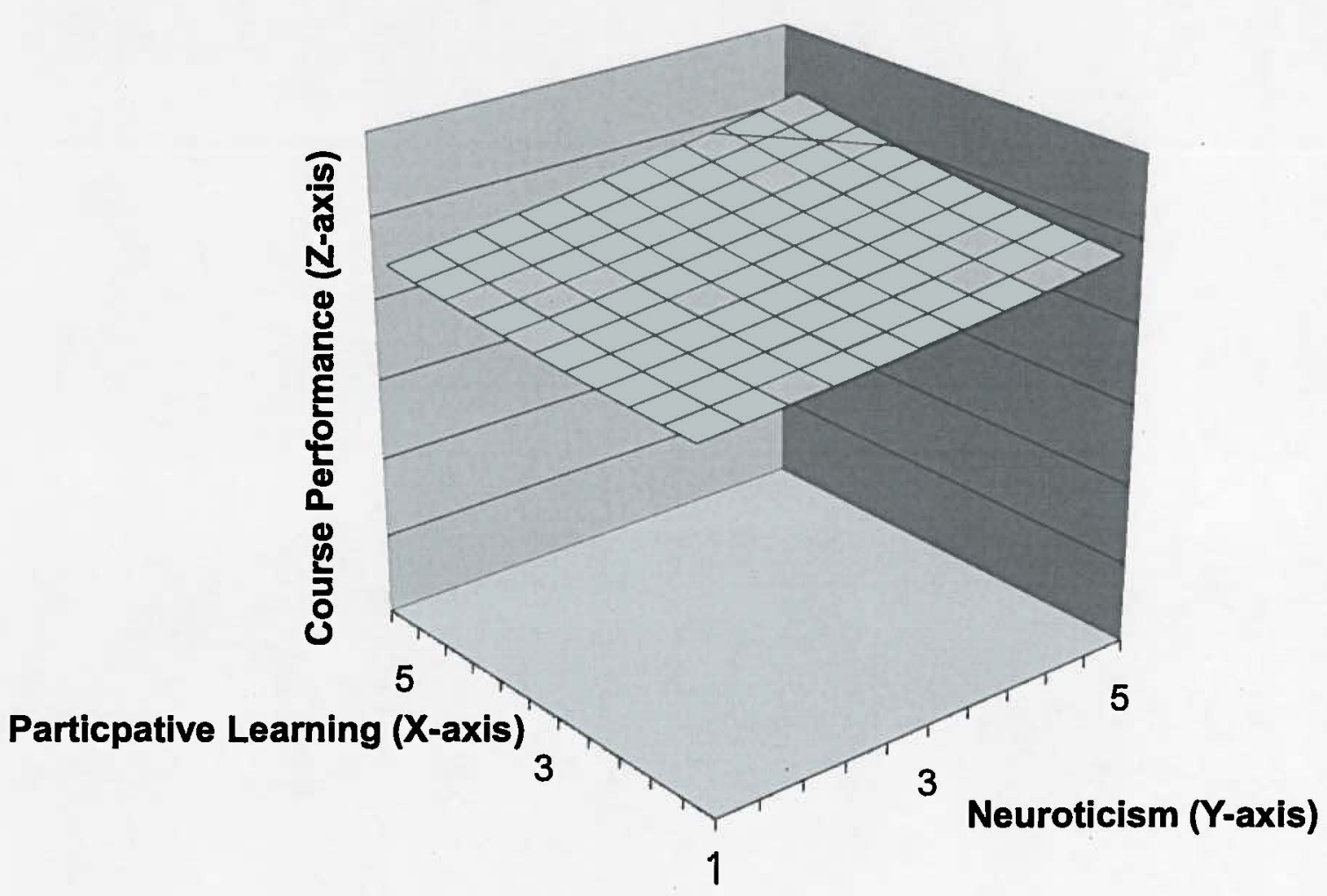

Figure 22. Functional form of objective fit between neuroticism and participative learning for the course performance outcome. 


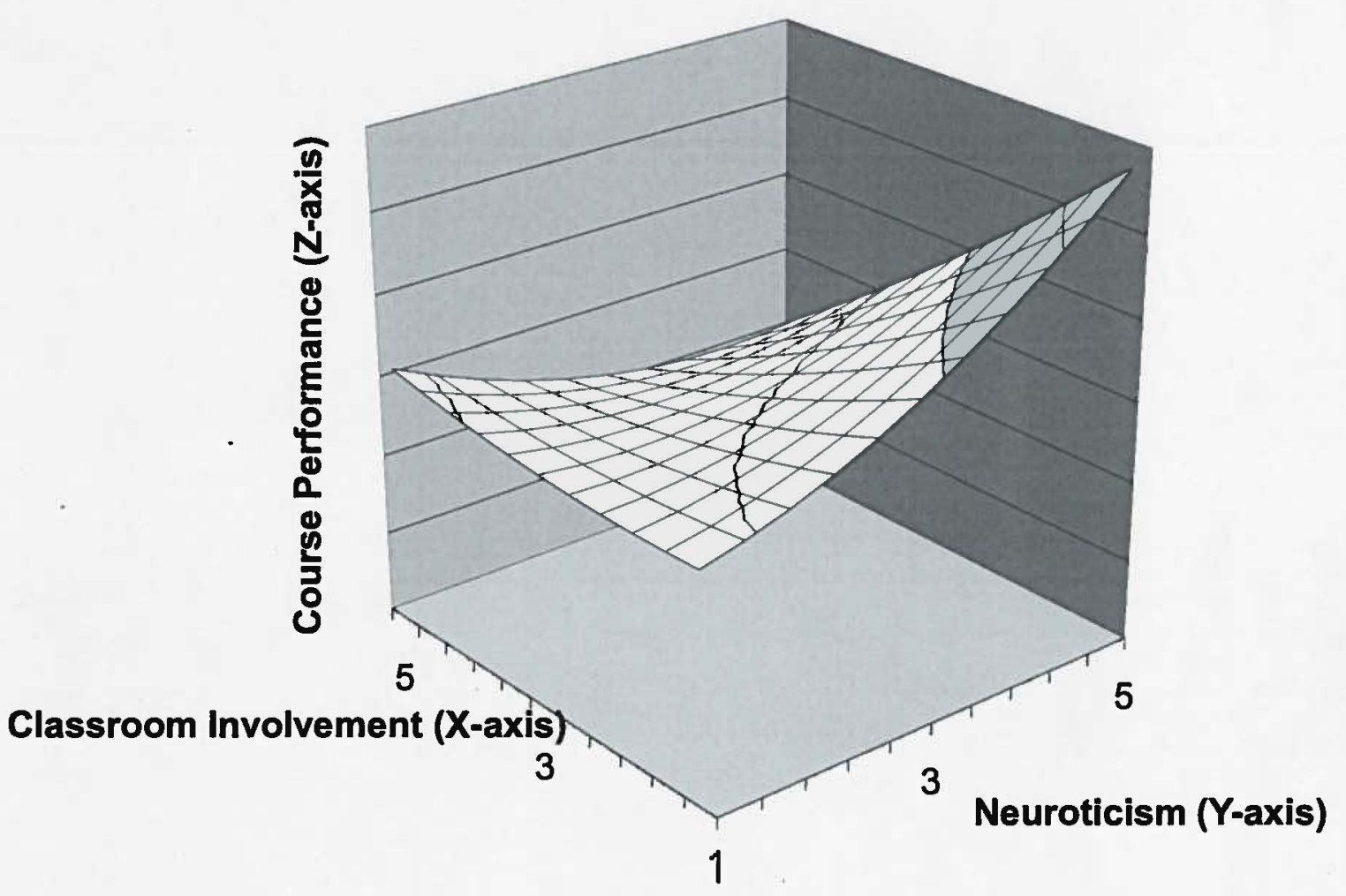

Figure 23. Functional form of objective fit between neuroticism and classroom involvement for the course performance outcome. 


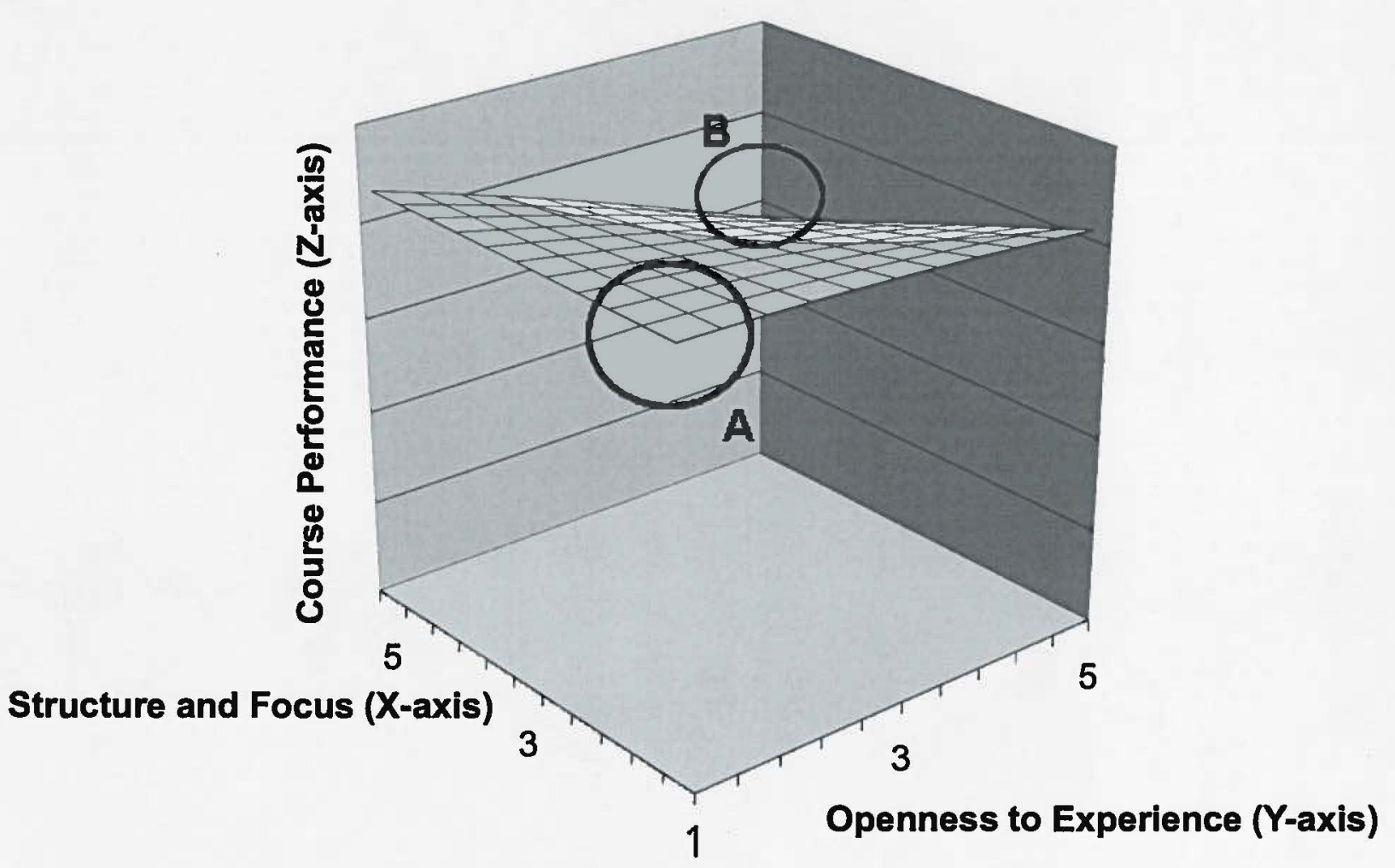

Figure 24. Functional form of objective fit between openness to experience and structure and focus for the course performance outcome. 


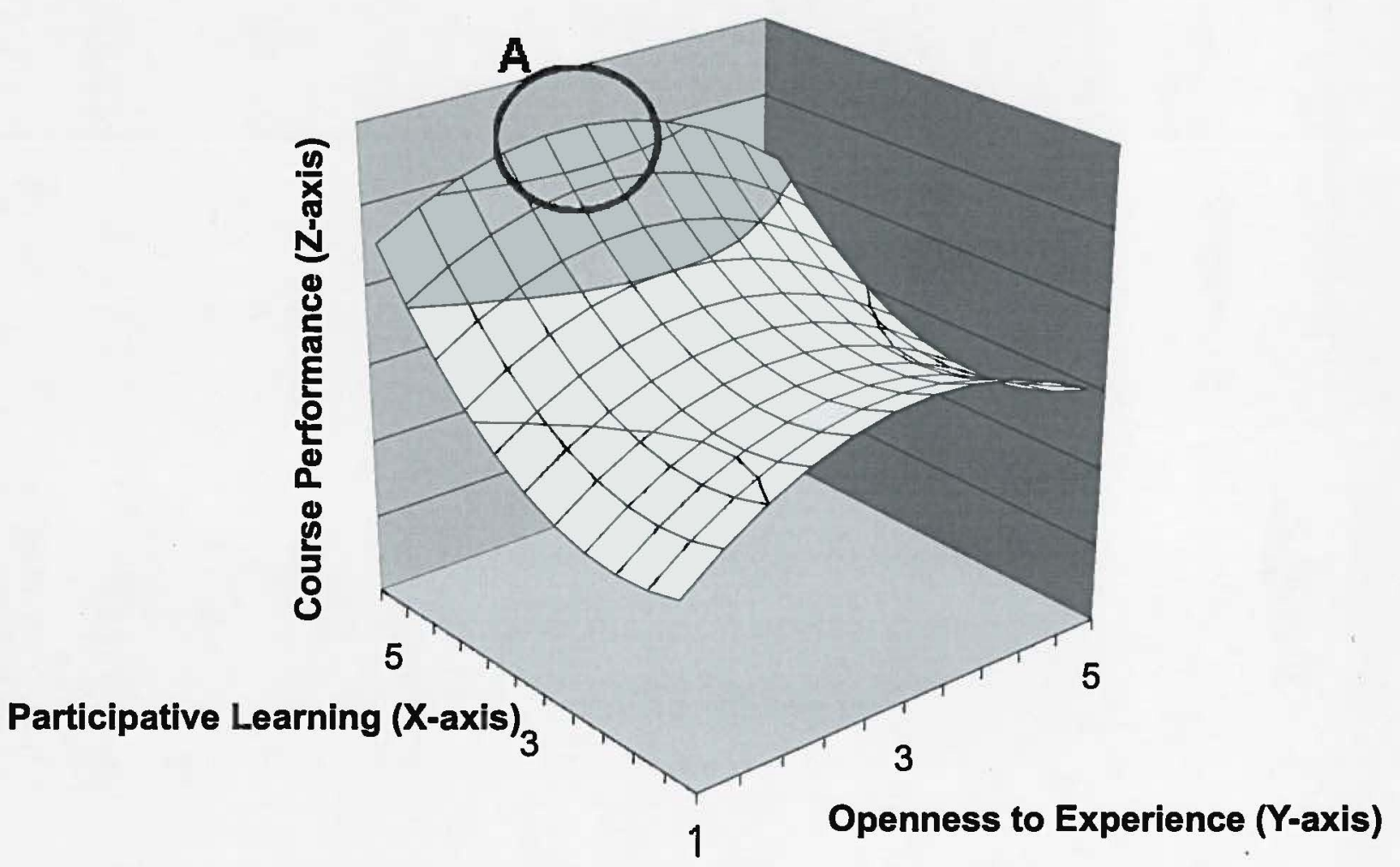

Figure 25. Functional form of objective fit between openness to experience and participative learning for the course performance outcome. 


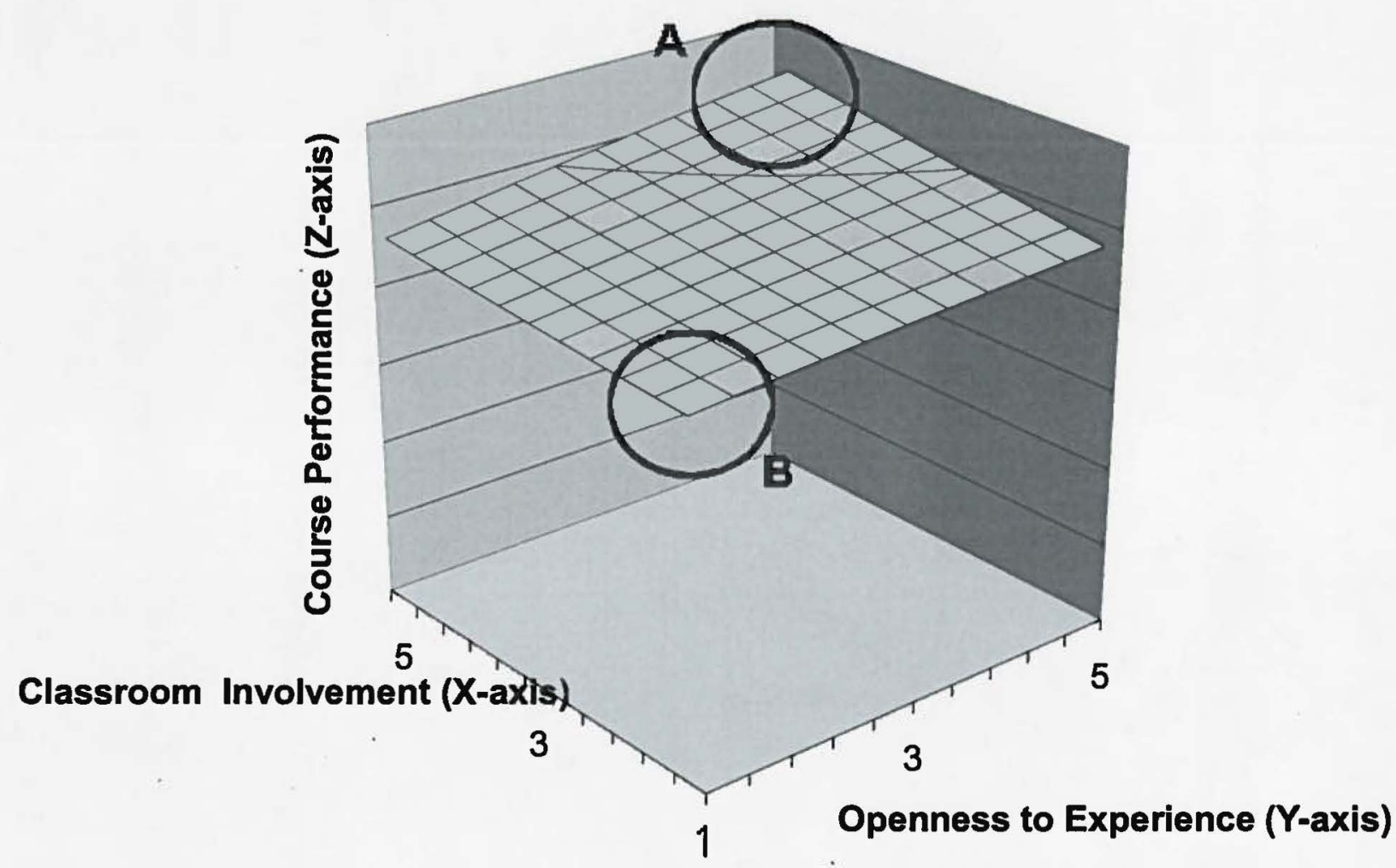

Figure 26. Functional form of objective fit between openness to experience and classroom involvement for the course performance outcome. 


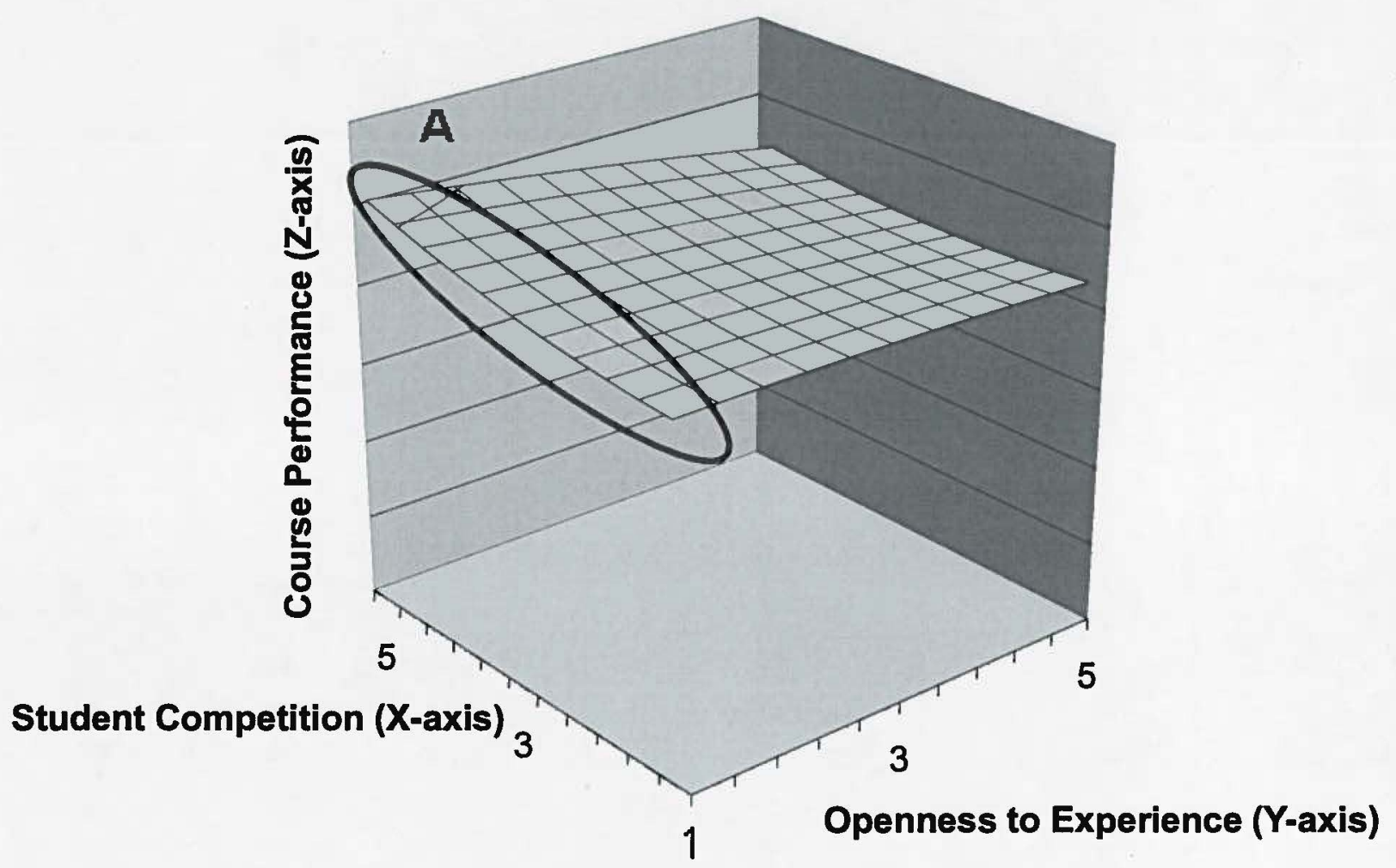

Figure 27. Functional form of objective fit between openness to experience and student competition for the course performance outcome. 


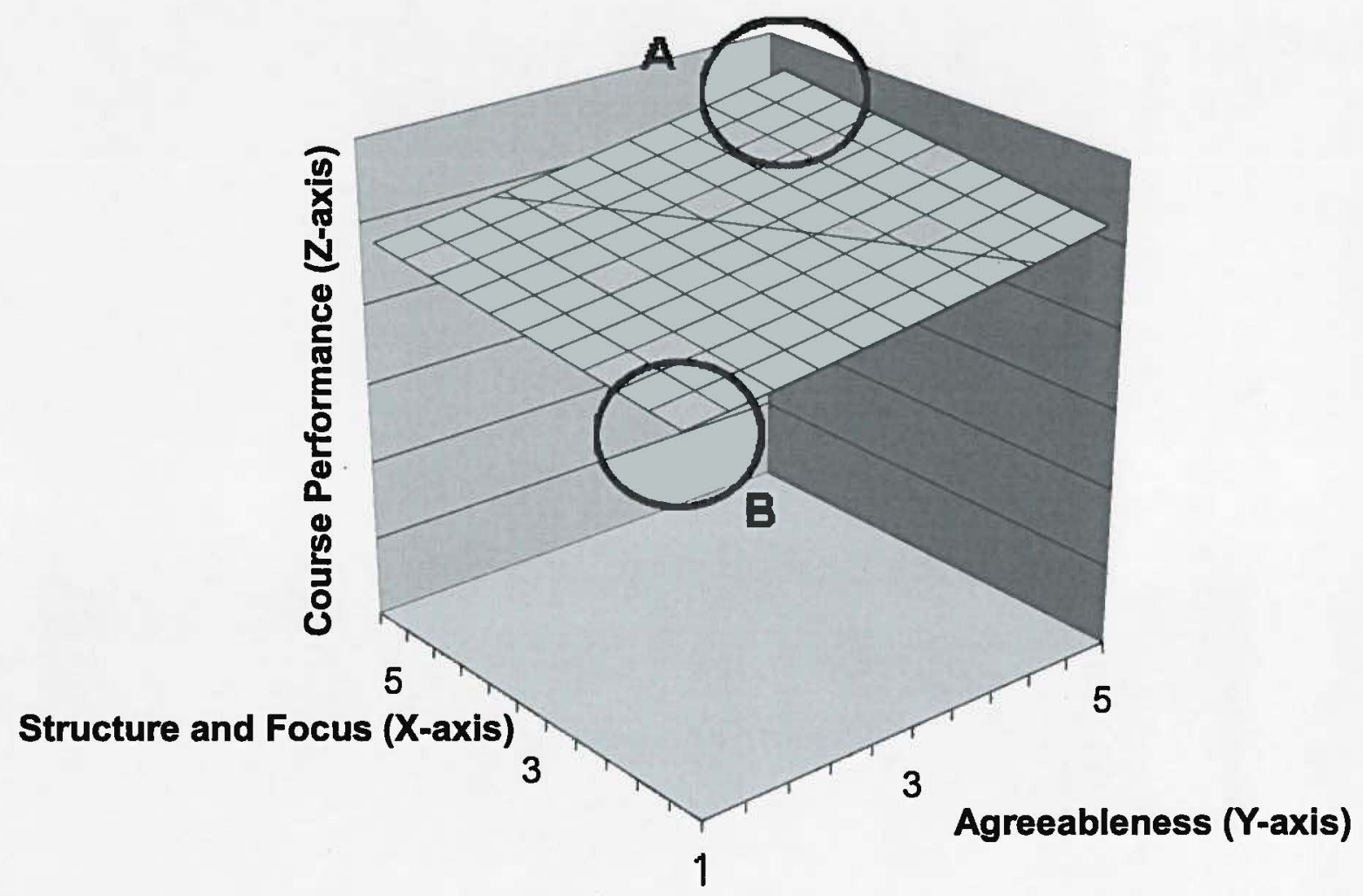

Figure 28. Functional form of objective fit between agreeableness and structure and focus for the course performance outcome. 


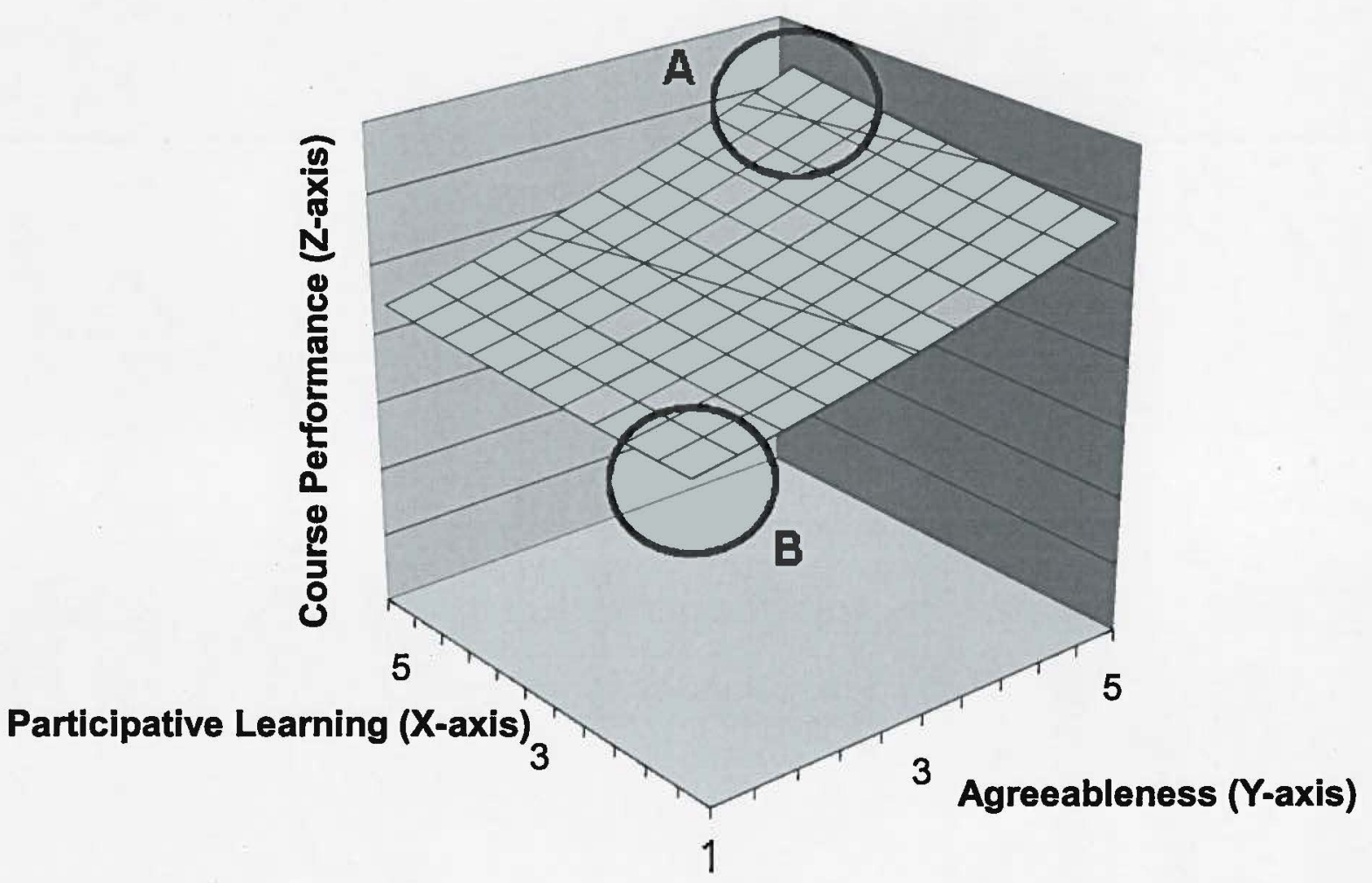

Figure 29. Functional form of objective fit between agreeableness and participative learning for the course performance outcome. 


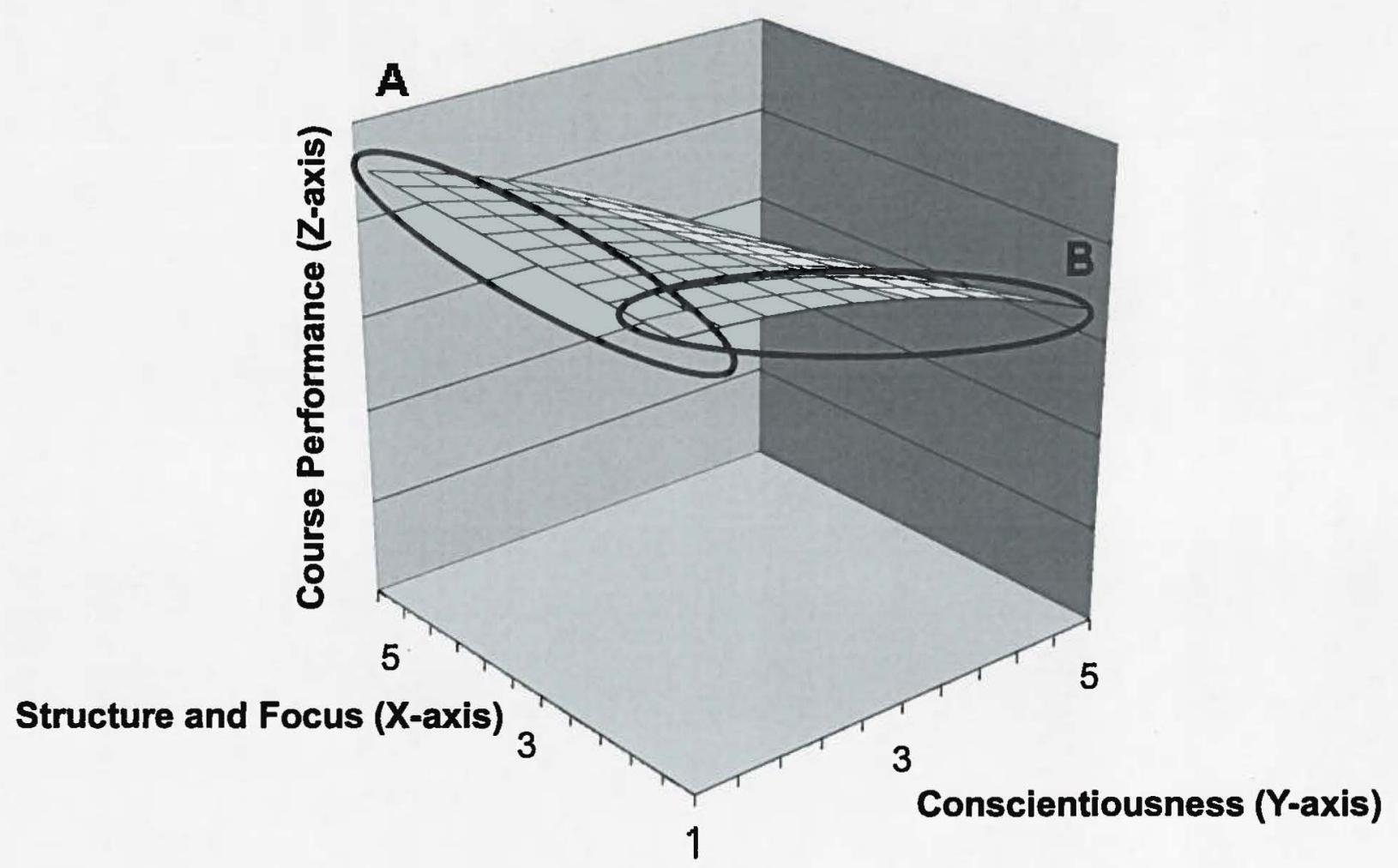

Figure 30. Functional form of objective fit between conscientiousness and structure and focus for the course performance outcome. 


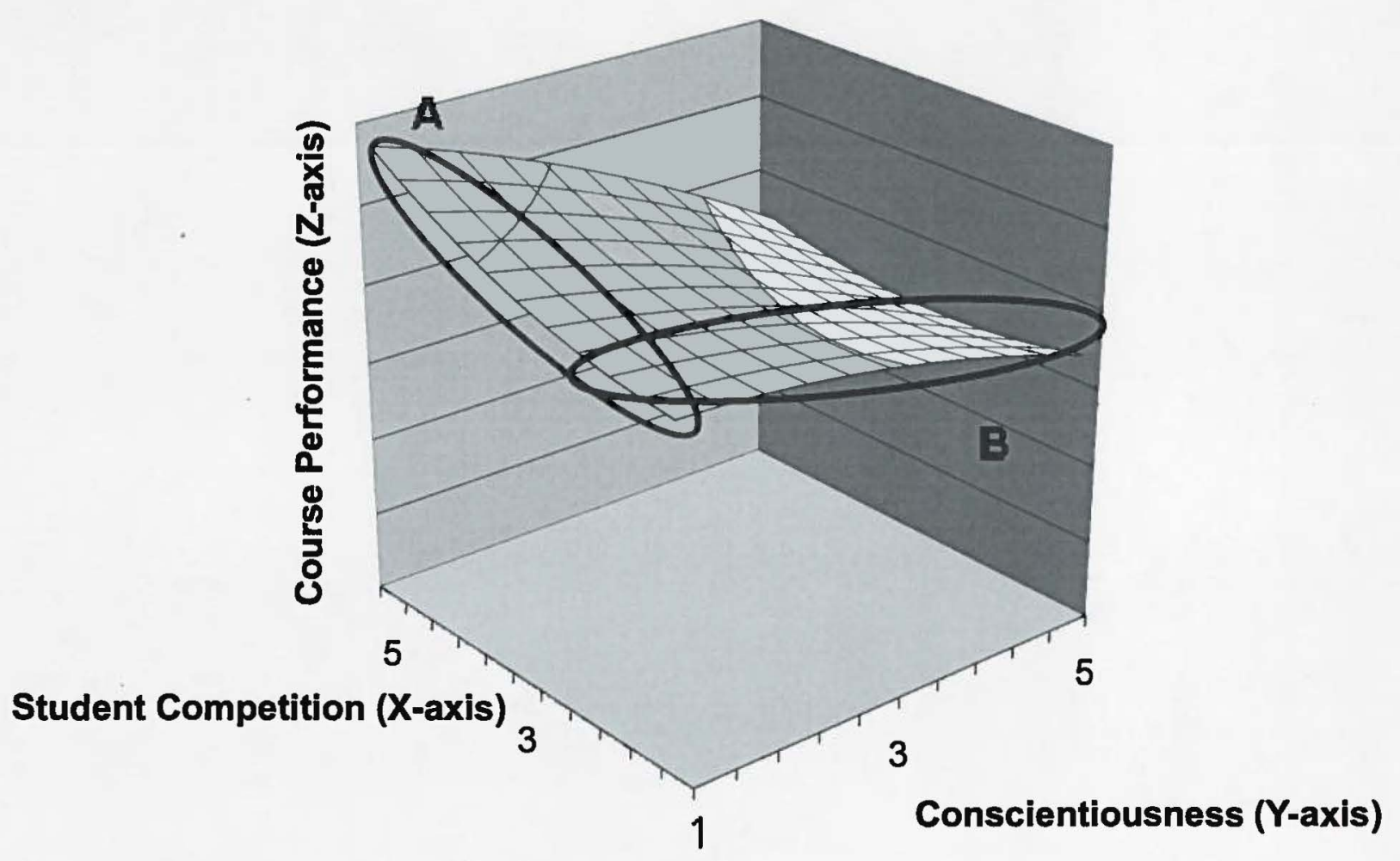

Figure 31. Functional form of objective fit between conscientiousness and student competition for the course performance outcome. 


\section{Vita}

Dagmara K. Pawlowska was born in Gdansk, Poland. She graduated high school from Harding University High School in Charlotte, North Carolina. Ms. Pawlowska earned a Bachelor of Arts degree in Psychology from Appalachian State University in December 2008. She then went on to receive a Master of Arts degree in Industrial-Organizational Psychology and Human Resource Management from Appalachian State University in May 2011. During the course of her graduate education, Ms. Pawlowska participated in an internship in human resources at Family Dollar Stores, Inc. in Charlotte, North Carolina. Following her Master's education, Ms. Pawlowska will be pursuing a doctorate in Social Psychology. 